Construcción de la escala SAMANTO para medir actitudes revictimizantes de los operadores judiciales hacia la víctima

Trabajo de Grado

Mantilla-Ojeda Saida Lastenia Ángela Tapias Saldaña*

UNIVERSIDAD SANTO TOMAS

FACULTAD DE PSICOLOGÍA

POSGRADOS EN PSICOLOGÍA JURÍDICA

MAESTRÍA EN PSICOLOGÍA JURÍDICA

Bogotá, D.C., Febrero de 2014

* Directora 


\title{
Construcción de la escala SAMANTO para medir actitudes de los operadores judiciales hacia la víctima
}

\author{
Mantilla-Ojeda Saida Lastenia, Tapias Saldaña Ángela*
}

\begin{abstract}
Resumen
La presente investigación fue validada en contenido por los jueces expertos, con validez facial, se aplicó la prueba de Kolmogorov-Smirnov que arrojó una puntuación total de ,736 también, se examinaron las propiedades psicométricas del instrumento con la ayuda del paquete estadístico spss y la escala obtuvo un Alfa de Cronbach de 0.957 que indica alta confiabilidad. Los participantes fueron 120 voluntarios entre los que se cuentan con profesiones del derecho, trabajo social, médicos, psicólogos y policías. Estudio cuantitativo de tipo instrumental que tuvo como objetivo diseñar y aplicar la escala SAMANTO para medir actitudes revictimizantes de los operadores judiciales, escala tipo Likert de cuatro puntos. La media total de este grupo fue 134 y la desviación estándar de 23,07 lo que indica baja actitudes revictimizantes promedio, lo cual era esperado, confirma la literatura, la sensibilidad del instrumento y presenta la necesidad de combatir esta problemática.
\end{abstract}

Palabras clave: actitudes revictimizantes, operadores judiciales, víctima.

\section{SAMANTO construction scale to measure the attitudes of judicial operators to the victim}

\author{
Saida Lastenia Mantilla-Ojeda, Tapias Saldaña Ángela *
}

\begin{abstract}
Abstrac
The present research was validated in its content by the expert judges, with facial validity. Kolmogorov-Smirnow test was applied and the result was a final score of ,736; it was also examinated the psychometric properties of the instrument with the help of spss statistics package and the scale got Alfa of Cronbach of 0.957 which show high reliability. The participants were 120 volunteers among social workers, physicians, psychologists, and police officers. This was a quantitative instrumental study which objective was to design, built, and apply the SAMANTO scale to measure revictimizing attitudes, Likert kind of scale of four points. The media in this group was 134 and standar deviation was 23,07 shows low average revictimizing attitudes, as was to be expected, confirms the literature, the implementation of the instrument and shows the need of root out this problematic.
\end{abstract}

Keywords: attitudes revictimizing, judicial operators, victim.

\footnotetext{
* Directora.
} 


\section{Tabla de contenido}

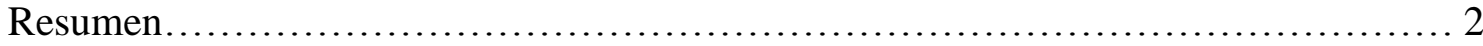

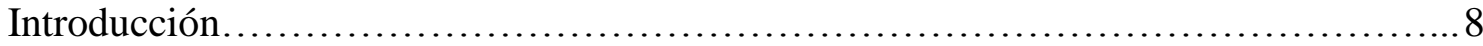

Fundamentación bibliográfica............................................... 14

Definición de víctima.............................................................. 14

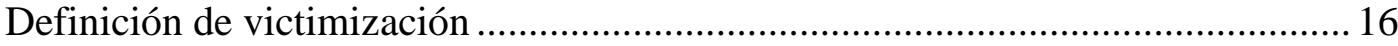

La víctima, victimizaciones y el sistema jurídico .................................................... 20

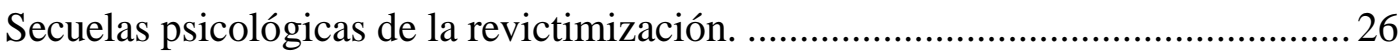

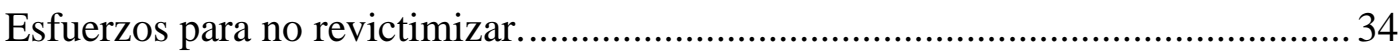

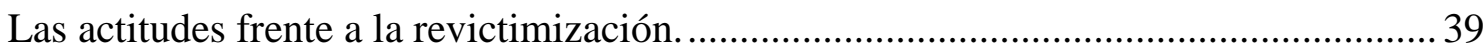

Medición de actitudes revictimizantes encaminadas a modificar conductas.........47

Conceptos psicométricos.................................................. 56

Instrumentos de medición cuantitativos..........................................57

Construcción de una escala Likert....................................................60

Pasos que se sugieren para la construcción de escalas en general............................. 66

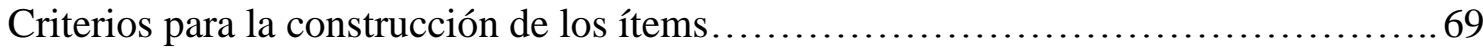

Proceso de construcción con calidad de un instrumento..............................73

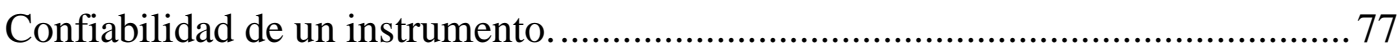

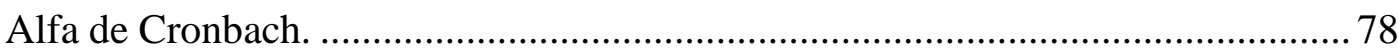

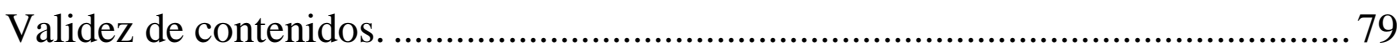

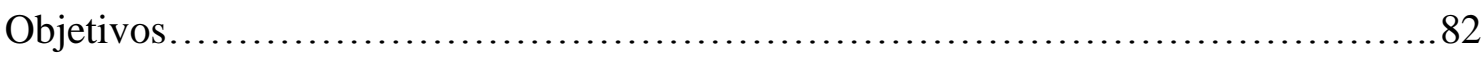

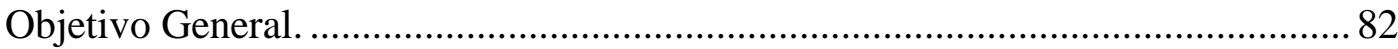

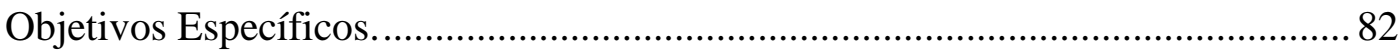

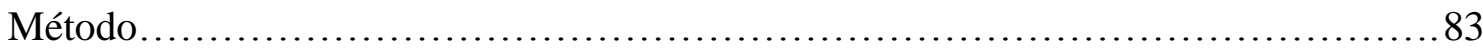

Diseño y tipo de investigación................................................ 83

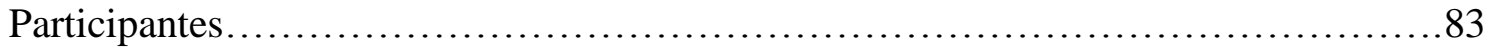

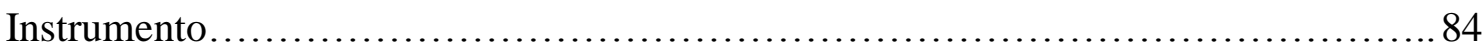

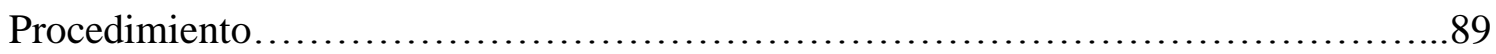

Consideraciones éticas. ...................................................................................... 91 
Resultados............................................................ 94

Discusión.................................................................. 115

Conclusiones.............................................................. 123

Recomendaciones....................................................... 125

Referencias........................................................ 127

Apéndice................................................................... 136

Apéndice A: Formato de consentimiento informado...........................136

Apéndice B: Cuadernillo instrumento SAMANTO............................. 137

Apéndice C: Ficha técnica................................................ 141

Apéndice D: Estadísticos por componentes................................. 142 


\section{Lista de Tablas}

Tabla 1 Síntesis del concepto el escalamiento tipo Likert....................... 62

Tabla 2 Proceso para la construcción de un instrumento de medición............. 73

Tabla 3 Validez de contenido de los ítems............................... 96

Tabla 4 Síntesis del índice de validez.................................... 97

Tabla 5 Índices de validez aparente.................................. 99

Tabla 6 Resultado del análisis estadístico de la evaluación cuantitativa de los ítems......................................................... 102

Tabla 7 Resultados de la escala SAMANTO................................. 105

Tabla 8 Media y desviación de todos los ítems de la muestra total............... 106

Tabla 9 Estadísticos totales de los componentes cognitivo, afectivo y comportamental............................................... 107

Tabla 10 Correlaciones de la escala....................................... 111

Tabla 11 Estimación confiabilidad de la prueba Alfa de Cronbach............... 112

Tabla 12 Estadísticos de las escalas y total del instrumento.................... 113

Tabla 13 Síntesis de los estadísticos descriptivos.......................... 113

Tabla 14 Tabla de percentiles.......................................... 114

Tabla 15 Ficha técnica del instrumento SAMANTO......................... 141

Tabla 16 Estadísticos totales de los ítems del componente cognitivo.............. 142

Tabla 17 Estadísticos totales de los ítems del componente afectivo.............. 144

Tabla 18 Estadísticos totales de los ítems del componente comportamental....... 145

Tabla 19 Estadísticos de los ítems....................................... 147

Tabla 20 Estadísticos del total de los ítems.............................. 151

Tabla 21 Estadísticos de los resultados en las sub-escalas y puntaje total......... 155 
Escala SAMANTO para medir actitudes de los operadores judiciales hacia la víctima 6

Tabla 22 Estadísticos del puntaje componente cognitivo........................ 156

Tabla 23 Estadísticos del puntaje componente afectivo...................... 157

Tabla 24 Estadísticos de los puntajes componente comportamental............... 158

Tabla 25 Estadísticos de los puntajes totales de los componentes.............. 159

Tabla 26 Prueba de Kolmogorov-Smirnov............................... 165 
Escala SAMANTO para medir actitudes de los operadores judiciales hacia la víctima 7

\section{Lista de Figuras}

Figura 1 Resultado de los datos del componente cognitivo.................... 162

Figura 2 Resultado de los datos del componente afectivo..................... 163

Figura 3 Resultado de los datos del componente comportamental.............. 164

Figura 4 Resultado de los datos totales de los tres componentes................. 165 
Escala SAMANTO para medir actitudes de los operadores judiciales hacia la víctima 8

\section{Introducción}

Las personas independientemente de la edad, sexo, raza, idioma y nación precisan ser atendidas por el aparato de justicia con toda la consideración que atañe a sus necesidades, ya que, una adecuada asistencia podría contribuir en el proceso de formación psicosocial, aun en medio de las vicisitudes o pesares que puedan llegar a padecer. Razón por la cual, se precisa recordar que desde los inicios de la humanidad surge el delito y con ello la víctima. Que a su vez, y en algunas ocasiones al entrar en contacto con el sistema jurídico puede llegar a ser revictimizada.

Por esta razón, autores como Marchiori, Biodo y Fortete (2004) afirman que las víctimas de los diversos delitos al entrar en contacto con el aparato jurídico, pueden llegar a padecer la revictimización, al quedar expuestas ante los operadores de justicia ya que estos en el cumplimiento de su trabajo pueden propiciar mayor maltrato a la víctima que el provocado inicialmente por el agresor. De ahí que, las víctimas de los diversos delitos deben enfrentar múltiples situaciones de origen jurídico, llegando hasta el agotamiento por la defensa de sus derechos en busca de justicia y consideración por las secuelas físicas y psíquicas que dejan las diferentes transgresiones (Beristain, 2000).

En el mismo sentido, los sobrevivientes de los diversos delitos, en especial los niños, niñas y adolescentes (NNA) víctimas del abuso sexual, quienes a su vez merecen toda la atención y consideración posible por la alta vulnerabilidad en la que se encuentran, no solo son afectados por este delito tan atroz, sino aun más, al entrar en contacto con el aparato jurídico son revictimizados por aquellos profesionales encargados de ejercer “justicia y protección” para los más frágiles de la sociedad. Así que, los reiterados procesos de indagación y relatos en búsqueda de la "verdad" generan 
Escala SAMANTO para medir actitudes de los operadores judiciales hacia la víctima 9

la revictimización y la posibilidad de un mayor daño psíquico y emocional (Beristain, 2000; Marchiori, 2004; Vásquez, 2003).

Por otra parte, estos sobrevivientes de los diversos sucesos delictivos, en los que con mucha frecuencia se encuentran en medio del conflicto ya sea armado, desplazamiento en todas sus formas, destierro y abuso sexual entre otros, deben padecer los suplicios de un sistema jurídico-penal que en ocasiones pareciera sobresalir más por la ineptitud que por la eficiencia de su función. De ahí que, el aparato jurídico carece de credibilidad y confiabilidad por parte de aquellos que logran sobrevivir en medio de la tragedia (Beristain, 1999; Landrove, 1990).

En consecuencia, son considerables las secuelas que se desencadenan cuando los individuos no reciben un trato justo y considerado ante sus aflicciones. Por consiguiente, esta indiferencia refleja el maltrato hacia la víctima, y a la postre es probable que repercuta en un marcado resentimiento social, entorpeciendo las relaciones interpersonales entre el sobreviviente y quienes le rodean (Marchiori, Biodo y Fortete, 2004; Vásquez, 2003).

De tal manera, es necesario mencionar a la población de niños, niñas y adolescentes (NNA), ya que estos son los más vulnerables de la sociedad. Razón por la cual, se encuentran mayormente en alto riesgo de peligrosidad, no solo ante el victimario, sino también, ante el aparato de justicia. En consideración a lo anterior, se debe velar aun más por el buen trato y vida digna, los cuales se consagran en los derechos fundamentales de los niños, niñas y los adolescentes (NNA) en el Código de la Infancia y la Adolescencia (“Congreso de Colombia”, Ley 1098 de 2006).

De otra manera, el maltrato que reciben las víctimas por los operadores de justicia, ha conllevado a que en la mayoría de los delitos no se denuncien por temor a 
ser revictimizados(a). En otras palabras, son múltiples los miedos e inseguridades que las personas desencadenan frente a los operadores de justicia al denunciar determinado delito. En especial, los niños, niñas y los adolescentes (NNA) que acuden en búsqueda de protección, en los cuales se evidencia diversas manifestaciones fisiológicas como: estremecimiento en las manos, resequedad en los labios, voz disonante, estrés, empalidecimiento en el rostro y en algunas ocasiones presentan enuresis y encopresis (Castañer y Griesbach, 2008; Garrido y Masip, 2004; Marchiori, 2010; Soria y Sánchez, 2009; Vásquez, 2003). En consecuencia, los (NNA) víctimas de diversos delitos, en especial el delito del abuso sexual, desarrollan tal pavor ante el ambiente jurídico-penal, que en ocasiones se evidencia más la angustia por compadecer a la indagación, que el trauma o dolor del delito que motivo la denuncia. Lo anterior expuesto, obedece al tortuoso padecimiento e inadecuada asistencia por parte de los operadores de la justicia y por la experiencia que registran los que han sido sometidos al maltrato por parte del aparato jurídico, el cual deja incredulidad por el sistema en cargado de hacer "justicia" en los sobrevivientes de determinados delitos (Castañer y Griesbach, 2008; Marchiori, 2010).

Por otro lado, la falencia del sistema jurídico-penal se evidencia en la indiferencia y poco cuidado que se les otorga a las víctimas, en especial al (NNA) que acude a denunciar que fue víctima de agresión sexual. Esto en razón, que probablemente se esté prestando mayor importancia a los hechos del delito, que a la asistencia de la víctima que padeció el acometimiento. Por consiguiente, se resta importancia al perjudicado(a), centrando la atención en los hechos y al acto en sí mismo; en algunos casos es probable que el victimario tenga mayor atención, que la 
víctima la cual termina por ser relegada (Beristain, 2000; Marchiori, 2010; Vásquez, 2003).

En efecto, a la víctima se le volverá a tener en cuenta todas las veces que el profesional considere preciso que deba presentarse para ser nuevamente indagada. Por lo tanto, es necesario acercar una propuesta que permita al operador ver que la víctima es un ser humano herido en la vulnerabilidad y fragilidad de su ser. Por ende, merece toda la consideración y cuidado que dentro de las posibilidades del profesional a cargo se le pueda otorgar y más cuando se trata de un niño, niña o adolescente (NNA). Así que, probablemente un cambio en las actitudes por parte del profesional resulte en una sana relación entre la víctima y el operador de justicia que atiende determinado delito.

Más aún, se consultó acerca de las diversas afectaciones psicológicas que la revictimización causa, entre las que se presentan ya sean psíquicas, físicas o sociales. Otros estudios han confirmado, que en ocasiones son más los problemas generados por la revictimización que ocasiona el sistema jurídico representado por sus profesionales, que los derivados por el delito en sí (Castañer y Griesbach, 2008; Marchiori, 2010; Soria y Sánchez, 2009; Suárez y Espinosa, 2011; Vásquez, 2003).

Es decir, la falta de una adecuada atención a la víctima puede dejar secuelas que a la postre resultaran en perjuicio social. Por tanto, se evidenciaran en el crecimiento personal, interacción social y proyecto de vida. Por lo cual, se hará evidente en la baja autoestima, depresión, descontento por el entorno, desconfianza por la justicia, autorechazo, aislamiento social, tendencias suicidas y delictivas, que a su vez acrecentarán los índices de la criminalidad (Beristain, 2000; Dallos, Pinzón, Barrera y González 2009; Restrepo, 1995; Marchiori, 2011; Soria y Sánchez, 2009; Vásquez, 2003; Volnovich, 2008). 
Ahora bien, ante el fenómeno de la revictimización es importante considerar la construcción de instrumentos y escalas que permitan medir las actitudes revictimizantes por parte de los operadores que atienden los diferentes tipos de delitos. Especialmente, que contribuya develando no solo la revictimización, sino que también aporte a la prevención de la misma, inspirando programas que propendan por la capacitación de los profesionales. Por ende, contribuir en la disminución del maltrato evidenciado en la revictimización, y con ello, promover la denuncia del delito como aporte a la reducción de la criminalidad. Por consiguiente, es vital que las víctimas que han sido sometidas a diferentes tipos de agresión, alcancen justicia y puedan continuar con su vida al encontrar operadores judiciales con un alto sentido de humanidad.

Por lo tanto, en el actual documento se encontraran diversos estudios relacionados con la victimización originada por parte del sistema jurídico, el cual está representado por los profesionales encargados de atender los diversos tipos de delitos. Siendo así, se devela la importancia en la actitud del profesional cuando atiende a las víctimas de los diversos delitos. En efecto, las actitudes de los operadores judiciales son de suma importancia, puesto que, desempeñan un papel fundamental a la hora de atender la denuncia por parte de las víctimas. Dado que, son las actitudes las que pueden llegar a marcar la diferencia entre la revictimización y una adecuada atención.

Razón por la cual, se procedió a la consulta y búsqueda durante varios meses de múltiples autores, quienes a su vez son autoridad en el presente tema de investigación. Asi, se indagó en la literatura en español como en inglés, pero, los resultados no fueron alentadores ya que no existe para este fenómeno ninguna herramienta que permita la detección de las actitudes revictimizantes por parte de quienes atienden a las víctimas. 
De esta manera, nace la propuesta de investigación del diseño y creación de la escala SAMANTO para medir las actitudes de los operadores judiciales hacia la víctima.

En consecuencia, el diseño y construcción del instrumento SAMANTO, objeto de la presente investigación, procura identificar y medir actitudes revictimizantes por parte de los operadores judiciales, para que en futuros estudios, otros científicos puedan intervenir, prevenir y disminuir la victimización con el uso del instrumento. Por consiguiente, con el mismo propósito y bajo los anteriores parámetros ya expuestos, el documento en mención se fundamenta en la pregunta específica que conduce este estudio ¿Cómo construir la escala SAMANTO que mide actitudes revictimizantes de los operadores judiciales? 


\section{Fundamentación bibliográfica}

Antes de entrar de lleno en el tema de la revictimización, es necesario definir brevemente algunos conceptos para tener claridad del contenido que se estará abordando en la presente investigación. Así, como la importancia en el aporte que este estudio pretende dejar como legado para las generaciones que continuaran haciendo de este planeta un mejor mundo. Razón por la cual, se diseñó y construyó la escala SAMANTO para medir actitudes de los operadores judiciales hacia la víctima.

\section{Definición de víctima}

Su origen se sitúa en los decenios de la postguerra, es decir entre 1945 y 1973, dado que, en septiembre de este último año se celebró en Jerusalén, el Primer Symposium Internacional sobre Victimología, el cual marcaría el nacimiento en la historia de la actual victimología a nivel mundial. Es así, como a partir de 1945, el principal concepto de víctima gira alrededor de la macrovictima, o de la víctima del abuso de poder, concretamente del nazismo, con su genocidio de seis millones de judíos. Posteriormente, se extiende el estudio y el concepto acerca de las víctimas de los diversos delitos en comunes, con especial y mayor atención a la población de mujeres y niños, puesto que son los más vulnerables de la sociedad (Beristain, 2000).

En otras palabras, autores como Beristain (2000) consideran que son víctimas las personas naturales o jurídicas que sufren daños en los bienes jurídicamente protegidos por las leyes (especialmente en lo que respecta a la vida, la salud, la propiedad, el honor, la honestidad, etc.), En el mismo orden de ideas, víctima también es la persona que padece un sufrimiento físico, emocional y social a consecuencia de la violencia, de una conducta agresiva antisocial, a través del comportamiento del 
Escala SAMANTO para medir actitudes de los operadores judiciales hacia la víctima 15

individuo-delincuente que transgrede las leyes de su sociedad y cultura (Marchiori, 1998).

De este modo, la víctima está íntimamente vinculada a las consecuencias del delito, el cual se refiere a los acontecimientos, que es el resultado de la conducta antisocial, principalmente el daño, la extensión del mismo y su peligrosidad. De ahí que, el perjuicio causado a nivel individual y colectivo, afectan directamente al conglomerado social. Por consiguiente, el impacto del delito por lo general llega a tener consecuencias de tal gravedad, que pueden propiciar arbitrarias modificaciones en la vida de la víctima y la de sus familiares, y en numerosos casos estas alteraciones puede ser irreversibles (Marchiori, 1998).

También, la Organización de las Naciones Unidas [ONU], mediante resolución 40/34 (1985), dice que:

Se ha de entender por víctimas las personas que individual o colectivamente hayan sufrido daños, inclusive lesiones físicas o mentales, sufrimiento emocional, pérdida financiera o menoscabo substancial de sus derechos fundamentales, como consecuencia de acciones $\mathrm{u}$ omisiones que violen la legislación penal vigente en los Estados miembros, incluida la que proscribe el abuso de poder. En la expresión víctima se incluye además, en su caso, a los familiares o personas a su cargo que tengan relación inmediata con la víctima directa y a las personas que hayan sufrido daños al intervenir para asistir a la víctima en peligro o para prevenir su victimización (p. 12).

Así que, según lo señala en su definición Marchiori (1998) el impacto de la revictimización sobre las víctimas es tal, que las consecuencias pueden evidenciarse desde diversas áreas: 
Escala SAMANTO para medir actitudes de los operadores judiciales hacia la víctima 16

1. Físicas: en las que se encuentran las lesiones leves, graves y gravísimas que pueden incluir la pérdida de la vida de la víctima.

2. Emocionales: no se pueden determinar por su grado de complejidad, pero estas incluyen las secuelas del profundo estrés y la conmoción que causa y deja el delito.

3. Socio-cultural: esta repercuten en las relaciones interpersonales de la víctima con su entorno social.

4. Económicas: son todos los daños que ocasiona el delito, entre los que se cuentan, pérdidas materiales, físicas, emocionales, etc.

\section{Definición de victimización}

Es el proceso que hace alusión al abuso de poder entre el sistema jurídico y los individuos de la sociedad. De este modo, se puede comprender que la victimización es una cadena social degenerativa que está vinculada a los procesos de acumulación capital y control de la hegemonía del poder, que implica la necesidad continua de legitimización del Estado frente a la sociedad (Tapia, 2007). En el mismo sentido, y pese al criterio denotado en la clasificación con respecto al tema de la victimización, autores como Albertin (2006), Beristain (1999, 2000), Gutiérrez de Piñerez, Coronel y Pérez (2009), Landrove (1990), Marchiori, Biodo y Fortete (2004), Marchiori, Biodo, Fortete y Shulthess (2007), Marchiori (2010, 2011), Soria (1991), Suarez y Espinosa (2011), concuerdan en que la victimización se produce cuando la víctima entra en contacto con el sistema jurídico al interponer la denuncia por algún delito cometido hacia esta.

Por lo que es perentorio aclarar que, se genera la victimización primaria como derivación del impacto traumático de un hecho delictivo; en contraste con la victimización secundaria, que se produce como consecuencia posterior de la relación o 
el encuentro entre la víctima y el sistema jurídico-penal en el que se incluyen todos y cada uno de los operadores que trabajan con el aparato jurídico. Cabe mencionar, que uno de los aspectos más relevantes de la victimización secundaria, es el prolongamiento de los procesos, en el cual no se proporciona respuesta de resultados a las víctimas Albertin (2006), Beristain (1999, 2000), Gutiérrez de Piñerez, Coronel y Pérez (2009), Landrove (1990), Marchiori, Biodo y Fortete (2004), Marchiori, Biodo, Fortete y Shulthess (2007), Marchiori (2010, 2011), Soria (1991), Suarez y Espinoza (2011).

Razón por la cual, se genera en la víctima incertidumbre en el proceso penal e incluso desconfianza en el sistema jurídico, este aspecto en un sinnúmero de casos contribuyen a empeorar la situación emocional y salud mental de la víctima. A continuación se hablara más detalladamente del asunto.

Son alarmantes las consecuencias psicológicas y sociales que deja la victimización en las víctimas de los diversos delitos, quienes en busca de protección y justicia encuentran una asistencia hostil, que en numerosos casos raya con la frialdad e indiferencia que genera la actitud de los profesionales encargados de recibir las denuncias por diversos delitos. Razón por la cual, se debe prestar mayor atención a las actitudes negativas del profesional al momento de intervenir en la denuncia que realiza la víctima. Dado que, el impacto de la victimización desencadena una serie de alteraciones en la conductas de las víctimas a nivel psicosocial, originando la revictimización por parte del sistema jurídico-penal (Beristain, 2000).

Por otra parte, es posible que una inadecuada asistencia a las víctimas de los delitos en general termine por afectar su proyecto de vida y su relación con el entorno, por lo tanto se hace necesario mencionar específicamente lo siguiente: verbigracia, en el caso de los delitos de abuso sexual el incremento de violencia en niños, niñas y 
Escala SAMANTO para medir actitudes de los operadores judiciales hacia la víctima 18

adolescentes víctimas de esta agresión es alarmante. De ahí que, autores como Marchiori, Biodo y Fortete, (2004) sostiene que en la mayoría de estos casos la agresión sexual, indirectamente conlleva a que la víctima sea revictimizada y sufra un mayor daño.

También, añade que los profesionales encargados de recibir las denuncias de estos delitos no asumen la mejor actitud hacia la víctima, siendo indiferentes a su dolor, no demostrando consideración alguna por el sufrimiento en el que estas se encuentran, al parecer se sistematizan tanto, al punto de la deshumanización. Por ende, olvidan toda consideración a su prójimo, que ahora, es vulnerado en su frágil humanidad, por el sistema jurídico-penal, al cual acudieron en búsqueda de protección (Marchiori, Biodo y Fortete, 2004).

Por consiguiente, los operadores de justicia debieran propender por un mejor encuentro entre la víctima y el sistema jurídico, evitando de esta forma la revictimización. Además, tener presente la debida consideración a las víctimas, en especial a las víctimas de abusos sexuales. Puesto que, se entiende como victimas a todas las personas que individual o colectivamente, hayan sufrido daños, inclusive lesiones físicas o mentales, sufrimiento emocional, pérdida financiera o menoscabo sustancial de los derechos fundamentales, como consecuencia de acciones u omisiones, entre las que se incluyen las relacionadas con la sexualidad (ONU, 1985).

En el mismo sentido, autores como Melup, Viano y Emilio (2009) concuerda en que las víctimas de los delitos sexuales deben tener una adecuada asistencia y que los principios de la justicia en cuanto a estos delitos sean aplicados en justa medida. Así que, se favorezca a la víctima mediante una eficaz asistencia de todos sus operadores, otorgándose el cuidando que esta merece, previniendo de esta manera que no sufra la 
frialdad del sistema jurídico-penal. Dicho en otras palabras, evitar la victimización y el daño psicosocial en aquella persona que de hecho, ya padece las consecuencias de un determinado delito.

Aunado a lo anterior, el impacto de los delitos en general y como lo señalan Dallos, Pinzón, Barrera y González (2009) no solo afectaran la salud mental de las víctimas, sino que al tener que volver a revivir los hechos de la agresión, alterara la salud psíquica de forma significativa, lo cual se demostrara en el comportamiento que estas empezaran a evidenciar en la cotidianidad en sus relaciones interpersonales, también se podría ocasionar el decrecimiento negativo de sus redes sociales.

En efecto, el incremento de la victimización que padecen las víctimas en la actualidad, devela el fracaso de las instituciones jurídicas, evidenciándose la falta de preparación de los profesionales para atender las denuncias por delitos en general o denuncias por delitos concretos. Es otras palabras, la dignidad de las víctimas se ve afectada cuando no encuentran en el aparato jurídico una asistencia justa como lo sería: el acceder al sistema judicial, asistencia social, médica, psicológica, económica, acompañamiento durante el proceso, etc. También es cierto, que en varios casos la víctima termina por ser difamada, sospechosa, criticada y en el peor de los casos cuestionados y abandonados a su suerte (Beristain, 2000).

Razón por la cual, se hace necesario velar por la integridad de las víctimas, por sus derechos y acompañamiento antes, durante y después del evento agresivo, garantizándoles con ello el cuidado y protección que estas demandan del sistema jurídico-penal. Toda vez, que los operadores de justicia reciban capacitación pertinente que contribuya en la atención y asistencia a las víctimas. En consecuencia, se aseguraría un trato humano y asistencia integral para las mismas (Beristain, 2000). 
Por otra parte, según lo indagado con anterioridad en la literatura de diversos autores afines al presente tema, no existen instrumentos ni escalas para detectar el fenómeno de la revictimización. Así que, es necesario diseñar y construir instrumentos y escalas confiables, que permitan medir las diversas actitudes revictimizantes por parte de los operadores responsables de recibir las denuncias de los diferentes delitos. Siendo asi, se detectaría a tiempo estos tipos de conductas, generando un trabajo de prevención en la concienciación de los profesionales al buen trato y a la no victimización.

\section{La víctima, victimizaciones y el sistema jurídico}

De otra manera, autores como Landrove (1990) mencionan que la victimología ha influido en gran manera en el derecho penal moderno sobre todo en cuanto a la sensibilización del sistema, viendo al ser humano desde una óptica más digna por ser la víctima la que sufre un daño a consecuencia del delito. Asimismo, se refleja la experiencia individual del agredido(a) y las diversas consecuencias perjudiciales primarias producidas por estos tipos de transgresión de índole física, económica o psicosocial.

En efecto, con frecuencia los daños que padece la víctima no se limitan únicamente a las lesiones físicas, la víctima sufre a menudo un severo impacto psicológico en el cual se incrementa el daño material o físico del delito, la impotencia ante la agresión, o el miedo por que se repita el evento, producen ansiedad, angustia o decaimiento y con cierta frecuencia complejos de culpabilidad. Por consiguiente, estas secuelas se evidencian en los hábitos del individuo y en las relaciones interpersonales que con frecuencia terminan por ser conflictivas e indolentes. Por otro lado, la respuesta social ante los padecimientos de la víctima no es siempre solidaria, en el mejor de los 
casos terminan en actitudes compasivas o de conmiseración, lo cual, genera aislamiento de la o las víctimas, a esto se le conoce como victimización primaria (Landrove, 1990).

No obstante, la falta de credibilidad y seguridad en el orden social, la soledad, inseguridad, miedo, impacto psicológico y la angustia que se derivan de la relación de la víctima con el sistema jurídico, ocasionan que en diversos casos la victimización secundaria resulte más negativa que la primera victimización, que ya se incrementa el daño causado por el delito inicial que promovió a la denuncia. Asimismo, cuando la víctima entra en contacto con la administración de justicia o la policía, el perjudicado(a) experimenta muchas veces el sentimiento de estar perdiendo el tiempo, de ser ignorado(a) por la indiferencia y el maltrato al que es sometido(a) (Landrove, 1990).

También, puede llegar a ser tratado(a) como acusado(a) o culpable y padecer la falta de credulidad de determinados profesionales que atienden delitos de abuso sexual. Por ende, en ocasiones los interrogatorios de la defensa se orientan a tergiversar su intervención en los hechos que se juzgan; verbigracia: el abogado que intenta hacer “confesar" a la víctima de abuso sexual que este se produjo con su consentimiento (Landrove, 1990).

Precisamente, las anteriores razones son algunas de las actitudes inadmisibles que exigen una urgente modificación, ya que es el mismo sistema quien revictimiza a la víctima que ha acudido en busca de "justicia y protección”. A la postre, esto afecta el prestigio del propio sistema y condiciona de forma negativa la actitud de la víctima y del colectivo social respecto del mismo aparato jurídico-penal (Landrove, 1990).

Consecuentemente, el agraviado se convierte en objeto de una victimización por parte del mismo sistema jurídico, razón por la cual la víctima puede ser objeto de una tercera victimización que resulta de la vivencia del proceso a lo cual se le añade los 
efectos de la publicidad del caso, lo que la hace convertir en una víctima "héroe", adoptando a su vez conductas delictivas como forma de vengarse por el abandono y las injusticias padecidas por el sistema jurídico. Por tanto, con la finalidad de proteger al agredido/a de una segunda victimización, el comité de Ministros del Consejo de Europa aprobó, el 28 de junio de 1985, una serie de recomendaciones encaminadas a mejorar la situación de la víctima en el proceso penal, es decir, la víctima debe ser tratada de tal forma que no sufra ningún daño psíquico (Landrove, 1990).

También, se debe proporcionar la posibilidad de recibir de las instituciones públicas o privadas ayudas materiales, médicas y psicológicas, además, a la víctima se le debe informar sus derechos de reparación en contra del victimario. Aunado a lo anterior, se reitera la importancia en la atención satisfactoria que debe recibir la víctima que ha padecido algún tipo de delito, en especial el delito de abuso sexual por ser este el más sensible para que se propicia la revictimización. Por tanto, tener el cuidado de no promover la victimización entre las víctimas que acuden al sistema legal.

En el mismo sentido, otros autores como Castro y Garay (s.f) verificaron e insisten en que es importante tener claro cómo actuar ante las víctimas de abuso y más si las víctimas son niños, niñas o adolescentes (NNA). Por tanto, en la asistencia a víctimas deben considerarse las necesidades especiales mediante un abordaje con los lineamientos descritos a continuación:

- Se debe responder igualitariamente, con respeto y compasión, a todas las víctimas.

- Protegerlas de futuras victimizaciones, estableciendo las medidas cautelares o medidas de protección procedentes.

- Referir a las víctimas a servicios de contención en crisis y de apoyo. 
Escala SAMANTO para medir actitudes de los operadores judiciales hacia la víctima 23

- Informarles acerca de sus derechos.

- Empoderarlas para que participen activamente dentro del proceso.

- Tener como objetivo la reparación del daño ocasionado.

- Alentar a las víctimas a que cuenten su historia y escucharlas cuidadosamente.

- Involucrar a las víctimas en el diseño e implementación de protocolos de atención.

También, Castro y Garay (s.f) verificaron que cuando una persona resulta víctima de una conducta lesiva:

"Es deber legal de la justicia y de las instituciones públicas y privadas que les prestan servicios, brindarles una respuesta positiva, no sólo asumiendo la responsabilidad de proveer una justicia pronta y cumplida, sino procurando allanar el camino a lo largo del proceso, para poder lograr de esta manera minimizar el sufrimiento y la revictimización. Esto sólo se podrá lograr en la medida en que asumamos nuestras obligaciones legales y éticas; y nos visualicemos como agentes de cambio desde las diferentes instituciones públicas y privadas en las que nos desempeñamos”. (p. 7).

Dicho de otro modo, la victimización secundaria radica en los sufrimientos derivados de las víctimas y testigos. Los cuales, involucran principalmente a los participantes pasivos de un delito, como lo son las instancias judiciales encargadas de hacer justicia (policías, psicólogos, psiquiatras, trabajadores sociales, médicos, abogados, jueces, peritos, criminólogos, funcionarios de instituciones penitenciarias, etc.) Dado lo anterior, es importante tener en cuenta que la constante reiteración de lo sucedido puede formar parte de una nueva experiencia traumática la cual, es difícil de 
Escala SAMANTO para medir actitudes de los operadores judiciales hacia la víctima 24

explicar o justificar cuando el temor y la vulnerabilidad está presente en la víctima (Beristain, 2000).

Cabe resaltar que las víctimas de los diversos delitos son objeto de asistencia oportuna y eficaz, pero, es necesario centrar esfuerzos en la atención a las víctimas que sufren el delito de abuso sexual, puesto que, son cruelmente agredidos en su vulnerabilidad e indefensión. Por tanto, se encuentran mayormente expuestos a múltiples riesgos como el silencio a la no denuncia si volviere a ser objeto de agresión sexual (Hernández y Tapias, 2010).

De ahí que, el profesional encargado de recibir la denuncia de la agresión sexual por parte de la víctima, tendría el deber humano con este sobreviviente del delito de aportar al mejoramiento en el sistema legal. Es decir, que la institución y la víctima se acerquen por medio del buen-trato y se continúe trabajando en el fortalecimiento de la relación entre los dos (Hernández y Tapias, 2010).

Adicionalmente, la indiferencia ante la realidad en la que se encuentran los niños, niñas y los adolescentes (NNA) que han sido y son víctimas de delitos sexuales, conlleva a la propagación de este delito que como resultado también tendrá el silencio de los inocentes. Porque, en los casos de abuso sexual los (NNA), además, de sufrir el mal infinito de la agresión, se verán expuestos al tortuoso calvario del proceso penal. Por tanto, no se puede negar que nuestro sistema penal es vindicativo, jurídico punitivo, no pretenden como finalidad primera la protección del (NNA), sino la aplicación de la ley por cuanto se ha transgredido la misma. Es decir, la imposición de una pena al autor del delito (Save the children Alliance, 2001).

Adicionalmente, la revictimización también se entiende como toda acción u omisión que empeore el estado físico o psíquico de la víctima cuando busca ayuda y se 
Escala SAMANTO para medir actitudes de los operadores judiciales hacia la víctima 25

relaciona con el sistema legal, instancias en las que puede encontrar insensibilidad, incomprensión, nuevas agresiones. Además, que se le ponga en tela de juicio, dilataciones en el proceso, falta de información pertinente (Echeburúa, Corral y Amor, 2004 citado en Tapias, 2011). Otros autores, concuerdan en que la revictimización también se entiende como toda acción u omisión que contribuya al detrimento del estado físico, mental o afectivo-emocional de la persona víctima de determinado delito (Beristain, 2000; Landrove, 1990).

Entonces, se entiende por revictimización la mala intervención y asistencia psicológica terapéutica o médica que brindan profesionales inescrupulosos y faltos de preparación asertiva para atender las diversas situaciones que revisten ciertos aspectos particulares. En el mismo orden de ideas, la revictimización o doble victimización se refiere a las repetidas situaciones por las que tienen que pasar las víctimas después de haber sido afectadas por determinado delito, propiciándose el encuentro con los órganos judiciales y viéndose en la penosa situación de testificar infinidad de veces. Como consecuencia de lo anterior, surge el daño psicológico que perturbara emocionalmente y afectará a la víctima de una manera significativa, profunda y traumática (Rozanski, 2003 citado en Gutiérrez de Piñeres, Coronel y Pérez, 2009).

Por consiguiente, a partir de la denuncia las víctimas o dolientes de cualquier delito, deben enfrentar diversidad de situaciones en el ámbito de la justicia. Al mismo tiempo, que las hace padecer largas esperas en pasillos, interminables recorridos en diferentes oficinas, reiteradas indagaciones y nuevas citaciones que con frecuencia las llevan a arrepentirse de haber realizado la denuncia. Por tanto, esta experiencia negativa es lo que origina el silencio de los inocentes (Rozanski, 2003 citado en Gutiérrez de Piñeres, Coronel y Pérez, 2009). 


\section{Secuelas psicológicas de la revictimización.}

En el mismo sentido, y haciendo hincapié de los modelos de revictimización enfocados en las secuelas traumáticas las cuales se asocian a los delitos en general, se ha demostrado que estas afectan de forma psicológica, cognitiva y comportamentalmente. En consecuencia, terminaran por influenciar las relaciones interpersonales de las víctimas. De ahí, que con respecto al delito de abuso sexual, subsecuencialmente se incremente el riesgo de revictimización en los niños y niñas que son víctimas de esta infracción (Cloitre y Rosenberg, 2006; Marx, Heidt y Gold, 2005; Messman-Moore y Long, 2003 citados en Terri, Moore, Walshb y DiLillo, 2010).

Por consiguiente, los delitos en general y las numerosas formas de abuso sexual a niños, niñas y adolescentes (NNA) están relacionados con diversas sintomatologías. Las cuales, han sido vinculadas a la revictimización e incluyen: estrés postraumático, disociación de la realidad, riesgo de la percepción, abuso de alcohol y de sustancias psicoactivas (Casey y Nurius, 2005 citados en Terri, Moore, Walshb y DiLillo, 2010). En efecto, estas a su vez se enlazan con dificultades interpersonales (Rich, Gidycz, Warkentin, Long y Weiland, 2005 citados en Terri, Moore, Walshb y DiLillo, 2010) y múltiples riesgos de comportamiento antisocial (Orcutt, Cooper y García, 2005 citados en Terri, Moore, Walshb y DiLillo, 2010).

Aunado a lo anterior, los diversos delitos entre los que se cuentan el abuso sexual, han conllevado al desarrollo de numerosos estudios obteniendo resultados alarmantes como los reportado por 113 mujeres afrodescendientes entre los 11 y 31 años de edad, quienes han relatado historias de la revictimización que genera el abuso sexual cuando son menores. Precisamente, en ellas se ha encontrado que el $30 \%$ de las mujeres que han reportado abuso sexual fueron revictimizadas al registrar la denuncia siendo 
niñas, desencadenando en su vida adulta conductas antisociales y logrando en varios casos huir de la ley (Fryer y Miyoshi, 1994; Levy, Markovic, Chaudry, Ahart y Torres, 1995 citados en Spatz, Czaja y Dutton, 2008).

En el mismo sentido, un gran número de mujeres que fueron abusadas en la niñez registraron un alto rango de revictimización del 51\%, comparado con las mujeres que tienen solo una historia de abuso sexual físico con el $36 \%$, o con abuso sexual solamente el 13\% (Finally, Cloitre, Tardiff, Marzuk, Leon y Portera, 1996 citados en Gold, Sinclair y Balge, 1999). Asimismo, mujeres que fueron abusadas sexualmente en la niñez manifestaron haber sido mayormente revictimizadas, con respecto a la mujer adulta que haya pasado por abuso sexual. Por consiguiente, es nocivo el patrón que opera en la victimización, puesto que las secuelas del niño(a) abusado(a) es de considerarse en razón a los diversos daños psicosociales y problemas somáticos susceptibles a desencadenarse los cuales resultaran en perjuicio de la sociedad (Beichman, Zucker, Hood, Dacosta y Akman, 1991; Beichman, Zucker, Hood, Dacosta y Akman, 1992; Kendall-Tackett, William y Finkelhor, 1993 citados en Gold, Sinclair y Balge, 1999).

Por ende, la revictimización solo incrementa los problemas en la víctima (S.R. Gold, Milan, Mayall y Johnson, 1994; Koverola, Proulx, Battle y Hanna, 1996; Wind y Silvern, 1992 citados en Gold, Sinclair y Balge, 1999). Razón por la cual, es de esperar que las mujeres que fueron en la niñez revictimizadas, comparadas con las mujeres que fueron abusadas en la niñez pero no revictimizadas, presenten una mayor predisposición a adquirir en la adultez intervención psicológica, servicios médicos, psicoterapia. Además, tendrán dificultades en su vida marital y laboral. Por consiguiente, es difícil estimar el costo que deja los diferentes tipos de revictimización en la niña que ha 
Escala SAMANTO para medir actitudes de los operadores judiciales hacia la víctima 28

padecido abuso sexual y que a la postre se verán los resultados de dicha agresión en la adultez, como lo han comprobado los estudios que afirman que existe una alta probabilidad de que estas niñas terminen infringiendo la ley en su vida como mujer adulta (Gold, Sinclair y Balge, 1999).

En otras palabras, el prolongamiento de las situaciones revictimizantes es un problema substancial para los niños, niñas y los adolescentes (NNA) sobrevivientes de abuso sexual, entre otros delitos que las víctimas en general afrontan. Sin embargo, es necesario aclarar que lo que se sabe con respecto a la victimización viene de una retrospectiva del estudio del testimonio de víctimas adultas que recuerdan los sucesos del abuso sexual en la niñez o de algún otro delito en la que fueron afectadas de forma directa o indirecta (e.g., Arata, 1999; Cloitre, Cancienne, Brodsky, Dulity, Perry, 1996; Merrill, 1999; Stermac, Reist, Addison y Millar, 2002; Urquiza y Goodlin-Jones, 1994 citados en Barnesa, Noll, Putnama y Trickett, 2009).

En el mismo sentido, los profesionales de la salud mental concuerdan en que un gran número de los casos por delitos en general en especial los que refieren al abuso sexual a niños, niñas y adolescentes (NNA) puede convertirse en una problemática de orden psicolegal. Razón por la cual, el sistema jurídico en representación de los profesionales que atienden los diversos delitos deben estar prestos a no complicar los procesos por las inconsistencias que en ocasiones suelen presentarse con respecto a la transgresión de la ley, y aun más, cuando se trata de delitos sexual proferidos a niños, niñas y adolescentes (NNA) o mujeres adultas, en los que se ha constatado el maltrato de los operadores de la justicia en contra de estas víctimas (Gold, Sinclair y Balge, 1999). 
Escala SAMANTO para medir actitudes de los operadores judiciales hacia la víctima 29

Con el mismo propósito, existen diversos estudios cuyos resultados soportan la hipótesis de una angustia psicológica que igualmente precede a una posterior revictimización. De esta manera, se hace evidente las diferentes formas de victimización las cuales incluyen al crimen convencional, maltrato, victimización entre hermanos, victimización sexual y victimización a testigos. En efecto, las investigaciones han comprobado que la victimización psicológica está encausada hacia la angustia y traumas sintomatológicos que padecerán las víctimas y aun más si se trata de niños, niñas y adolescentes (NNA) (Boney-McCoy y Finkellhor, 1995; Briere y Elliott, 2003; Finkelhor, Ormrod y Turner, 2007 citados en Cuevas, Finkelhor, Clifford, Ormrod y Turner 2010).

Ahora bien, respecto a la credibilidad del testimonio de los niños, niñas y adolescentes (NNA) es un riesgo no creerles cuando realmente son víctimas, pero, se debe tener gran cuidado, postura científica y objetiva, ya que, autores como Garrido y Herrero (2006) manifiestan que los (NNA), si pueden ser manipulados y esto se convierte en un riesgo en el proceso judicial.

En el mismo sentido, la Ley 1098 de noviembre 8 de 2006 la cual, es concerniente a los derechos, deberes y cuidados que se otorgan a la infancia y la adolescencia, incorpora la doctrina de la protección integral de la niñez, reconociéndolos como sujetos de derechos, asimismo, las consideraciones debido a la edad que se deben tener presente cuando han sido víctimas de algún delito, para no incurrir en la victimización de los niños, niñas y los adolescentes (NNA), y con ello, cuidar de no vulnerar los derechos consagrados en dicha Ley.

Por lo tanto, el gobierno Colombiano se ha esforzado en que los derechos de los niños, niñas y adolescentes (NNA) sean cumplidos, exigiendo el cuidado y protección 
por parte de los organismos judiciales, velando porque se les otorgue la debida atención cuando han sido víctimas de los diversos delitos. Razón por la cual, cuando el niño, niña o adolescente (NNA), acude al sistema jurídico para denunciar, hay ciertas consideraciones dependiendo del delito, que se deben tener en cuenta ("Congreso de Colombia”, Ley 1098 de 2006; Ley 1620 de 2013).

- Registrar debidamente la denuncia. El operador judicial es clave en este proceso, ya que, de la atención que se le preste al (NNA) se aclararán los hechos, toda vez, que se concede el cuidado y protección a la víctima.

- Otorgar un ambiente de confianza. Los niños que acuden al sistema judicial en busca de protección, se sentirán más cómodos en medio de un ámbito que les proporcione seguridad, asu vez, esto permitirá que la víctima acuda a las diversas etapas del proceso sin temor alguno.

- Proveer información del proceso a la víctima. Explicar en un lenguaje sencillo, facilita al (NNA) la comprensión del avance, estancamiento u obstrucción del asunto.

- Entrevista. Cuidar que el estilo de preguntas no se han inducidas o sesgadas, el uso de la cámara Gesell es de gran ayuda al momento de efectuar la entrevista, así como el micrófono y el audio.

- Representante legal. Para los procesos que atañen al esclarecimiento de los hechos, los (NNA) acudirán en compañía del representante legal, defensor de familia si fuere el caso.

- Garantizar la protección. El (NNA) no tendrá audiencias o careos frente al presunto agresor, tampoco se le expondrá al escarnio público, ya que, el sistema 
Escala SAMANTO para medir actitudes de los operadores judiciales hacia la víctima 31

jurídico es el garante y responsable de velar por el derecho superior del niño, niña y adolescente.

- Recuperar el bienestar de la víctima. Durante el proceso, el (NNA) tendrá el acompañamiento y tratamiento que fuere necesario para el equilibrio psíquico y biológico por la afectación de la que fue víctima, también, propender por el bienestar integral y reparación por el daño ocasionado.

- Operadores judiciales especializados. Poco a poco Colombia se ha ido posesionando dentro de los países líderes en cuanto al trato y consideraciones que se debe otorgar a los (NNA), puesto que cuenta con el profesionalismo de la policia de infancia y adolescencia. Además, jueces, fiscales y abogados capacitados para los determinados delitos en que se hallen involucrados los niños, niñas y adolescentes. También, se les insta para que aparte de hacer cumplir la ley, se comprometan en ser guardianes de los derechos de los niños, niñas y adolescentes, humanizando el quehacer profesional en medio de esta población vulnerable.

Por otra parte, Save The Children Alliance, (2008). Manifiesta que los efectos nocivos de la revictimización pueden provocarse en las personas que ya una vez han sido víctimas de algún delito, y vuelven a serlo cuando funcionarios del Estado efectúan intervenciones no especializadas o interrogatorios estereotipados. Asimismo, se debe tener en cuenta que los interrogatorios excesivos y los procesos largos pueden ser otro medio de revictimización, por tanto, deben asegurarse que las acciones e intervenciones no tengan efectos negativos para la persona; es decir, evitar nuevas formas de vulneración a sus derechos fundamentales, teniendo ante todo presente el sufrimiento de la víctima. 
Según lo afirma, Anep-Consejo de Educación Primaria - CEP (2007) se ha encontrado que el inadecuado manejo por parte de los operadores de la justicia en la asistencia jurídica-penal, que se da a los (NNA) víctimas de algún delito, a la postre resultan en perjuicios lamentables para la sociedad. Razón por la cual, es importante disminuir los daños de estas situaciones en la vida de los niños, niñas y los adolescentes (NNA), es necesario que las medidas que se adopten para intervenir en ellas prioricen la restitución de los derechos vulnerados y la construcción de un proyecto de vida que habilite vínculos sociales basados en el respeto, la confianza y ante todo evitar la revictimización, con lo que se pretende impedir futuros delincuentes, (NNA) que en su vida adulta presenten diversas afectaciones psicológicas.

En este mismo orden de ideas, fundaciones como Amparo y Justicia, preocupada por la victimización que padecen las víctimas en general, en especial los niños, niñas y adolescentes (NNA), afirma que es desalentador el panorama puesto que los delitos en contra de los (NNA) continúan en aumento, mientras que las denuncias son pocas y no superan ni el $20 \%$ de los ilícitos cometidos. Esta abstinencia al denuncio se debe al temor de comparecer ante los operadores de justicia arriesgándose hacer revictimizados, la cual se produce durante el proceso investigativo y judicial. Por ende, las condiciones inadecuadas y la falta de formación de los profesionales es un factor relevante y decisivo al momento de instaurar o no la denuncia (Suárez y Espinosa, 2011).

De este modo, el alto número de entrevistas a las que son sometidos las víctimas durante el proceso, puede llegar a resultar un atentado contra los derechos y dignidad de las mismas. De igual forma, una encuesta realizada por la fundación Amparo y Justicia, concluyó que en cuanto a los niños, niñas y adolescentes (NNA) víctimas de 
delitos sexuales, estos pueden llegar a ser entrevistados hasta siete veces durante el proceso. Inclusive, el mismo estudio revela el grado de insatisfacción de las víctimas en general con el sistema investigativo y judicial en el que se evidencia una clara desconfianza (Suárez, y Espinosa, 2011).

De ahí que, la revictimización incluye la inadecuada intervención tanto psicológica, terapéutica o médica que brindan los profesionales a la víctima una vez que entra en contacto con el sistema judicial. Por ende, uno de los factores que contribuye al fenómeno de la victimización secundaria es el desconocimiento por parte de las autoridades y funcionarios encargados de la atención a los afectados, y el desconocimiento de los derechos que las víctimas tienen por ley (Beristain, 1996; Rivera, 1997; Rozanski, 2003 citados en Gutiérrez de Piñeres, Coronel y Pérez, 2009).

Adicionalmente, no debe perderse de vista que la revictimización es un fenómeno que afecta a las víctimas de los delitos en general. Puesto que, a la víctima se le debiera garantizar la protección durante su interrogatorio, después de que este concluye y durante todos los actos del procedimiento judicial que la involucren directa e indirectamente. Por consiguiente, no se debe ahondar sobre la afectación personal que ha provocado el delito, por el contrario se debe evitar la victimización secundaria (Gallego, 2008).

Paralelamente, Albertin (2006) menciona otros factores causantes de la victimización secundaria por parte del sistema jurídico-penal:

- Dar prioridad a la búsqueda de la realidad del suceso delictivo olvidando la atención a la víctima o despersonalizando su trato.

- La falta de información sobre la evolución del proceso, sobre la sentencia y sobre el destino del victimario. 
Escala SAMANTO para medir actitudes de los operadores judiciales hacia la víctima 34

- La falta de un entorno de intimidad y protección.

- Excesivos tecnicismos jurídicos.

- Desconocimiento de los roles profesionales por parte de la víctima.

- La excesiva lentitud el proceso judicial y su interferencia con el proceso de recuperación y readaptación de la víctima.

- El juicio oral: la narración del delito, la puesta en entredicho en su credibilidad y el sentimiento de culpabilidad son importantes inductores de tensión.

\section{Esfuerzos para no revictimizar.}

Por otra parte, según el reporte del Fondo de las Naciones Unidas para la Infancia (United Nations Children's Fund) (UNICEF, 2010) sostienen que en cuanto a los delitos cometidos en contra de los niños y niñas, el sistema de justicia tiene que esforzarse por ser eficiente, oportuno y cercano a los menores y sus familias. Sin duda, este no es tan solo el ideal, más bien debiera ser la cualidad y el estandarte de todos las instancias que atienden a los menores víctimas de los diversos delitos.

Precisamente, los esfuerzos que (UNICEF, 2010) El Salvador realiza respecto a este tema, están encaminados a la no revictimización motivada por una inadecuada asistencia por parte de los operadores de la justicia. Sin embrago, es necesario tener presente que los jueces, abogados, psicólogos, médicos forenses, entre otros profesionales, necesitan pasar por un proceso que los capacite para saber abordar a la niñez que hoy día padece los suplicios de los diversos delitos, evidenciando una asistencia cálida, humana, justa e integral, lo que incluirían afectividad y humanización en su quehacer, para proteger verdaderamente la dignidad del (NNA) y evitar con esto que el mismo sistema de justicia lo revictimice. 
De tal manera, que las actitudes de los profesionales debieran estar dirigidas a la protección y cuidado de las víctimas en general y no en el desencadenamiento de actitudes revictimizantes que es lo que se evidencia en el proceso penal. Verbigracia, son las salas de capacitación de la Corte Suprema de Justicia de El Salvador, en las que se puede constatar a un grupo de personas sentadas en el suelo, no se podría adivinar que se trata de una juez o jueces. Entre los que se cuentan, 120 operadores que reciben técnicas de comunicación no verbal (UNICEF, 2010).

En efecto, este esfuerzo forma parte de la preparación para el uso correcto de las cámaras Gessell, que son instrumentos tecnológicos facilitados por el fondo internacional de ayuda a la infancia de las naciones unidas con el apoyo de la cooperación Italiana, con el fin de evitar la revictimización por las actitudes negativas de los operadores hacia las niños, niñas y adolescentes (NNA) durante los procesos penales. Como resultado, de la modificación de la conducta en los profesionales, se ha evidenciado una actitud que favorece los procesos y motiva a la denuncia en general (UNICEF, 2010).

Por consiguiente, el éxito de la preparación que han tenido estos operadores para ejercer un proceso penal amigable a la niñez y a sus familiares, es intentar que ellos mismos contacten con su niño interno y a partir de allí, aprendan a comunicarse con los niños, niñas y adolescentes (NNA) que llegan a sus tribunales, en un lenguaje reparador que incluye mirarlo a los ojos con consideración, hablarle en un tono pausado y afectuoso. Seguidamente, se procede a romper esquemas y superar ciertas creencias acerca de las características de los (NNA) víctimas de delitos, también, evidenciar agilizamiento en los diversos procesos (UNICEF, 2010). 
Escala SAMANTO para medir actitudes de los operadores judiciales hacia la víctima 36

Por consiguiente, es necesario tener presente que cada víctima es única, es diferente al momento de la vulneración de sus derechos y de su dignidad e intimidad, cada una va a responder de acuerdo a los recursos internos adquiridos hasta ese momento. No se puede juzgar por apariencias o bien, generalizar. A través de la revisión de mecanismos psicológicos como la "teoría del doble vínculo" y la "resiliencia". Asimismo, los operadores de la justicia deben aprender a cuidarse a sí mismos de los efectos del desgaste que produce el contacto permanente con el dolor. Todo lo anterior, se desarrolla dentro de simulacros que se llevan a cabo al interior de las Cámaras Gessell (UNICEF, 2010).

En consecuencia, varios de los operadores judiciales que participaron en las respectivas sesiones de formación, era la primera vez que se encontraban en un espacio diseñado para protección de los niños, niñas o adolescentes (NNA) víctimas de algún delito. En razón del alcance, fueron muchas las manifestaciones de alegría y también de expectación frente al reto de llevar los conocimientos adquiridos y la tecnología de las cámaras Gessell, a los lugares más apartados de El Salvador. Lo que es más importante, el sistema de justicia de este país, tiene la esperanza de que este modelo de atención y el uso de nuevas herramientas alcance a toda la niñez y adolescencia que hoy día son objeto de dolor por los diversos delitos que padecen. Además, contribuir en la disminución de la revictimización que es propiciada por las actitudes despiadadas de los órganos judiciales (UNICEF, 2010).

Por lo tanto, las sesiones antes mencionadas, han propiciado los espacios de descubrimiento de los operadores con un profundo sentido de la dignidad y claro conocimiento de las condiciones de vulnerabilidad de la infancia salvadoreña y demás países. Por ende, hoy día no es de extrañarse en El Salvador que una juez tome 
declaración a una niña de tres años teniéndola sentada en su regazo, o que un juez en ausencia de otra herramienta, utilice su propio abrigo para evitar que la niña quede a la vista de su agresor, o que un juez de casi 80 años, ordene que le sean quitadas las esposas a los jóvenes sospechosos de un delito y les explique los motivos por los cuales están siendo procesados, así también, no es de extrañarse que una juez durante los simulacros, se siente en la silla infantil de la cámara Gessell y participe en un psicodrama simulando ser una víctima, y que permita que esto sea grabado y utilizado con fines didácticos para la formación de operadores de otros países, con el fin de aportar a la disminución de la revictimización (UNICEF, 2010).

Por este motivo, es interesante el proceso de transmisión de conocimientos, y el cambio en el comportamiento de las actitudes que estos generan. En definitiva, la decisión de hacer "justicia asertiva" es una inversión que a la postre repercutirá en la confianza y credibilidad hacia el sistema jurídico-penal, y en el progreso de un país (UNICEF, 2010).

Por su parte, autores como Rochel (2005), señala algunos factores que influyen para que se desarrolle un ambiente de maltrato y revictimización en un ámbito judicial, dentro de los que se incluyen:

- Falta de información a la víctima de los protocolos y tiempos procesales (especialmente cuando el victimario no es detenido).

- Frustración de sus expectativas cuando no se llega a la condena.

- La víctima debe dar la versión de los hechos en presencia del victimario.

- Lentitud procesal-penal.

- La propia subjetividad de los profesionales y sus condiciones de trabajo (maltrato institucional, etc.) 
Escala SAMANTO para medir actitudes de los operadores judiciales hacia la víctima 38

- Racionalización por parte de algunos profesional de la situación de la víctima ("algo estaría haciendo para que le ocurriera lo que le paso")

- La forma en que se tipifican los delitos en los códigos penales y la definición del sujeto pasivo de dicho delito (en la legislación penal argentina no se utiliza la palabra incesto sino que la acusación se hace por "abuso sexual agravado por el vínculo").

- Intervenciones iatrogénicas, en las cuales el personal encargado de la atención a las víctimas, con su intervención, producen más daño que el mismo hecho delictivo.

Por estas razones, las actitudes revictimizantes se refieren a las múltiples victimaciones a las que es expuesta la víctima en el proceso penal, así, la actitud generada por la conducta de los operadores en ocasiones influye para que se desarrolle un ambiente de maltrato y revictimización, el cual resulta más nocivo que el abuso sexual en sí. Dado que, la victimización secundaria parece ser un fenómeno psicológico, social y político que no recibe la suficiente atención por parte del sistema judicial. Existen varias mediadas y alternativas que podrían eventualmente ayudar a minimizar este fenómeno disminuyendo su impacto a nivel psicológico, social y económico en las víctimas (Gutiérrez de Piñeres, Coronel y Pérez, 2009).

Adicionalmente, la victimización secundaria puede combatirse a través de acciones como: facilitar la información pertinente a la víctima, adecuar los espacios donde se realizarán las entrevistas, espera y evaluaciones con el fin de que estos sean agradables y acogedores, diseñar entrevistas apropiadas para víctimas y testigos de diversos delitos. Además, se debe tener presente que las anteriores recomendaciones se resumen en: información, compensación, tratamiento y protección, de hecho estas fueron 
Escala SAMANTO para medir actitudes de los operadores judiciales hacia la víctima 39

aprobadas desde el 28 de julio de 1985, en el Consejo Europeo (Gutiérrez de Piñeres, Coronel y Pérez, 2009).

\section{Las actitudes frente a la revictimización}

Las actitudes implican apreciaciones que bien pueden ser positivas o negativas ante diversas condiciones y escenarios, además, es una expresión bidireccional puesto que hay una persona que la realiza y otra que la recibe. También, exterioriza pensamientos, intereses, emociones y acciones hacia una persona u objeto determinado, así que, si las personas son controladas por el ambiente que las rodea, entonces, pueden ejercer control sobre sus propias actitudes. Ahora bien, los procesos cognoscitivos son internos y estos se visibilizan por medio de diversos estímulos externos, es decir, variables de la conducta que son aprendidas, entonces, por ser aprendidas se pueden modificar y con ello, contribuir al mejoramiento de las relaciones interpersonales y de buen trato, según lo fundamentaron autores como (Allport, 1967; Bandura, 1973; Cattell, 1998; Coll, Pozo, Sarabia y Valls, 1994; Skinner, 1990).

Por otra parte y en el mismo orden de ideas, cabe resaltar que desde los inicios de la psicología hasta la actualidad, se ha venido desarrollando la teoría de los constructos hipotéticos la cual hace referencia a la actitud, cualesquiera que sea esta, es real, y se visibiliza ante determinados estímulos ambientales o situaciones. De tal manera que, las actitudes se caracterizan por poseer tres componentes que en la cotidianidad de las relaciones interpersonales se interrelacionan generando diversos efectos en quienes la perciben, dichos componentes son: componente cognitivo, componente afectivo, componente conativo o comportamental (Coll, Pozo, Sarabia y Valls, 1994).

De otra manera, es pertinente el aporte de autores como Kaiser, quien sostiene que la importancia de la entropatía (relación profunda que se establece desde todo punto 
de vista con las víctimas) es vital, ya que con ello se pudiera evitar las actitudes revictimizantes por parte de los operadores de justicia. Asimismo, Kaiser, menciona que las obligaciones del sistema jurídico-penal al igual que las de sus profesionales, deben centrarse en una atención humana hacia las víctimas antes, durante y después del proceso penal y con ello empezar a quitarse la venda que el órgano de justicia tiene, buscando con ello contribuir en la no revictimización o promover procesos de desvictimización (Beristain, 2000).

Ahora bien, las distintas formas de victimización tales como: victimización primaria, la que se deriva directamente del crimen; victimización secundaria, sufrimientos que a las víctimas o testigos de un delito les infieren directamente las instituciones encargadas de hacer "justicia” policías, jueces, peritos, criminólogos, etc., victimización terciaria, es la que procede principalmente de la conducta posterior de la misma víctima y que en ocasiones emerge como resultado de las vivencias y de los procesos de etiquetamiento como consecuencia de las victimizaciones primaria y secundaria mencionadas anteriormente, estas son ocasionadas por la inadecuada atención y asistencia por parte de los órganos judiciales. Por consiguiente, la víctima que fuera revictimizada, estará propensa a querer vengarse de las injusticias padecidas por parte de sus victimarios (sistema legal y agresor) optando por conductas delictivas (drogodependencia, terrorismo, traficante, prostitución, extorsión, entre otras), razón por la cual, se hace necesario estudiar la relación entre los suplicios generados por la victimización primaria y secundaria, y el resultado de estas dos la revictimización; en cuanto a la victimización terciaria, es tal vez la más nociva, ya que esta desencadena conductas antisociales y tendencias delictivas que causan perjurio en contra de los que 
integran la sociedad, puesto que la víctima fue abandonada por el sistema judicial y ahora está busca venganza (Beristain, 1999).

Por otra parte, la revictimización está precedida por diversas actitudes las cuales se miden en las distintas situaciones u objetos de estimulo, lo cual permite entender que la actitud es la predisposición aprendida para responder consistentemente de una manera favorable o desfavorable ante un objeto o sus símbolos. Siendo así, la mayoría de los seres humanos poseen actitudes de aceptación o de rechazo hacia los distintos estímulos ante los cuales ya existe una predisposición a causa de las interacciones que han tenido con estos a lo largo de la vida (Méndez y Peña, 2006).

También, se pueden presentar ciertas actitudes perjudiciales hacia un objeto o persona determinada. Por ende, las actitudes son predisposiciones aprendidas que reaccionan de determinada manera, si se identifican es posible corregir comportamientos en cierto modo. De ahí que, es necesario tener presente que las actitudes solo son indicadores de conducta que no predicen con exactitud lo que podría pasar, pero son guías útiles de acciones a seguir en la población seleccionada. En el mismo sentido, las actitudes poseen ciertas características las cuales se mencionan a continuación (Méndez y Peña, 2006).

- Dirección. La actitud puede ser favorable o desfavorable al objeto de estudio. Es decir, es posible una actitud neutral cuando el individuo no está a favor ni en contra del objeto de estudio.

- Intensidad. La actitud es alta si el sujeto se encuentra convencido de que la actitud es justificada, mientras que puede bajar si el individuo no piensa de esta manera. Dicho en otras palabras, la intensidad indica el grado en el cual se está a favor o en contra. 
Escala SAMANTO para medir actitudes de los operadores judiciales hacia la víctima 42

- Estabilidad. La actitud es estable si permanece invariable por un periodo considerable. Para efectuar esta medición, es importante realizarla en dos momentos diferentes.

- Fortaleza. Una actitud es fuerte cuando es impersuasible, y suave si cambia con facilidad. Dicho en otras palabras, para medir la fortaleza de una actitud se aplican los opuestos en las propiedades de estabilidad.

Por otra parte, existen otras características importantes de las actitudes que no se develan en un escalamiento de medición, pero que es importante tener presente. Por esta razón, se mencionan a continuación (Méndez y Peña, 2006).

- Importancia. La actitud es grande si esta influye sobre la conducta de una persona en la cotidianidad y en los diversos ámbitos en que se desenvuelve.

- Visibilidad o relevancia externa. Es alta si es fácil concluir, a partir de observaciones sobre la conducta del individuo (manera de hablar, acciones), para lograr esta medición es indispensable llevar a cabo observaciones minuciosa.

- Relevancia interna. Es detectable si en la experiencia del sujeto la actitud por si misma tiene una parte importante en su mundo de referencia. Para conocer la relevancia interna de una actitud en la persona, es necesaria la aplicación de entrevistas profundas.

- Involucramiento del ego. Se involucra el ego cuando este llega a constituir una parte importante de la personalidad o es algo que esta adherido a ella. En este punto se requieren de entrevistas profundas para la indagación.

- Integración y aislamiento. Indica la relación que tiene la actitud en concordancia con un sistema mayor de actitudes interrelacionadas (perspectiva de la vida, ideologías). 
Escala SAMANTO para medir actitudes de los operadores judiciales hacia la víctima 43

- Especificidad o precisión. Es la exactitud de la actitud, lo cual quiere decir que entre más interrelaciones haya tenido el individuo a lo largo de su vida con el objeto estímulo más precisa será esa actitud.

- Verificabilidad. Es el grado en el cual se puede comprobar la existencia de la actitud en la persona. Ejemplo: el conocimiento es verificable, mientras que la fe no.

En el mismo orden de ideas, las actitudes tienen objetos de referencia específicos e implican evaluaciones positivas o negativas las cuales se pondrán en evidencia a la hora de entrar en contacto con la víctima, es decir, a favor o en contra. De ahí que, estas llevan a la persona a amar u odiar, aceptar o rechazar, acercarse u alejarse; una actitud implica un juicio o evaluación tanto del que la evidencia, como del que la percibe (Allport, 1967).

De igual forma, las actitudes son nuestros intereses, emociones y comportamientos hacia una persona, objeto o acontecimiento Cattell (1998) la actitud es más, que estar a favor o en contra de algo. Según él autor los rasgos dinámicos, los ergios y sentimientos, se relacionan con nuestras actitudes mediante el concepto de subsidiariedad, que significa que dentro de nuestra personalidad, algunos elementos subsidian a otros componentes para que finalmente se produzcan aciertos o desaciertos ante determinada situación.

Ahora bien, a lo largo del desarrollo de la psicología como ciencia, ésta ha ido elaborando unas hipótesis, así como unos constructos teóricos destinados a comprender mejor y medir aspectos del comportamiento humano. A estos, se les ha llamado constructos hipotéticos. Así que, un constructo hipotético es un proceso o entidad que suponemos existe aun cuando no sea directamente observable o medible. Uno de estos 
Escala SAMANTO para medir actitudes de los operadores judiciales hacia la víctima 44

constructos hipotéticos elaborados por los psicólogos es la actitud que se evidencia ante determinadas situaciones (Coll, Pozo, Sarabia y Valls, 1994).

En el mismo orden de ideas, las actitudes son propuestas como una propiedad de la personalidad individual, a su vez, es menos duradera que el temperamento, pero más duradera que un motivo, el humor o el estado de ánimo. Por lo tanto, los principales determinantes de las actitudes se entienden en términos de influencias sociales, tales como normas, roles, valores o creencias, esto no las diferencia por completo de otros constructos de personalidad. Consecuentemente, se considera que una actitud es un constructo hipotético, por lo que ha de ser definida por las propiedades que se le asignan. Otros autores verificaron que la actitud es un ordenamiento duradero de procesos motivacionales, emocionales, perceptuales y cognitivos con respecto a alguna apariencia del mundo del individuo. Mientras que otros investigadores manifestaron que la actitud es una predisposición del individuo para evaluar un objeto o el símbolo del mismo (Krech y Crutchfield, s.f; Katz y Stotland, s.f, citados en Coll, Pozo, Sarabia y Valls, 1994).

Autores refirieron que la actitud es una predisposición relativamente estable de la conducta en relación con un objeto o sector de la realidad. Así que, en concordancia con estas definiciones, si el componente motivacional (de activación y orientación de la conducta hacia un objetivo) no estuviera presente, no podríamos hablar de actitud. Entonces, según concuerdan varios autores, la actitud involucra tres componentes: el cognitivo, el afectivo y el comportamental, estos tres son los que se tendrán en cuenta en el instrumento SAMANTO para medir actitudes revictimizantes por parte de los operadores de la justicia (Cattel, 1998; Castillejo, s.f, citado en Coll, Pozo, Sarabia y Valls, 1994). 
Por otra parte, las manifestaciones verbales de las actitudes se denominan opiniones las cuales expresan un posicionamiento evaluativo o predictivo de la persona respecto del objeto de su opinión. Estas a su vez, se diferencian de las cogniciones o creencias por la presencia del afecto específico en la persona. Entonces, las actitudes se discriminan de las habilidades, capacidades o inteligencia no sólo por la presencia de un componente afectivo, sino también, porque la presencia del objeto de la actitud, la cual es suficiente para desencadenar la respuesta y esta a su vez no requiere una motivación adicional (Cattel, 1998; Coll, Pozo, Sarabia y Valls, 1994).

De igual forma, la capacidad de una persona para dar cuenta de sus acciones marca la frontera entre actitudes y hábitos. Entendiéndose como hábito, aquel que se ejecuta en la praxis, en la cotidianidad ya sea verbal o de acción. Mientras que la actitud, se evidencia en un estado de conciencia que puede ser expresado en el lenguaje verbal o no verbal, aunque, es probable que el individuo que lo exprese pueda no estar siguiendo su preferencia en ese momento por otras múltiples situaciones (Coll, Pozo, Sarabia y Valls, 1994).

En este mismo sentido, es posible definir las actitudes como tendencias o disposiciones adquiridas y relativamente duraderas a evaluar de un modo determinado en un objeto, persona, suceso o situación. Las actitudes se caracterizan por poseer tres componentes básicos y definitivos que develan la complejidad de la realidad social, ellos son (Coll, Pozo, Sarabia y Valls, 1994):

- Componente cognitivo (se refiere a los conocimientos y creencias del individuo).

- Componente afectivo (se refiere a los sentimientos y preferencias del individuo).

- Componente conductual o conativo (se refiere a las acciones manifiestas y declaraciones de intención que el individuo tiene). 
Como resultado, estos tres componentes actúan de manera interrelacionada en los diferentes enfoques de la psicología. Que es la encargada de explicar que es lo que ocurre con las actitudes que puede llegar a desencadenar el individuo.

De igual forma, las actitudes tienen su utilidad y funciones, razón por la cual en el acontecer diario se delibera la respuesta actitudinal del individuo. Dado que, las actitudes poseen un carácter funcionalista por lo que las personas tienen una serie de necesidades ya sean biológicas o sociales, es así como adoptan determinadas actitudes que les ayudan a satisfacer esas exigencias. Por consiguiente, las diversas motivaciones y consecuencias que las actitudes dejan en las personas son estudiadas por la psicología. Por ello, esta disciplina ha propuesto cuatro funciones psicológicas de las actitudes, fundamentadas en la naturaleza motivacional, según, lo señalado por los autores a continuación (Coll, Pozo, Sarabia y Valls, 1994): (a) función defensiva: ante los hechos de la vida cotidiana que nos desagradan, las actitudes actuarían como mecanismos de defensa. Dos de estos mecanismos son la racionalización y la proyección. Por ejemplo, una actitud positiva dentro de un grupo podría proteger a una persona de los sentimientos negativos hacia sí mismo o hacia el grupo. Mediante el mecanismo de proyección se tiende con frecuencia, a imputar a personas o grupos; (b) función adaptativa: según esta función, las actitudes ayudan a alcanzar objetivos deseados, es decir, maximización de las recompensas y a evitar los no deseados minimización de los castigos o las penalidades. Así, por ejemplo, adoptar actitudes semejantes a las de la persona hacia la que se siente simpatía puede resultar funcional para conseguir simpatía o un acercamiento; (c) función expresiva de los valores: esta función supone que las personas tienen necesidad de expresar actitudes que reflejen sus valores más relevantes sobre el mundo y sobre sí mismos. Así, las actitudes ayudarían a confirmar socialmente 
Escala SAMANTO para medir actitudes de los operadores judiciales hacia la víctima 47

la validez del concepto que uno tiene de sí mismo, o autoestima, y la de sus valores; (d) función cognoscitiva: las actitudes constituyen, según esta función, un modo de ordenar, clarificar y dar estabilidad al mundo en el que vivimos. A lo largo de la jornada y en los diferentes escenarios en los que nos movemos las personas, recibimos gran cantidad de información que puede suponer una sobrecarga. Las actitudes nos ayudan a categorizar y simplificar mejor ese mundo aparentemente caótico. Por ejemplo, si a un profesor le gusta en particular el trabajo que realiza uno de sus estudiantes, este a su vez esperará que apruebe los exámenes. Su actitud le guía para saber qué puede esperar en determinada situación.

\section{Medición de actitudes revictimizantes encaminadas a modificar conductas.}

Por otra parte, y aunado a lo anterior es pertinente mencionar que el estudio de la conducta en cuanto a los rasgos, develó que la conducta humana es más compleja, mientras que la conducta animal es más simple. Asimismo, esta idea fundamental sostiene que la conducta puede ser controlada por sus consecuencias, es decir, por lo que le sigue. Entonces, es posible entrenar a un animal o ser humano para realizar prácticamente cualquier acto y que el tipo de reforzamiento que siguiera a la conducta sería responsable de determinarla. De ahí que, la conducta respondiente se refiere a respuestas producidas o provocadas por estímulos ambientales específicos y el reforzamiento el cual sería el acto de fortalecer una respuesta al agregar una recompensa, incrementando la probabilidad de que la respuesta se repita (Skinner, 1990).

Ahora bien, para Skinner (1990) la conducta respondiente es menos importante que la conducta operante la cual se emite espontánea o voluntariamente y opera en el ambiente para modificarlo. Así que, el ser humano está condicionado a responder de 
forma directa a diversos estímulos del ambiente que le rodea, cabe aclarar que buena parte de la conducta humana parece ser espontánea y no debe atribuirse directamente a un estímulo específico. Por este motivo, la conducta es emitida más que provocada por un estímulo, el cual responde en forma que pareciera ser voluntaria más que una reacción involuntaria a un estímulo al que se ha sido condicionado.

Consecuentemente, la naturaleza y frecuencia de la conducta operante serán determinadas o modificadas por el reforzamiento que sigue a la conducta, la cual actúa sobre el ambiente, y como resultados se producen cambios positivos o negativos. Por ende, la modificación de la conducta aplica técnicas del condicionamiento operante a problemas del mundo real. Es decir, las conductas deseables se refuerzan positivamente, mientras que las indeseables se ignoran; aunque las personas son controladas por el ambiente, pueden ejercer control de sus actitudes al diseñar ese ambiente de manera apropiada. En efecto, el condicionamiento operante había ofrecido una técnica para mejorar la naturaleza humana y las relaciones interpersonales que se dan en los diferentes ámbitos sociales, así que, lo importante era cambiar la conducta no la personalidad. Pero, otros autores manifestaron que la conducta puede aprenderse mediante el comportamiento vicario al observar la conducta de otros y al anticipar las recompensa por comportarse de la misma manera. Así, los procesos cognoscitivos son mecanismos que median entre el estímulo y la respuesta produciendo el control de la conducta a través de la autorregulación y el autorreforzamiento. Es decir, la conducta es controlada por procesos cognoscitivos internos y estímulos externos, a esto, se le denomino determinismo recíproco, el cual se refiere a la interacción entre variables conductuales, cognoscitivas y ambientales. Además, la mayor parte de la conducta es 
aprendida, por lo tanto los factores genéticos desempeñan un rol menor (Bandura, 1973 y Skinner, 1990).

Por lo tanto, las conductas se pueden modificar en pleno uso de conciencia de la persona, de hecho, la autoconciencia y la autorregulación son vitales para cualquier programa de modificación o aprendizaje de conductas. Por ende, las técnicas de modificación no son eficaces a menos que la persona pueda entender que conductas están siendo reforzadas para producir cambios conductuales deseados. Precisamente, la meta de Bandura al desarrollar su teoría cognoscitiva social fue modificar o cambiar aquellas conductas aprendidas que la sociedad considera indeseables o anormales, por lo que Bandura se centra en los aspectos externos, aquellas conductas inapropiadas o destructivas para la sociedad (Bandura, 1973).

Así que, la no revictimización es un ideal alcanzable y este es un compromiso que debieran pactar los operadores encargados de la asistencia adecuada e intervención pertinente en los diversos delitos. En efecto, al modificar la conducta se obtendrán mejores resultados en los procesos penales que deben afrontar las personas que son víctimas de diferentes delitos (Marchiori, Biodo y Fortete, 2004; Beristain, 2000 y Gallego 2008).

Siendo así, la cognición, emoción y conducta, estarían orientadas hacia actitudes que envisten de calidez y humanidad a los operadores que atienden a víctimas que padecen la furia de los detractores de la ley, que cometen todo tipo de delitos en contra de quienes integran la sociedad. A su vez, las actitudes humanas ejecutadas en la cotidianidad, demuestran el cambio de conducta, el cual, permitirá el acercamiento positivo entre la víctima y los operadores encargados de la atención a la misma (Marchiori, Biodo y Fortete, 2004; Beristain, 2000 y Gallego 2008). 
Aunado a lo anterior, se han identificado dos formas de justicia que pueden contribuir a la minimización del impacto negativo que desencadena la victimización secundaria, como siguen: justicia interaccional y justicia procedimental. Estas a su vez, han sido abordadas tanto por la psicología social y la psicología de las organizaciones (Greenberg y Cropanzano, 2001; Latham, 2006; Vardi y Weitz, 2004).

Entonces, la justicia interaccional, se refiere al trato digno y respetuoso que deben recibir las personas, así, como lo que las personas creen en relación al trato que han recibido, y a la información que se les brindó en relación al procedimiento que los afectaba. Por tanto, en la justicia interaccional propuesta por Greenberg y Cropanzano, se espera que los operadores brinden calidad en el tratamiento interpersonal recibido durante la denuncia y el procedimiento que le sigue (Greenberg y Cropanzano, 2001; Omar, 2006; Vardi y Weitz, 2004).

Consecuentemente, la primera (interaccional) denominada justicia informacional, también se refiere a los determinantes sociales de la justicia procedimental, al uso de la información apropiada para explicar como una decisión fue tomada y la rigurosidad de determinado informe. Asimismo, la justicia Informacional puede solicitarse para obtener conocimiento sobre un procedimiento de interés para las personas. Por ende, en la medida en que las personas reciben una información adecuada sobre el proceso, perciben que son tratadas de forma justa, imparcial y equitativa, por tanto, la víctima es dignifica como ser humano. Lo cual, se refiere a la autenticidad y justificación según los autores (Greenberg y Cropanzano, 2001; George y Brown, 2004). 
De la misma forma, la segunda (procedimental) nombrada como justicia interpersonal, hace alusión al tratamiento imparcial recibido durante la presentación de un procedimiento, al respeto y el pudor con el que fueron tratados(as) como víctimas. Por consiguiente, esta ha sido descrita como el comportamiento que incluye preocupación y sensibilidad por los demás, evidenciándose a través de la expresión de empatía, educación y respeto hacia los demás, es decir, respeto por la otredad. De manera que, en esta dinámica se incluye la ética de la alteridad (Greenberg y Cropanzano, 2001; George y Brown, 2004).

Por otra parte, la justicia procedimental es descrita como el conjunto de procesos para resolver dificultades y asignar recursos. Un aspecto de justicia procedimental está relacionado con los procedimientos legales y la administración de justicia. Por su parte, esta justicia es conocida en otros países por nombres como: justicia fundamental (Canadá), debido proceso (Estados Unidos), equidad procedimental (Australia) y justicia natural (otras jurisdicciones). De ahí que, el beneficio de esta justicia se puede aplicar en contextos que aunque no son legales, para solucionar conflictos o repartir alguna rentabilidad, resulta siendo útil (Miller, Williams, y Bernstein, 1982; Lind y Allan, 1988 citado en Gutiérrez de Piñeres, Coronel y Pérez, 2009).

Por esta razón, es necesario que los operadores que atienden los diversos delitos, se sensibilicen ante el sufrimiento y requerimientos de las víctimas, con políticas claras que priorizan el trabajo mancomunado. El cual, permite una deconstrucción constante en la víctima, haciendo que esta vuelva a reinsertarse en la sociedad, y continúe adelante con su proyección de vida. Asimismo, es posible que una aproximación sistémica pueda contribuir en la optimización de los recursos materiales y humanos en torno a la atención a víctimas (Gutiérrez de Piñeres, Coronel y Pérez, 2009). 
Siendo así, la disminución de la victimización secundaria representa un desafío en los programas de atención, compensación y reparación de víctimas de delitos, por ello, es importante que se reconozca la existencia del fenómeno revictimizante y la trascendencia que aportaría el diseño y construcción del instrumento SAMANTO con el cual se pretende medir las actitudes revictimizantes por parte de los operadores de la justicia. A su vez, que las instituciones reconozcan la falta de capacitación pertinente al tema, así, como la responsabilidad en su desarrollo y mantenimiento, toda vez, que asuman el compromiso a implementar medidas, políticas e instrumentos que midan la revictimización y eviten con ello que la victimización se siga presentando reiteradamente al punto de evolucionar en revictimización. Empero, para la víctima ya es suficiente con tener que soportar y enfrentar las consecuencias directas de delitos. Razón por la cual, se hace el llamado a la reflexión, mesura y acción que puede transcender positivamente en quienes padecen estas infracciones de la ley (Gutiérrez de Piñeres, Coronel y Pérez, 2009).

De tal manera, y como si fuera poco, la agonía de tener que soportar una atención hostil, cruel y fría por parte del sistema penal, resulta en muchas ocasiones más nociva que la agresión de la cual fueron víctimas. Definitivamente, la actitud por parte de los operadores judiciales hace la diferencia desde el momento que la víctima instaura la denuncia y durante el proceso que la misma afronta (Gutiérrez de Piñeres, Coronel y Pérez, 2009).

En el mismo orden de ideas, autores como Neuman (2001) mencionan que el olvido de la victima debe ser reparado de múltiples maneras, y quienes llegan a ellas con mayor rapidez -unidades médicas, policía, justicia, parientes, amigos, vecinosdeberían tener una amplia posibilidad de conexión con organismos públicos y privados 
Escala SAMANTO para medir actitudes de los operadores judiciales hacia la víctima 53

de asistencia, que se traduce en ayuda a la víctima. Cuanto antes se llegue a ella mediante el apoyo preciso, puede reconstruir su mundo y reconstruirse del impacto y consecuencias del hecho lesivo que se abatió contra ella.

Por consiguiente, es imprescindible enfatizar en la atención y asistencia adecuada a las víctimas en general y más cuando se trata de niños, niñas y adolescentes (NNA), es ineludible ya que la falta de una apropiada asistencia podría generar afectaciones psicológicas futuras. Por tal motivo, se insta a los profesionales para que se capaciten debidamente en la atención y asistencia a víctimas. De tal manera, que se evidencie una mejor actitud y disposición en el trato hacia las mismas (Castañer y Griesbach, 2009).

En realidad, la actitud que el operador ejecuta es vital no solo para el mejoramiento de los procesos judiciales, sino que, contribuye a la pronta recuperación del doliente. De ahí que, el brindar la asistencia oportuna, cuidado y protección que estos impactos delictivos dejan en quienes son víctimas, aportan de forma significativa en la construcción de una mejor sociedad. Por tanto, es pertinente que se evidencie la asistencia amable y una eficaz atención. Puesto que, estos elementos constituyen uno de los múltiples compendios dentro del proceso que favorece la protección e intervención adecuada de la víctima. Al mismo tiempo, es un factor protector de la víctima y el testigo que acompaña, porque permite elaborar los sentimientos de angustia, duda, confusión o abandono que pudieran aparecer durante el proceso de denuncia y acompañamiento (Castañer y Griesbach, 2009).

En este sentido, la denuncia es un elemento clave para prevenir futuros delitos, razón por la cual, la actitud del profesional se convierte en la ficha que hace la diferencia entre la justicia y la desavenencia del sistema penal. De igual manera, es una obligación jurídica propiciar situaciones que permitan a la víctima en general, acceder a la justicia 
Escala SAMANTO para medir actitudes de los operadores judiciales hacia la víctima 54

para exigir que se protejan sus derechos. En otras palabras, no se debiera dejar esta obligación penal como un acto opcional o restarle importancia (Castañer y Griesbach, 2009).

Ahora bien, la administración de justicia es un elemento central para los derechos humanos y el estado de derecho, que logran realizarse en un ambiente en el que existe y se cumple la ley. En consecuencia, si deseamos vivir en una sociedad que respete y permita el despliegue de la dignidad humana, en particular que proteja y permita el desarrollo óptimo de sus niños, adolescentes y jóvenes, se debe defender y promover la justicia (Castañer y Griesbach, 2009).

De otra manera, el riesgo de revictimización consiste en que a los efectos que aparecen debido al delito sufrido, se le sumen otros efectos provocados (o aumentados) por las experiencias a que es sujeta la víctima una vez que inicia el proceso legal. Así que, cuando existe revictimización el propio proceso penal se vuelve contra la víctima que sufre ahora la victimización institucional (Castañer y Griesbach, 2009).

Se espera que en futuros estudios los operadores judiciales, encargados de atender las denuncias por diversos delitos, se encuentren fortalecidos mediante el entrenamiento profesional en lo que respecta a la prudencia y la adecuada asistencia. Al mismo tiempo, que se esmeran por el enriquecimiento de una sociedad justa y en paz. Lo anterior con el propósito de otorga una mejor atención a las víctimas, teniendo el cuidado de no revictimizarlas durante el proceso, motivo por el cual, se hace necesaria la creación de la escala SAMANTO, para identificar y medir actitudes revictimizantes por parte de los operadores de justicia. Con ello, se espera contribuir en la no revictimización, toda vez, que se propende por el bienestar de las víctimas (Castañer y Griesbach, 2009). 
Precisamente, después de una ardua búsqueda en la literatura tanto en español como en inglés de un instrumento o escala que midiera actitudes revictimizantes, se concluyo que no existía un instrumento para ello. Como resultado de la presente investigación se diseñó y aplicó la escala SAMANTO, para medir actitudes revictimizantes por parte de los operadores de justicia hacia las víctimas.

Por consiguiente, en futuras investigaciones se espera contribuir en la disminución de la revictimización en las víctimas de los delitos en general. Siendo así, la escala SAMANTO aportara al mejoramiento en las actitudes humanas y de buen trato por parte de los operadores encargados de atender las diversas infracciones. Igualmente, generará concienciación por un acercamiento afable entre el profesional y la víctima, que para efectos del presente estudio se refiere a todo tipo de población. 
Escala SAMANTO para medir actitudes de los operadores judiciales hacia la víctima 56

\section{Conceptos psicométricos}

La palabra prueba en el plano de la investigación implica el criterio o procedimiento que se utiliza para evaluar y determinar la validez de los instrumentos o escalas con que se va a probar una hipótesis, por medio de la demostración empírica o del razonamiento. También, se entiende como el examen para determinar la validez y exactitud de las conclusiones a que se ha llegado en la investigación (Tamayo, 2006).

En el mismo sentido, cabe resaltar que existen gran variedad de pruebas las cuales se clasifican según su contenido, la forma en que se elaboran, el parámetro para cuya dimensión se diseñaron, el propósito de su aplicación, e incluso de acuerdo con la manera en que se administran, califican e interpretan. Igualmente, las pruebas psicológicas y otros instrumentos de evaluación se aplican en una extensa categoría de entornos con el fin de detectar o predecir un estimulo determinado hacia el objeto (Aiken, 2003).

Es más, los procedimientos para administrar y calificar pruebas varían en cierta medida según el tipo de prueba y las personas a las que está dirigida. Por lo tanto, al aplicar determinada prueba se debe considerar que los examinados deben estar preparados, motivados para responder sinceramente, en lo posible que estén exentos de tensión entre otras condiciones distractoras que bien pudieran entorpecer el resultado (Aiken, 2003).

Por otra parte, el término psicometría hace referencia a la teoría e investigación concerniente respecto a la medición de las características psicológicas (cognoscitivas y afectivas). De ahí que, el método psicométrico ha originado infinidad de pruebas de inteligencia y diversos métodos estadísticos para analizar las calificaciones de estas pruebas. Asimismo, se centra en las diferencias individuales en cuanto a habilidades 
Escala SAMANTO para medir actitudes de los operadores judiciales hacia la víctima 57

cognoscitivas y en la búsqueda de las causas de estas diferencias. De igual forma, permite la medición cuantitativa de las características psicológicas por medio de técnicas estadísticas (Engler, 1997 y Aiken, 2003).

\section{Instrumentos de medición cuantitativos}

Ahora bien, en la investigación disponemos de diversos tipos de instrumentos o escalas para medir las variables de interés y en algunos casos llegan a combinarse varias técnicas de recolección de los datos. A continuación se describen brevemente (Hernández, Fernández y Baptista, 2010):

Cuestionarios: posiblemente sea el instrumento más utilizado para recolectar los datos, consiste en un conjunto de preguntas respecto de una o más variables a medir, debe ser congruente con el planteamiento del problema e hipótesis. En efecto, el contenido de las preguntas de un cuestionario es tan variado como los aspectos que mide, se consideran dos tipos de preguntas: preguntas cerradas y preguntas abiertas (Brace, 2008 citado en Hernández, Fernández y Baptista, 2010).

Preguntas cerradas: contienen categorías u opciones de respuestas que han sido previamente delimitadas. Es decir, se presentan las posibilidades de respuesta a los participantes, quienes deben señalar a éstas. Pueden ser dicotómicas (dos posibilidades de respuesta) o incluir varias opciones de respuestas (Hernández, Fernández y Baptista, 2010).

Como puede observarse, en las preguntas cerradas las categorías de respuestas son definidas a priori por el investigador y se le muestran al encuestado, quien debe

elegir la opción que describa más adecuadamente su respuesta. Autores como Gambara (2002), Meltzoff (2000) y León y Montero (2003), hacen referencia a algo lógico, pero que en ocasiones se descuida y resulta fundamental: cuando las preguntas presentan 
Escala SAMANTO para medir actitudes de los operadores judiciales hacia la víctima 58

varias opciones, estas deben recoger todas las posibles respuestas, también, existen preguntas cerradas en las que el participante puede seleccionar más de una opción o categoría de respuesta (posible multirrespuesta).

Preguntas cerradas. Son más fáciles de codificar y preparar para su análisis. Por lo tanto, requieren un menor esfuerzo por parte de los encuestados, que no tienen que escribir o verbalizar pensamientos, sino seleccionar la alternativa que resuma mejor su respuesta. Además, el cuestionario con preguntas cerradas toma menos tiempo que contestar que uno con preguntas abiertas (Burnett, 2009 citado en Hernández, Fernández y Baptista, 2010).

Por otra parte, la principal desventaja de las preguntas cerradas reside en que limitan las respuestas de la muestra y, en ocasiones, ninguna de las categorías describe con exactitud lo que las personas tienen en mente. Puesto que, no siempre se logra capturar lo que pasa por la cabeza de los participantes (Vinuesa, 2005 citado en Hernández, Fernández y Baptista, 2010).

Así que, para formular preguntas cerradas es necesario anticipar las posibles alternativas de respuesta. De no ser así, es difícil plantearlas. Además, el investigador debe tener la certeza de que los participantes a quienes se les administrarán conocen y comprenden las categorías de respuesta (Hernández, Fernández y Baptista, 2010).

Es decir, en ocasiones sólo basta una pregunta bien formulada para recolectar la información necesaria sobre la variable considerada. También, con base en las variables se construyen índices, cada una de ellas tiene un coeficiente y al final se otorga una puntuación. Por consiguiente, es recomendable hacer sólo las preguntas necesarias para obtener la información deseada para medir la variable o las variables. En el mismo sentido, cuando se justifica hacer varias preguntas para medir una o varias dimensiones 
Escala SAMANTO para medir actitudes de los operadores judiciales hacia la víctima 59

o componentes, es necesario tener claridad sobre los indicadores (Hernández, Fernández y Baptista, 2010).

Ahora bien, es conveniente iniciar con preguntas neutrales o fáciles de contestar, con el fin de que el participante o examinado se adentre en la situación. No se recomienda iniciar con preguntas difíciles o directas. Por tanto, lo más recomendable es que las primeras preguntas deben resultar interesantes para los examinados. Asimismo, tener presente que la característica fundamental del cuestionario consiste en que las preguntas importantes nunca deben ir al final, se les debe otorgar una buena colocación dentro del mismo, sin que ello signifique que sean las primeras o las últimas (Hernández, Fernández y Baptista, 2010).

En efecto, en la construcción de una prueba se precisa tener claridad acerca de los lineamientos para elaborar reactivos de opción múltiple. También, saber qué es lo que se precisa medir, para así, empezar la construcción de las variables o ítems. En cuanto, a la presente investigación el objetivo consiste en la construcción del instrumento SAMANTO razón por la cual, se tendrán en cuenta las actitudes de los profesionales que trabajan con el aparato jurídico, para elaborar las diversas variables en torno a la dimensión que se desea investigar, las actitudes revictimizantes (Aiken, 2003; Hernández, Fernández y Baptista, 2010).

Precisamente, como se ha venido mencionando en los apartados anteriores, la actitud es la predisposición aprendida para responder coherentemente de manera favorable o desfavorable ante un objeto, ser vivo, actividad, concepto, persona o sus símbolos (Fishbein y Ajzen, 1975; Haddock y Maio, 2007; Oskamp y Schultz, 2009 citados en Hernández, Fernández y Baptista, 2010). 
Escala SAMANTO para medir actitudes de los operadores judiciales hacia la víctima 60

Así, los seres humanos tenemos actitudes hacia diversos objetos; las actitudes están relacionadas con el comportamiento que mantenemos en torno a los objetos a que hacen referencia, desde luego, las actitudes sólo son un indicador de la conducta, pero no la conducta en sí. Por ello, las mediciones de actitudes deben interpretarse como "síntomas" y no como "hechos". De ahí que, la actitud es como una semilla que bajo ciertas condiciones suele "germinar en comportamiento" (Aiken, 2003; Hernández, Fernández y Baptista, 2010; Padua, 2000 citado en Méndez y Peña, 2006).

\section{Construcción de una escala Likert}

Su importancia y utilidad radica en la medición de las diversas características que permiten medir actitudes por medio de cuestionarios diseñados de manera cuidadosa, los cuales son desarrollados basándose en técnicas teóricas y estadísticas. Además, es un instrumento de evaluación que se aplican en un amplio rango de ambientes académicos, clínicos-consultivos, de negocios-industriales, de justicias criminal-forenses, gubernamentales y militares. Es así como, los psicólogos dedican una parte considerable de su tiempo profesional a calificar e interpretar los resultados que arroja la escala Likert (Engler, 1997 y Aiken, 2003).

La construcción de una escala tipo Likert exige gran cantidad de esfuerzo en su elaboración. Por tanto, es de tenerse en cuenta que los procedimiento empleados en la elaboración de una prueba psicológica requiere de cierto grado de planeación del contenido antes de escribir los reactivos que contendrá el instrumento. Asimismo, la planeación de la prueba deberá incluir definiciones claras de las variables o constructos que van a medirse, tales como; descripciones de las personas que van a ser examinadas, las condiciones bajo las cuales se administrara la prueba o instrumento, e información 
Escala SAMANTO para medir actitudes de los operadores judiciales hacia la víctima 61

concerniente en cuanto a la calificación, interpretación de las puntuaciones y el uso que se dará a los resultados (Aiken, 2003).

En el mismo sentido, la meta principal de la planificación de una escala tipo Likert, es la preparación detallada de un bosquejo, como una tabla de especificaciones, que sirva como guía al elaborar los reactivos con los que se van a evaluar o predecir ciertos objetivos. En consecuencia, una vez elaborada dicha tabla o bosquejo detallado del contenido de la prueba, el paso que le sigue es la preparación de los reactivos, por lo general es recomendable que se elaboren alrededor de $20 \%$ más de reactivos de los que en realidad se van a necesitar, esto con el fin, de tener un buen abastecimiento de reactivos para la versión final de la prueba. De ahí que, las normas habitualmente se han establecido evaluando una muestra (aleatoria, aleatoria estratificada, por grupo) de la población para la que se está destinada la prueba. De igual manera, la confiabilidad y la validez son fundamentales en la construcción de una escala tipo Likert o de cualquier otra prueba psicológica (Aiken, 2003)

De forma similar, las escalas son instrumentos de gran ayuda en las pruebas psicológicas, ya que mediante el sistema de números graduados, empleados al asignar valores medidos a características seleccionadas de objetos, eventos o personas, contribuyen a la detección de problemáticas evidenciadas en los resultados de determinada población; en el caso del presente estudio la población estará conformada por operadores de la justicia en quienes se aplicara la escala SAMANTO para medir actitudes revictimizantes de los operadores judiciales hacia la víctima. Es así que, para la forma de la escala SAMANTO se eligió usar la escala Likert, que es un instrumento de medición o recolección de datos cuantitativos utilizados dentro de la investigación. También, es un tipo de escala aditiva que corresponde a un nivel de medición ordinal el 
Escala SAMANTO para medir actitudes de los operadores judiciales hacia la víctima 62

cual, consiste en una serie de ítems o juicios a modo de afirmaciones ante los cuales se requiere la reacción de la persona (Méndez y Peña, 2006).

Así que, el estímulo (ítems o juicio) que se presenta al individuo representa la propiedad que el investigador está interesado en medir (en este caso las actitudes revictimizantes) y las respuestas son solicitadas en términos de grados de acuerdo o desacuerdo que el individuo tenga con la sentencia en particular. Precisamente, son cinco (5) el número de opciones de respuestas más usados, así, a cada categoría se le asigna un valor numérico que llevará a la persona a una puntuación total producto de las puntuaciones de todos los ítems. Esta puntuación final indica la posición del individuo dentro de la escala. A continuación, se explica el anterior concepto en todas sus dimensiones y para ello se ha dividido en ocho aspectos (Méndez y Peña, 2006).

\section{Tabla 1.}

Síntesis del concepto el escalamiento tipo Likert

\begin{tabular}{lll}
\hline \multicolumn{2}{c}{ Aspecto } & \multicolumn{1}{c}{ Ilustración del aspecto } \\
\hline $1 \quad$ Escala. & $\begin{array}{l}\text { Se trata de una escala porque indica la posición o el } \\
\text { nivel que tiene la persona con respecto a algo. }\end{array}$ \\
& Nivel de medición ordinal. & $\begin{array}{l}\text { A través del escalamiento es posible dar un orden a } \\
\text { cada persona que conteste la escala. Es decir, según } \\
\text { su puntuación se ubica en 1er. Lugar, 2do. Lugar, } \\
\end{array}$ \\
& $\begin{array}{l}\text { 3cer. Lugar, etc., acorde con el grado con el cual } \\
\text { presenta la actitud o la variable a medir. }\end{array}$ \\
& Serie de ítems a modo de & $\begin{array}{l}\text { La escala se compone de enunciados redactados de } \\
\text { manera afirmativa, llamados ítems. }\end{array}$ \\
\hline
\end{tabular}




\section{Continuación tabla 1.}

Síntesis del concepto el escalamiento tipo Likert

Aspecto

Ilustración del aspecto

4 Se solicita la reacción de la persona en grados de acuerdo o desacuerdo
La reacción de la persona se pide al finalizar cada enunciado. La persona después de leerlo tendrá que dar su respuesta en función de las opciones presentadas, las cuales varían según grados de acuerdo o desacuerdo o según la frecuencia con la cual se presenta el comportamiento o el indicador de la variable a medir.

5 El estimulo representa la propiedad que se desea medir.

6 Número de opciones de respuestas.

El número de opciones de respuestas más usado es cinco, pero puede variar según el grado de estudios o conocimientos de la población.

7 A cada categoría se le asigna un valor numérico.

Todos los ítems de la escala poseen las mismas opciones de respuestas (categorías) y a cada opción se le asigna un valor numérico el cual depende del tipo de ítem que se trate de una escala aditiva.

8 Puntuación total. La puntuación total se obtiene de la suma algebraica de las puntuaciones de todos los ítems. Ésta ubica a la persona en un punto dentro de la escala. De ahí, que se trate de una escala aditiva.

Por otra parte, la escala también emplea el método de rangos sumarizados el cual empieza con la recopilación o elaboración de una gran cantidad de reactivos de enunciados que expresan diversas actitudes positivas y negativas hacia un objeto o 
Escala SAMANTO para medir actitudes de los operadores judiciales hacia la víctima 64

acontecimiento especifico. A continuación se presentan algunas sugerencias para la elaboración de enunciados de actitud para una escala tipo Likert (Aiken, 2003):

1. Los enunciados deben referirse al presente más que al pasado.

2. Los enunciados no deben ser objetivos ni susceptibles de interpretarse como objetivos.

3. Los enunciados no deben interpretarse en más de un sentido.

4. Los enunciados deben ser relevantes para el concepto psicológico que se analiza.

5. Los enunciados deben ser oraciones sencillas que incluyan sólo un razonamiento y no oraciones compuestas ni complicadas.

6. Deben evitarse enunciados que contengan negaciones dobles, palabras poco comprensibles para los participantes, palabras con más de un significado, adjetivos o adverbios no específicos (por ejemplo, muchos, en ocasiones) o universales (como todos, siempre, ninguno o nunca).

7. Debe evitarse usar coloquialismos o jergas, ya que tienden a volver ambiguas y poco claras las oraciones.

Por consiguiente, después de diseñar un conjunto de enunciados preliminares, se indica a un grupo de 100 a 200 personas seleccionadas, (no necesariamente jueces expertos) que en una escala de 4 a 7 puntos señalen la medida en que están de acuerdo o en desacuerdo con cada enunciado. Por lo tanto, los jueces son los que aprobaran o no cada uno de los enunciados (Aiken, 2003). 
Ahora bien, en el caso típico de una escala de cinco (5) puntos, los reactivos expresados en forma positiva se califican con 0 para muy en desacuerdo, 1 para en acuerdo, 2 para indeciso, 3 para de acuerdo y 4 para muy de acuerdo; los reactivos expresados de manera negativa se califican con 4 para muy en desacuerdo, 3 para en acuerdo, 2 para indeciso, 1 para de acuerdo y 0 para muy de acuerdo. En consecuencia, la calificación total de la persona en el conjunto inicial de reactivos se calcula como la suma de sus calificaciones en los reactivos individuales. Una vez obtenidas las calificaciones totales para todas las personas que respondieron en el conjunto de reactivos inicial, se aplica a cada reactivo un procedimiento estadístico (prueba $t$ o índice de discriminación de los reactivos). Seguidamente, se seleccionan cantidades iguales de reactivos expresados de manera positiva y negativa (por lo regular, diez de cada uno) que distingan de manera significativa a los participantes cuyas calificaciones totales correspondan al $27 \%$ superior de aquellos cuyas calificaciones se ubique en el $27 \%$ inferior (Aiken, 2003).

A pesar del mal uso del método de rangos sumarizados, este continúa teniendo varias ventajas sobre el método de intervalos de igual aparición, puesto que no se requiere de jueces expertos, razón por la cual, es más fácil elaborar una escala tipo Likert. Además, las escalas Likert permiten el uso de reactivos que están directamente relacionados con la actitud evaluada mientras estén correlacionados significativamente con las calificaciones totales. (Aiken, 2003). 
Escala SAMANTO para medir actitudes de los operadores judiciales hacia la víctima 66

\section{Pasos que se sugieren para la construcción de escalas en general.}

Posteriormente, se enunciaran los pasos que condujeron la construcción y diseñó de la escala SAMANTO (Méndez y Peña, 2006):

1. Conocer la actitud o variable que se desea medir.

2. Elaborar ítems relacionados con la actitud o variable que se desea medir.

3. Administrar la escala a una muestra de personas que van a actuar como jueces.

4. Asignar los puntajes a los ítems según su posición positiva o negativa.

5. Asignar los puntajes totales a los sujetos de acuerdo al tipo de respuesta en cada ítem.

6. Efectuar el análisis de ítems (Validez y Confiabilidad).

7. Construir con base en los ítems seleccionados la escala final.

8. Aplicar la escala final a la población en la cual se validó el instrumento.

Sintetizando, se debe recordar que al diseñar una escala tipo Likert es necesario saber lo que se puede medir en ella, para el presente estudio se midieron actitudes revictimizantes. Por tal razón, la escala SAMANTO permite la medición de estas actitudes, empleando dicho instrumento como un recurso que permita registrar información o datos sobre las variables que se pretenden indagar (Méndez y Peña, 2006).

Por otra parte, los enunciados del escalamiento tipo Likert se redactan de una manera impersonal, al estar midiendo las actitudes. Por lo tanto, se pueden escribir ítems que indiquen, según su categoría de respuesta, el grado de acuerdo que tiene sobre el objeto de estudio sin preguntárselo directamente al individuo. De ahí que, cualquier organización, ya sea en el campo profesional o en la investigación, necesita saber si las personas presentan conductas de aprobación o desaprobación frente a ciertos 
Escala SAMANTO para medir actitudes de los operadores judiciales hacia la víctima 67

acontecimientos o comportamientos de otras personas, por esta razón es que se miden las actitudes (Méndez y Peña, 2006).

Otros autores como Carretero Dios y Pérez (2005) manifiestan que el contexto de aplicación es aquel en el que se hace necesario el empleó de instrumentos objeto de medida, puesto que, para el desarrollo de un trabajo se necesita evaluar un constructo a partir de una prueba desarrollada para tal fin. Por lo que, resulta conveniente hacer uso de directrices generales para una óptima selección de entre los instrumentos disponibles dentro de los múltiples y variados instrumentos que pueden ser empleados en un contexto de investigación psicológica, asimismo, la utilización de tests de evaluación son necesarios dentro de la práctica profesional ya que, la psicología trabaja con fenómenos no directamente observables pero que, se pretenden medir usando aproximaciones indirectas.

De tal manera que, la medición está condicionada a la obtención de indicadores observables, estas respuestas sirven para generar puntuaciones que finalmente se utilizan para múltiples objetivos, tales como la puesta a prueba de teorías, la toma de decisiones acerca de la efectividad de un tratamiento psicológico, la verificación experimental del impacto de una o varias variables independientes, etc. Así pues, las puntuaciones que se obtienen a partir de los tests tienen implicaciones de suma importancia sobre el resultado final de cualquier investigación que haga uso de ellos, igualmente que sobre las consecuencias aplicadas que se derivan de la actividad de los profesionales (Carretero Dios y Pérez, 2005).

De hecho, el método Likert, se encuentra a la vanguardia y es uno de los más empleados. Puesto que, consiste en un conjunto de ítems, presentados en forma de afirmaciones o juicios, ante los cuales se solicita la reacción de los participantes. Es 
Escala SAMANTO para medir actitudes de los operadores judiciales hacia la víctima 68

decir, cada afirmación se presenta y se pide a la persona que visibilice su reacción eligiendo uno de los cinco puntos o categorías de la escala. En consecuencia, cada punto tiene asignado un valor numérico, así, el participante obtiene una puntuación respecto de la afirmación y al final su puntuación total, sumando las puntuaciones obtenidas en relación con todas las afirmaciones (Hernández, Fernández y Baptista, 2010).

Entonces, las afirmaciones califican al objeto de actitud que se está midiendo. El objeto de actitud puede ser cualquier "cosa física" (un vestido, un carro...), un individuo (el presidente, un líder histórico, una madre, un hijo, un sobrino...), un concepto o símbolo (patria, sexualidad, la mujer cantante...), una marca (Adidas, Ford...), una actividad (comer, beber, tomar café...), una profesión, un edificio, etc. Dichas frases u oficios deben expresar sólo una relación lógica. Además, es recomendable que no se excedan de 20 palabras (Hernández, Fernández y Baptista, 2010).

Ahora bien, es indispensable señalar que el número de categorías de respuesta deben ser igual para todas las afirmaciones. Pero, siempre respetando el mismo orden o jerarquía de presentación de las opciones para todas las frases. Así, la escala Likert tiene condiciones en las que a veces se disminuye o se incrementa el número de categorías, sobre todo cuando los participantes potenciales tienen una capacidad limitada de discriminación o, por el contrario muy amplia (Hernández, Fernández y Baptista, 2010).

También, la escala Likert asume que los ítems o las afirmaciones miden la actitud hacia un único concepto subyacente, este es un aspecto importante de dicha escala. En términos generales, la escala Likert, se construye con un elevado número de afirmaciones que califiquen al objeto de actitud y se administran a un grupo piloto para obtener las puntuaciones del grupo en cada ítem o frase. Así, estas puntuaciones se correlacionan con las del grupo a toda la escala (la suma de las puntuaciones de todas las 
Escala SAMANTO para medir actitudes de los operadores judiciales hacia la víctima 69

afirmaciones), y las frases o reactivos, cuyas puntuaciones se correlacionen significativamente con las puntuaciones de toda la escala, se seleccionan para integrar el instrumento de medición. Asimismo, debe calcularse la confiabilidad y la validez de la escala (Hernández, Fernández y Baptista, 2010).

Entonces, al construir una escala tipo Likert se debe tener la completa seguridad de que las afirmaciones y alternativas de respuesta serán comprendidas por los participantes a los que se les aplicará y que estos tendrán la capacidad de discriminación requerida. Ello, se evalúa cuidadosamente en la aplicación de la prueba piloto (Hernández, Fernández y Baptista, 2010).

Por otra parte, en la medida en que se elaboren pruebas psicológicas mediante el proceso de construcción con calidad que ameritan los instrumentos para medir determinada dimensión se obtendrá la eficacia de los mismos. Igualmente, en la medida en que se logre la confiabilidad de la escala SAMANTO, se podrá mantener su implementación para contribuir en la disminución de la revictimización. Por esta razón, la presente investigación analizó las propiedades psicométricas de la escala SAMANTO para medir actitudes revictimizantes por parte de los operadores de la justicia hacia la víctima.

\section{Criterios para la construcción de los ítems}

Ahora bien, al redactar los ítems se debe tener en cuenta ciertos aspectos que ayudarán a afirmar la validez de la escala SAMANTO para evitar posibles confusiones por parte de los sujetos al momento de contestarla. De ahí que, algunos autores proponen los criterios que a continuación se mencionan para la construcción de ítems de una escala Likert (Padua, 2001 citado en Méndez y Peña, 2006): 
- Evitar los ítems que apunten al pasado en lugar de al presente. La variable o actitud a medir representa un problema actual, por lo tanto, seria irrelevante e inútil preguntar sobre situaciones del pasado. Empero, en ocasiones el investigador se encuentra con tópicos ante los cuales se precisa investigar situaciones hipotéticas o que aun no acontecen; en tales casos se acepta la utilización del tiempo pospretérito.

- Evitar los ítems que dan demasiada información sobre hechos, o aquellos que pueden ser interpretados como tales. Puede ser que cuando un ítem proporciona demasiada información sobre la actitud, el juez sólo esté de acuerdo con una parte de ésta y no con todo el enunciado, por lo tanto le sería imposible medir el objeto de estímulo. Entonces, la opción es dividir al ítem en dos o más ítems, según el contenido de la información.

- Evitar los ítems irrelevantes con respecto a la actitud que quiere medir. Aquí se encuentran ítems en los cuales el investigador supone de manera personal que para que exista una variable es necesario que esté presente otra. La clave radica en no inferir, ni interpretar subjetivamente el objeto estimulo, ya que los ítems deben basarse en información bibliográfica reciente, verídica y confiable.

- Los ítems en la escala deben formularse según expresen actitudes o juicios favorables o desfavorables con respecto a la actitud. No se trata de elegir ítems que expresen distintos puntos en el continuo. Cuando se están midiendo actitudes los ítems positivos son aquéllos que están a favor del objeto estímulo (actitud) y los negativos son los que están en contra. Por lo tanto, solo se deben redactar juicios que estén $100 \%$ a favor y juicios que estén $100 \%$ en contra de la actitud, y no juicios un poco a favor y un poco en contra, puesto que, el grado de acuerdo 
Escala SAMANTO para medir actitudes de los operadores judiciales hacia la víctima 71

o desacuerdo lo marcarán las opciones de respuestas. Entonces, cuando lo que se pretende evaluar es una variable, el ítem positivo es aquél que indica que la variable se encuentra presente en el enunciado. Siendo el ítem negativo aquél que no contiene indicador alguno de la variable a medir. En este caso las categorías de respuesta indicarán la frecuencia con la cual se presenta dicha variable.

- Evitar los ítems con los cuales todos o más bien nadie concuerda.

- Los ítems deben ser formulados en lenguaje simple, claro y directo. Es necesario redactar los ítems con palabras que los jueces comprendan. Razón por la cual, antes de diseñar la escala es necesario conocer el nivel educativo de la población seleccionada. Asimismo, es importante evitar tecnicismos o palabras propias de la profesión del investigador, a menos que ésta sea aplicada a colegas.

- Solamente en casos excepcionales exceder de las 20 palabras cuando formule el ítem.

- Omitir los ítems que concluyan palabras como "todo", "siempre", "nadie", "nunca", etc.

- Los ítems deben ser formulados con frases simples y no compuestas. Se debe tratar de omitir las conjunciones "y", “e”, “o”, "u”. Ya que, en la mayoría de ocasiones cuando se emplean estas letras es posible fraccionar al ítem en dos ítems, así, la división la marca la presencia de la conjunción.

- Evitar las negaciones, particularmente las dobles negaciones. La palabra "no" debe obviarse en la redacción de los ítems. Su presencia suele confundir a los jueces al momento de contestar el instrumento. Sólo en casos particulares se permiten, sobre todo cuando su inserción en el enunciado no sugiere la respuesta. 
Escala SAMANTO para medir actitudes de los operadores judiciales hacia la víctima 72

- Combinar los ítems formulados positiva y negativamente en una proporción aproximada a 50\% - 50\%. De cada actitud o variable a medirse formulan la misma cantidad de ítems positivos (favorables) que de ítems negativos (desfavorables). De tal manera que, cada ítem positivo debe de tener su correspondiente ítem negativo.

- Al redactar los ítems que miden actitudes deben formularse de una manera impersonal. Y al tratarse de medición de variables (nivel de estrés, celos, insomnio) se requiere que se redacten en primera persona.

Entonces, cada ítem es un juicio o una sentencia a la cual el juez debe expresar su grado de acuerdo o desacuerdo cuando el objeto estímulo es una actitud. Por tanto, la graduación de acuerdo o desacuerdo varía en cantidad de alternativas que se le ofrecen al individuo dependiendo del tipo de investigación y la capacidad de discriminación de los jueces entre una respuesta y otra. De tal manera que, cuando lo que se está evaluando es la presencia de una variable, las opciones cambian a categorías de frecuencia con la cual se presentan comportamientos Empero, de igual manera, el número de opciones depende de la capacidad de discriminación entre respuestas de los jueces y de su nivel educativo. Asimismo, el número de opciones de respuestas puede ser 2, 3, 4, 5, 6 y 7 (Méndez y Peña, 2006). 


\section{Proceso de construcción con calidad de un instrumento}

Como ya se ha señalado anteriormente, existen varios tipos de instrumentos de medición, cada uno con características diferentes. Sin embargo, el procedimiento general para construirlos y aplicarlos es semejante. Éste se resume mediante etapas las cuales a continuación se mencionan (Hernández, Fernández y Baptista, 2010):

Tabla 2.

Proceso para la construcción de un instrumento de medición

\begin{tabular}{|c|c|c|}
\hline Fase & Etapa & Procedimiento \\
\hline 1 & $\begin{array}{l}\text { Redefiniciones } \\
\text { fundamentales }\end{array}$ & $\begin{array}{l}\text { En esta etapa se deberán reevaluar las variables de la } \\
\text { investigación (ver si se mantienen o modifican), el lugar } \\
\text { especifico donde se recabaran los datos, el propósito de tal } \\
\text { recolección, quienes y cuándo (momento) van a ser } \\
\text { medidos, las definiciones operacionales y el tipo de datos } \\
\text { que se quieren obtener (respuestas verbales escritas, } \\
\text { conductas observables, etc). }\end{array}$ \\
\hline 2 & $\begin{array}{l}\text { Revisión } \\
\text { enfocada de la } \\
\text { literatura }\end{array}$ & $\begin{array}{l}\text { Este paso debe servir para encontrar mediante la revisión de } \\
\text { la literatura, los instrumentos o sistemas de medición } \\
\text { empleados en otros estudios anteriores para medir las } \\
\text { variables de interés, lo cual ayudara a identificar qué } \\
\text { herramientas pueden ser de utilidad. }\end{array}$ \\
\hline 3 & $\begin{array}{l}\text { Identificación } \\
\text { del dominio de } \\
\text { las variables a } \\
\text { medir y sus } \\
\text { indicadores }\end{array}$ & $\begin{array}{l}\text { Se trata de identificar y señalar con precisión los } \\
\text { componentes, dimensiones o factores que teóricamente } \\
\text { integran a la variable. De igual manera se deben establecer } \\
\text { los indicadores de dada dimensión. }\end{array}$ \\
\hline
\end{tabular}


Continuación tabla 2.

Proceso para la construcción de un instrumento de medición

\begin{tabular}{lll}
\hline Fase & \multicolumn{1}{c}{ Etapa } & \multicolumn{1}{c}{ Procedimiento } \\
\hline 4 Toma de & En esta parte se deberán tomar tres decisiones importantes \\
decisiones clave & que tienen que ver con el instrumento o sistema de medición: \\
& 1. Emplear un sistema de medición ya elaborado, adaptarlo o \\
& desarrollar uno nuevo. \\
& 2. Si se trata de uno nuevo, decir de qué tipo (cuestionario, \\
& escala de actitudes, hoja de observación, etc.) y cuál será su \\
& formato (tamaño, colores, tipo de fuente, etc.) \\
& 3. Determinar el contexto de administración o aplicación \\
& (autoaplicado, cara a cara en hogares o lugares públicos, \\
& internet, observación en cámara Gesell, etc.)
\end{tabular}


Continuación tabla 2.

Proceso para la construcción de un instrumento de medición

\begin{tabular}{|c|c|c|}
\hline Fase & Etapa & Procedimiento \\
\hline 8 & $\begin{array}{l}\text { Entrenamiento } \\
\text { personal que } \\
\text { va a } \\
\text { administrar el } \\
\text { instrumento y } \\
\text { calificarlo }\end{array}$ & $\begin{array}{l}\text { Esta etapa consiste en entrenar y motivar a las personas que } \\
\text { habrán de aplicar y codificar respuestas o valores producidos } \\
\text { por el instrumento o sistema de medición. }\end{array}$ \\
\hline 9 & $\begin{array}{l}\text { Obtener } \\
\text { autorizaciones } \\
\text { para aplicar el } \\
\text { instrumento }\end{array}$ & $\begin{array}{l}\text { En esta etapa es fundamental conseguir los permisos } \\
\text { necesarios para aplicar el instrumento o sistema de } \\
\text { medición (por parte de una persona o representantes de } \\
\text { organizaciones que estén implicadas en el estudio. }\end{array}$ \\
\hline 10 & $\begin{array}{l}\text { Administración } \\
\text { del instrumento }\end{array}$ & $\begin{array}{l}\text { Aplicar el instrumento o sistema de medición a los } \\
\text { participantes o casos de la investigación, es la oportunidad } \\
\text { de confrontar el trabajo conceptual y de planeación con los } \\
\text { hechos. }\end{array}$ \\
\hline 11 & $\begin{array}{l}\text { Preparación de } \\
\text { los datos para el } \\
\text { análisis }\end{array}$ & $\begin{array}{l}\text { Así: } \\
\text { a) Codificarlos. } \\
\text { b) Limpiarlos. } \\
\text { c) Insertarlos en una base de datos (matriz). }\end{array}$ \\
\hline 12 & Análisis & Análisis \\
\hline
\end{tabular}

Entonces, el escalamiento Likert es un tipo de escala aditiva correspondiente a un nivel de medición ordinal, que consiste en una serie de ítems a modo de afirmaciones. Los ítems o juicios representan la propiedad que el investigador está interesado en medir. Mientras que, las etapas para la construcción de un instrumento de medición 
Escala SAMANTO para medir actitudes de los operadores judiciales hacia la víctima 76

corresponden a la parte del plan de recolección de datos (Méndez y Peña, 2006; Hernández, Fernández y Baptista, 2010).

Dado lo anterior, las fases 1 a 7 de la tabla 2, hacen referencia al desarrollo del instrumento o sistema de medición, mientras que las etapas 8 a 12 de la misma tabla, representan la administración del mismo y la preparación de los datos para su análisis. Mientras que otros autores refirieron que también es el proceso que vincula símbolos o valores a las propiedades de objetos o eventos de acuerdo con indicadores empíricos. El cual, se realiza mediante un plan explicito y organizado para clasificar (y con frecuencia cuantificar) los datos disponibles (los indicadores), en términos del concepto que el investigador tiene en mente (Carmines y Zeller, 1991 citados en Hernández, Fernández y Baptista, 2010).

Por otra parte, un instrumento de medición adecuado es aquel que registra datos observables que representan verdaderamente los conceptos o las variables que el investigador ha planeado. Así que, en toda investigación cuantitativa aplicamos un instrumento para medir las variables contenidas en las hipótesis (y cuando no existen hipótesis simplemente para medir las variables de interés). También, es un hecho que debemos acercarnos a la representación fiel de las variables a observar, mediante el instrumento de medición que se desarrolle, en este caso el instrumento SAMANTO, y tener presente que toda medición debe reunir tres requisitos esenciales como sigue (Hernández, Fernández y Baptista, 2010):

- Confiabilidad. Grado en que un instrumento produce resultados consistentes y coherentes.

- Validez. Grado en que un instrumento en verdad mide la variable que se busca medir. 
Escala SAMANTO para medir actitudes de los operadores judiciales hacia la víctima 77

- Objetividad del instrumento. Grado en que el instrumento es permeable a la influencia de los sesgos y tendencias de los investigadores que lo administran, califican e interpretan.

\section{Confiabilidad de un instrumento.}

La confiabilidad de un instrumento de medición es importante puesto que es el grado en que su aplicación repetida al mismo individuo u objeto produce resultados iguales. Asimismo, la estandarización es un paso importante en el diseño y la evaluación de pruebas psicológicas y otros instrumentos afines a la evaluación, pero este no es el último paso. Ya que, antes de que una prueba pueda emplearse con cierta seguridad, debe obtenerse información acerca de su confiabilidad y validez por lo que a sus propósitos específicos concierne (Aiken, 2003; Hernández, Fernández y Baptista, 2010).

Así qué, ningún instrumento psicométrico puede considerarse de valor a menos que sea una medida consistente o confiable. En efecto, más que ser una característica de una prueba, la confiabilidad es una propiedad de las puntuaciones obtenidas cuando se administra la prueba a un grupo particular de personas en una ocasión particular y bajo condiciones especificas, según (Thompson, 1994).

Por ende, en importante tener claridad que la confiabilidad no es lo mismo que la estabilidad, así, al determinar la confiabilidad se asume que la prueba mide una característica relativamente estable. A diferencia, que la inestabilidad, la falta de confiabilidad es resultado de errores de medición producidos por estados internos temporales, como la baja motivación o la falta de disposición, o de condiciones externas como un ambiente de prueba incómodo o con ciertas distracciones (Aiken, 2003).

Por otro lado, la confiabilidad de un conjunto de calificaciones en una prueba se expresa como un número decimal positivo que fluctúa entre .00 y 1.00, así, una 
Escala SAMANTO para medir actitudes de los operadores judiciales hacia la víctima 78

confiabilidad de 1.00 indica una confiabilidad perfecta y una confiabilidad de .00 indica una falta absoluta de confiabilidad de medición. Como la varianza de las calificaciones reales no puede calcularse de manera directa, la confiabilidad se estima analizando los efectos de varianza en las condiciones de la administración y el contenido de la prueba en las calificaciones observadas. A continuación, se menciona brevemente el significado del métodos que se empleará en la escala SAMANTO para estimar la confiabilidad (Aiken, 2003).

Por lo tanto, la consistencia interna es el grado en el cual todos los reactivos de una prueba miden la misma variable o constructo. La confiabilidad de una prueba calculada por las fórmulas Spearman-Brown, Kuder-Richardson o el coeficiente alfa de Cronbach es una medida de la consistencia interna de la prueba.

\section{Alfa de Cronbach.}

Medida de coherencia o consistencia interna, cuyo coeficiente estima la confiabilidad. El alfa de Cronbach desarrollada por J. L. Cronbach en 1951, requiere una sola administración del instrumento de medición. Su ventaja consiste en que no es necesario dividir en dos mitades a los ítems del instrumento, sencillamente se aplica la medición y se calcula el coeficiente alfa, puede considerarse como la medida de todos los posibles coeficientes por mitades, puesto que, el coeficiente alfa es un índice de la consistencia interna de los reactivos. Así, la mayoría de los programas estadísticos como SPSS y Minitab los determinan y solamente deben interpretarse (Gregory, 1943; Hernández, Fernández y Baptista, 2010).

Por otra parte, el alfa de Cronbach trabaja con variables de intervalo o de razón, con el fin de estimar la confiabilidad de un instrumento, el cual, se aplicará a la muestra y sobre la base de los resultados calcular tal coeficiente. Probablemente, se 
pudiera obtener un valor de alfa Cronbach de 0.96, que es relevante, lo cual significa que su medida respecto al objeto es sumamente confiable. En el mismo sentido, la confiabilidad varía de acuerdo con el número de ítems que incluya el instrumento de medición. Cuantos más ítems haya, mayor será ésta. Pero, se debe tener presente que demasiados ítems provocara cansancio en los participantes. (Gregory, 1943; Hernández, Fernández y Baptista, 2010).

\section{Validez de contenidos.}

Es la validez el grado en que un instrumento realmente mide la variable que pretende medir acorde a los propósitos específicos para los que fue diseñada, la población objetivo, las condiciones en que se aplica y el método para determinar la validez. Aparentemente, es sencillo lograr la validez de un instrumento, pero, cuando se trata de variables como la cognición, motivación, sentimientos y emociones, entre otras, la validez se torna más compleja de alcanzar en todo instrumento de medición que se aplique. Así que, la validez de contenido se determina por el grado en que las preguntas, tareas o reactivos de la prueba constituyen una muestra representativa del universo de conductas para el cual se crearon (Aiken, 2003; Gregory, 1943; Hernández, Fernández y Baptista, 2010).

Por consiguiente, los procedimientos que a continuación se mencionan, son útiles en la medida que mejoran la comprensión de lo que mide una prueba y proporcionan información para tomar decisiones sobre las personas. Así, los métodos por los cuales puede determinarse la validez incluyen (Aiken, 2003; Gregory, 1943):

- Analizar el contenido de la prueba.

- Calcular la correlación entre las calificaciones en la prueba y las calificaciones en el criterio de interés. 
Escala SAMANTO para medir actitudes de los operadores judiciales hacia la víctima 80

- Investigar las características psicológicas particulares o constructos medidos por la prueba.

Aunado a lo anterior, puede ser de interés evaluar la validez creciente de una prueba, es decir, qué tanto añade la prueba a la predicción y comprensión de los criterios que ya son anticipados por otras medidas. A diferencia de la confiabilidad, la cual es influida sólo por los errores no sistemáticos de medición. Entonces, la validez de una prueba es afectada tanto por los errores no sistemáticos como por los sistemáticos (constantes). Razón por la cual, una prueba puede ser confiable sin ser válida, pero no puede ser válida sin ser confiable, la confiabilidad es una condición necesaria, pero no suficiente, para la validez (Aiken, 2003; Gregory, 1943).

De manera que, la validez de contenido es importante en la medida en que éste produce un rango de respuestas que son representativas del dominio entero o universal de habilidades, entendimientos y otras conductas que supuestamente debe medir la prueba. Por lo tanto, se espera que las respuestas a la muestra de reactivos de una prueba bien diseñada sean indicativas de lo que serían las respuestas al universo entero de conductas de interés. También, la validez de contenido es de interés en las medidas de aptitud, interés y personalidad, aunque quizá menos que la validez de constructo o la relacionada con un criterio. En efecto, la validez de contenidos comprende el grado en que un grupo de expertos en la materia coinciden en que una prueba parece y actúa como un instrumento diseñado para medir lo que se supone debe medir, entonces se dice que posee validez de contenido (Aiken, 2003; Gregory, 1943; Hernández, Fernández y Baptista, 2010). 
En consecuencia, dichos juicios involucran no solo la apariencia de los reactivos de la prueba, sino también los procesos cognitivos implicados al responderlos, asimismo, el proceso de evaluar la validez de contenido no debería esperar hasta que se haya elaborado la prueba. Porque, el juicio de los expertos en lo que se refiere a qué reactivos incluir es necesario desde el principio del proceso de elaboración de la prueba. Al definir el universo del contenido de la prueba y la muestra de ese universo que se va a incluir, los diseñadores establecen las condiciones indispensables para lograr construir un instrumento con validez de contenido. En síntesis, cada vez que se administra un instrumento de medición debe calcularse la confiabilidad, al igual que evaluarse la evidencia sobre la validez (Aiken, 2003; Gregory, 1943; Hernández, Fernández y Baptista, 2010).

En cuanto a la interpretación de los distintos coeficientes mencionados, cabe indicar que no hay una regla que indique: a partir de este valor no hay fiabilidad del instrumento. Más bien, el investigador calcula su valor, lo reporta y lo somete a escrutinio de los usuarios del estudio u otros investigadores. Empero, -de manera más o menos general- si se obtiene 0.25 en la correlación o coeficiente, esto indica baja confiabilidad; si el resultado es 0.50 , la fiabilidad es media o regular. En cambio, si supera el 0.75 es aceptable, y si es mayor a 0.90 es elevada, para tomar en cuenta (Hernández, Fernández y Baptista, 2010). Por lo anterior expuesto, se considera que la pregunta de investigación es ¿Cómo construir la escala SAMANTO que mide actitudes revictimizantes de los operadores judiciales? 
Escala SAMANTO para medir actitudes de los operadores judiciales hacia la víctima 82

\section{Objetivos}

\section{Objetivo General.}

Construir la escala SAMANTO para medir actitudes revictimizantes de los operadores judiciales.

\section{Objetivos Específicos.}

1. Definir los constructos de la escala SAMANTO para medir actitudes revictimizantes de los operadores judiciales.

2. Validar el contenido de la escala SAMANTO para medir actitudes revictimizantes de los operadores judiciales a través de jueces expertos.

3. Evaluar cuantitativamente los ítems de la escala SAMANTO para medir actitudes revictimizantes de los operadores judiciales.

4. Identificar la dimensionalidad de la escala SAMANTO para medir actitudes revictimizantes de los operadores judiciales.

5. Estimar la confiabilidad de la escala SAMANTO para medir actitudes revictimizantes de los operadores judiciales. 


\section{Método}

\section{Diseño y tipo de investigación}

El diseño metodológico de esta investigación estuvo enmarcado en un estudio tipo instrumental, que consiste en desarrollar instrumentos de medida como los test psicológicos en general. Razón por la cual, para la presente investigación se empleó como modelo una escala Likert de valorización, para la que se diseñó un test compuesto por 67 ítems o juicios.

También, se suscribe dentro de la investigación cuantitativa por cuanto pretende medir variables (ítems), que para el presente estudio equivalen a las actitudes que causan la revictimización.

El método que se siguió es el propuesto por Carretero-Dios y Pérez (2005) que consisten en seis pasos, cada uno corresponde a una etapa crucial dentro del proceso de construcción o adaptación de un test (ver sección de método).

\section{Participantes}

La muestra de este estudio estuvo conformada por 120 operadores judiciales, entendiéndose por esta denominación a profesionales de diversas disciplinas que laboran en instituciones Estatales y están en contacto directo con víctimas. Dicha muestra estuvo integrada por participantes voluntarios - hombres y mujeres- de la ciudad de Bogotá, que laboran en diversas instituciones del Estado, como: Fiscalía General de la Nación (FGN), Instituto de Medicina Legal y Ciencias Forenses (INMLCF), Centro de Atención e Intervención a Víctimas de Abuso Sexual (CAIVAS), Instituto Colombiano de Bienestar Familiar (ICBF), Policía Nacional (PONAL), entre otras., quienes libremente decidieron participar en el estudio bajo consentimiento informado, de 
Escala SAMANTO para medir actitudes de los operadores judiciales hacia la víctima 84

acuerdo con las normas éticas para la investigación con humanos (American Psychological Association, 2002), (apéndice A)

\section{Instrumento}

La revictimización es un constructo frecuente en la psicología jurídica y en la victimología, por lo cual, estudiar este constructo y medirlo resulta de gran relevancia científica y social, adicionalmente, es importante la creación de instrumentos para medir actitudes revictimizantes, ya que no existe literatura ni estrategias de medición alguna.

Por este motivo, a partir de la teoría de la actitud, la cual, se fundamenta en tres componentes (componente cognitivo, componente afectivo y componente conativo o comportamental) según la propuesta de autores como Coll, Pozo, Sarabia y Valls (1994), y Catell (1998) se construye la escala SAMANTO para medir actitudes revictimizantes de los operadores judiciales hacia la víctima.

La escala SAMANTO conformada por 67 ítems, la cual, está compuesta por la dimensión víctima que contienen tres (3) categorías como sigue. Primera categoría: componente cognitivo, que incluye indicadores de los pensamientos como lo son las opiniones, ideas, creer que, razonar, suponer, imaginar, entre otras que hacen parte de una actitud revictimizante, consta de veinticuatro (24) ítems del uno (1) al veinticuatro (24), Segunda categoría: componente afectivo, segundo elemento de la actitud que alude a los sentimientos, afectos, sensaciones, sensibilidad, piedad, ternura, delicadeza y emociones que se asocian a la revictimización, consta de diecisiete (17) ítems del veinticinco (25) al cuarenta y uno (41), Tercera categoría: componente conductual o conativo, que hace alusión a manifestaciones abiertas de comportamiento, topografía conductual y proceder, consta de veinte seis (26) ítems del cuarenta y dos (42) al sesenta y siete (67), por medio de la escala SAMANTO se miden las actitudes de los 
Escala SAMANTO para medir actitudes de los operadores judiciales hacia la víctima 85

operadores jurídicos hacia la víctima, y se comprueba o se descarta si existe o no, actitudes revictimizantes por parte de los mismos.

Asimismo, se eligió un modelo cuantitativo de medición para fortalecer el análisis psicométrico riguroso del atributo como lo es la escala Likert. La cual, permitió mayor variabilidad en las respuestas y así más información con respecto a otras escalas dicotómicas. Además, este tipo de ítems e instrumento permiten realizar análisis de validez y confiabilidad. De igual forma, en la escala SAMANTO, se utilizó la escala de valorización propuesta por Likert, la cual está compuesta por los siguientes enunciados: (TA) totalmente de acuerdo, (A) de acuerdo, (D) en desacuerdo y (TD) totalmente en desacuerdo.

Por otra parte, para la construcción de la escala SAMANTO se tuvo como base los cinco primeros pasos del método de Carretero-Dios y Pérez (2005) porque hasta ahí se enmarcan los objetivos de la presente investigación, las fases planteadas por los autores son:

1. Delimitación conceptual del constructo objeto de evaluación. Como punto de partida, se tuvo en claro que lo que se deseaba evaluar eran las actitudes revictimizantes por parte de los operadores de la justicia. Además, el concepto de revictimización se revisó desde fuentes internacionales, las cuales, se relacionaron con el constructo de actitud y fue posible identificarles factores cognitivos, afectivos y conativos que permitieron construir indicadores a la luz de la fundamentación teórica.

2. Información sobre la construcción y evaluación cualitativa de ítems. En la fundamentación teórica se dejó constancia de los criterios de referencia empleados, ya que, se consideraron de suma importancia para la elaboración de 
Escala SAMANTO para medir actitudes de los operadores judiciales hacia la víctima 86

los ítems que se construyeron, los cuales fueron relevantes para los componentes del constructo. También, se previó que algunos ítems podrían eliminarse y por esta razón se construyeron ítems adicionales. Asimismo, para elevar su adecuación se ubicaron dentro de las tres categorías actitudinales que corresponden al pensamiento, sentimiento y comportamiento. A su vez, estos ítems fueron evaluados en contenido por jueces expertos quienes contribuyeron en la cualificación de la escala SAMANTO (Clark y Watson, 2003).

Consecuentemente, en la validación-jueces expertos, los reactivos fueron sometidos a la evaluación de los expertos en el tema. Para lo cual, se contactaron dos (2) psicólogos con amplia experiencia en trabajo con víctimas y aspirantes al título de psicología jurídica y forense, y una (1) psicóloga docente universitaria de postgrado en psicología jurídica y forense, y aspirante al título de doctor. Además, se conto con un (1) asesor metodólogo docente universitario de postgrado en psicología jurídica y forense, y un (1) asesor estadístico docente universitario de especialización en psicología jurídica y forense. En consecuencia, los jueces evaluaron la escala e hicieron las respectivas observaciones, enriqueciéndolas con una nutrida retroalimentación. De ahí que, algunas inconsistencias encontradas en la escala SAMANTO por los tres (3) jueces expertos fueron corregidas. Después de dichos ajustes, se volvió a socializar la escala SAMANTO con la directora de la investigación y el asesor estadístico, quienes dieron su aprobación para que la escala fuera aplicada a la muestra piloto.

Entonces, se procedió a la aplicación de la prueba piloto. Se contactaron diez (10) operadores judiciales de diversas instituciones como: Fiscalía General de la 
Escala SAMANTO para medir actitudes de los operadores judiciales hacia la víctima 87

Nación (FGN), Instituto Colombiano de Bienestar Familiar (ICBF), Policia Nacional (PONAL), Instituto Nacional de Medicina Legal y Ciencias Forense (INMLCF), Centro de Atención Inmediata a Víctimas de Abuso Sexual (CAIVAS), Comisarias de Familia, entre otras instituciones. La aplicación del pilotaje se realizó para observar el comportamiento de los reactivos y saber si los (67) ítems que compone la escala SAMANTO eran claros de comprender, o si por el contrario presentaban alguna inconsistencia.

3. Resultado del análisis estadístico de los ítems. Tras construir la escala SAMANTO se realizó una aplicación piloto y a este se le efectuó validez facial o aparente para prever dificultades en el diligenciamiento de la escala. Para ello, se empleó el estadístico alfa de Cronbach, con un promedio de diez (10) participantes que integraron la muestra piloto y muestra aparente y que a su vez diligenciaron el instrumento. Posteriormente, se aplicó la escala a la muestra final que comprendió 120 participantes en la que se usó el estadístico alfa de Cronbach el cual arrojó una confiabilidad de 0.948 En cuanto a la observación de los estadísticos de los ítems, se tuvo claridad para qué se iba a usar la escala, y así, estimar si los estadísticos encontrados permitían concluir que el test era o no adecuado. También, se fue prudente en la decisión de eliminar o conservar un ítem, cuya decisión, estaba fundamentada en la consideración de los criterios a la luz de la definición del constructo inicial y de los objetivos de aplicación para una revisión de los estadísticos comúnmente usados y cómo valorarlos, se tuvo en cuenta, que según el estadístico de Cronbach un índice superior de 0.7 era criterio de aceptación (Muñiz, Hidalgo, García-Cueto, Martínez y Moreno, 2005). 
Escala SAMANTO para medir actitudes de los operadores judiciales hacia la víctima 88

4. Evidencias empíricas de la estructura interna de la prueba. Se analizó la dimensionalidad de la escala SAMANTO, con el estadístico alfa de Cronbach para buscar estimar "el grado en el que los ítems y los componentes del test conformaran el constructo que se midió y sobre el que se basaron las interpretaciones" (Elosua, 2003).

5. Resultados de la estimación de la fiabilidad. En cuanto a la fiabilidad de las puntuaciones de la prueba se contó con el criterio esencial para tener en cuenta la selección de un test u otro. Por esta razón, no es hasta que se cuenta con un agrupamiento "definitivo" de ítems por componente, cuando se cuenta con el test "definitivo", y cuando la estimación de la fiabilidad adquiere su mayor alcance. No obstante, en muchas ocasiones se recurre a presentar estimaciones de la fiabilidad dentro de la fase de análisis de ítems, y se incluye normalmente el alfa de Cronbach como un indicador más del análisis de ítems. En general, los tests tienden a estimar la fiabilidad a partir de una única administración del instrumento, recurriendo a los procedimientos basados en el cálculo de la consistencia. Así pues, tras el pilotaje se realizó la aplicación a la muestra final y se formalizaron los análisis de confiabilidad con el estadístico Alfa de Cronbach, también, los de validez con el CVI, CVR. luego se procedió al agrupamiento definitivo para el respectivo análisis de los datos (Osburn, 2000).

En el caso de ítems con una escala tipo Likert, el índice de consistencia interna más usado es el alfa de Cronbach. Se podría afirmar que índices de fiabilidad situados alrededor de 0,70 resultarían adecuados si el objetivo de la escala es la investigación. Cuando el objetivo del test es el diagnóstico o clasificación, el 
Escala SAMANTO para medir actitudes de los operadores judiciales hacia la víctima 89

valor mínimo aconsejado debe situarse en torno a 0,80 (Nunnally y Bernstein, 1995).

6. Evidencias externas de la validez de las puntuaciones. Estas se basan, en el análisis de las relaciones entre la puntuación o puntuaciones ofrecidas por el test. Y: a) un criterio que se esperaba fuera predicho; b) otros test con el mismo objetivo de medición o con otros constructos con los que se esperaría relación; c) otras variables o constructos con los que se esperaría ausencia de relación, o una relación menor que la esperada con otras variables. En el actual estudio no fue posible realizar validez externa ya que no existen otros instrumentos que midan actitudes revictimizantes para comparar, por lo cual, tampoco se constituyó como objetivo de la presente investigación.

\section{Procedimiento}

El procedimiento de la investigación en general, coincide ampliamente con el proceso para construir instrumentos del apartado anterior. En términos generales comprende 2 fases: la construcción, validación y aplicación, las cuales permitieron lograr los objetivos planteados para diseñar una escala que midiera actitudes revictimizantes.

La construcción fue una fase que incluyó la identificación de los constructos pertinentes, dentro de los cuales están actitud, revictimización, validez y confiabilidad, y escala Likert, los cuales orientaron la generación del instrumento. Fue crucial la revisión del concepto de actitud por medio de la exploración en bases de datos, libros en físico y artículos con miras al enriquecimiento de la fundamentación científica que permitió establecer tres categorías de ítems: a) categoría cognitiva, b) categoría afectiva, 
Escala SAMANTO para medir actitudes de los operadores judiciales hacia la víctima 90

c) categoría comportamental. Así, teniendo claridad del constructo que se medió, se procedió a:

Al elegir el constructo de actitud revictimizante como objeto de medición, se decidió crear tantos ítems como fuera posible para cada categoría, una vez generada la escala, se adecuo al formato de opciones de respuesta y se procedió a la validación de contenido.

La validación y aplicaciones obedecieron a que la elaboración de instrumentos psicométricos requiere de estrategias de validación, para este caso se realizó a través de jueces expertos que evaluaran la validez de contenido. Como es recomendado en medición psicológica se realizaron dos aplicaciones en aras de construir adecuadamente el instrumento, la primera fue la aplicación piloto para valorar la validez facial y la segunda con una muestra mayor para valorar el comportamiento de los ítems. Esto implicó establecer los respectivos contactos con: muestra piloto (10), muestra aparente (10). Cabe resaltar que no fue sencillo contactar a los operadores judiciales si se tiene en cuenta la muestra que se requirió, aun así, después de un arduo trabajo en el que se incluyeron la elaboración de cartas institucionales cuyas respuestas oscilaron entre uno y dos meses aproximadamente y cuyas contestaciones fueron negativas, pues no se permitió el acceso a las instituciones por reestructuración interna y orden de Alcaldía.

Finalmente, se aplicó a una muestra más amplia (120) operadores judiciales, luego se tabularon las pruebas aplicadas, y aunque de estos se obtuvo resultados descriptivos, realmente se pretendía aplicar a un grupo mayor para observar el comportamiento del instrumento. Los lineamientos psicométricos sugieren que se aplique a muestras nacionales, pero como esto excedía los objetivos de este estudio, se sugiere para futuras investigaciones. Se prosiguió con el análisis estadístico de los 
Escala SAMANTO para medir actitudes de los operadores judiciales hacia la víctima 91

resultados, el análisis de los ítems, y con esto se allegó a la discusión de los hallazgos de la escala aplicada, pero, fundamentalmente se analizó el instrumento.

\section{Consideraciones éticas.}

En toda investigación en la que el ser humano sea sujeto de estudio, deberá prevalecer el criterio del respeto a su dignidad y la protección de sus derechos y su bienestar. Por tanto, la investigación que involucra seres humanos en sus estudios, deberá ser realizada por profesionales con conocimiento y experiencia para cuidar la integridad del ser humano. En razón, de garantizar la tranquilidad de las personas que participan de la investigación (Ministerio de salud, 1993).

Por lo tanto, la investigación se llevara a cabo cuando se obtenga la autorización del representante legal de la institución investigadora y de la institución donde se realice la investigación. Así como, el consentimiento informado de los participantes y la aprobación del proyecto por parte del comité de ética en Investigación de la institución (Ministerio de salud, 1993).

Por consiguiente, se entiende por consentimiento informado, el acuerdo por escrito mediante el cual la persona de investigación o en su caso, su representante legal, autoriza su participación en la investigación, con pleno conocimiento de la naturaleza de los procedimientos, beneficios y riesgos a que se someterá, con la capacidad de libre elección y sin coacción alguna. Igualmente, el consentimiento informado deberá ser explicado de forma sencilla, clara y completa a la(as) personas que van a participar de la investigación, o, en su defecto, a su representante legal, de tal forma que puedan comprenderla, como se señala a continuación (Ministerio de salud, 1993). 
Escala SAMANTO para medir actitudes de los operadores judiciales hacia la víctima 92

- La justificación y los objetivos de la investigación.

- Los procedimientos que vayan a usarse y su propósito incluyendo la identificación de aquellos que son experimentales.

- Las molestias o los riesgos esperados.

- Los beneficios que puedan obtenerse.

- Los procedimientos alternativos que pudieran ser ventajosos para el sujeto.

- La garantía de recibir respuesta a cualquier pregunta y aclaración a cualquier duda acerca de los procedimientos, riesgos, beneficios y otros asuntos relacionados con la investigación y el tratamiento del sujeto.

- La libertad de retirar su consentimiento en cualquier momento y dejar de participar en el estudio sin que por ello se creen perjuicios para continuar su cuidado y tratamiento.

- La seguridad que no se identificará al sujeto y que se mantendrá la confidencialidad de la información relacionada con su privacidad.

- El compromiso de proporcionarle información actualizada obtenida durante el estudio, aunque ésta pudiera afectar la voluntad del sujeto para continuar participando.

- La disponibilidad de tratamiento médico y la indemnización a que legalmente tendría derecho, por parte de la institución responsable de la investigación, en el caso de daños que le afecten directamente, causados por la investigación.

- En caso de que existan gastos adicionales, éstos serán cubiertos por el presupuesto de la investigación o de la institución responsable de la misma. 
Escala SAMANTO para medir actitudes de los operadores judiciales hacia la víctima 93

Después de haber aplicado la escala SAMANTO a los operadores judiciales que laboran en las diversas instituciones de la ciudad de Bogotá, se procedió a su respectiva tabulación, análisis de resultados e interpretación de todo lo concerniente al estudio estadístico, para saber si existe o no revictimización por parte de los órganos judiciales que conformaron la muestra. 
Escala SAMANTO para medir actitudes de los operadores judiciales hacia la víctima 94

\section{Resultados}

Los datos demográficos de la muestra conformada por 120 participantes voluntarios hombres y mujeres entre 21 y 61 años de edad que trabajan con instituciones del Estado como: Fiscalía General de la Nación (FGN), Instituto Colombiano de Bienestar Familiar (ICBF), Policia Nacional (PONAL), Instituto Nacional de Medicina Legal y Ciencias Forense (INMLCF), Centro de Atención Inmediata a Víctimas de Abuso Sexual (CAIVAS), Comisarias de Familia, entre otras instituciones, en cuyo desempeño laborar se encuentran profesionales del derecho, trabajo social, psicólogos, médicos y policías. En consecuencia, los datos recolectados que conformaron los resultados de la presente investigación se muestran mediante tablas y figuras analizándose cada uno de los datos mediante la herramienta tecnológica spss.

Por otra parte, una vez creados los ítems y las instrucciones de la escala SAMANTO junto con los demás aspectos formales del instrumento, se sometió a evaluación por tres (3) jueces expertos. Además, se contó con la asesoría de un (1) experto en metodología y un (1) experto en estadística, lo anterior, para detectar irregularidades en las instrucciones, ítems mal redactados, observar la relevancia del constructo de los ítems, la pertinencia de los ítems, proporción adecuada de los ítems, etc. De esta manera, de la evaluación cualitativa de los ítems que componen la escala SAMANTO, se obtuvieron las siguientes observaciones por parte de los tres (3) jueces expertos como sigue: Primer Juez, señaló que en efecto el instrumento guarda coherencia interna en todos sus reactivos, además añade, que a la víctima se le debe asistir constantemente debido a la vulnerabilidad que les asiste; asimismo recomienda, que se deben redactar mejor los ítems 45 y 57. Segundo Juez, mencionó que en términos generales el instrumento aplica para lo que se desea medir, pero, que era necesario 
revisar la redacción de los siguientes ítems: 3, 5, 7, 9, 15, 17, 31, 44, 45, 46, 49, 50 y 64 . Tercer Juez, refirió que en términos generales el instrumento estaba acorde al constructo que se deseaba medir, pero, que era importante revisar la redacción y claridad del ítem 1, así, como la categorización exacta del ítem 6 y del ítem 45.

Por consiguiente, una vez realizados los ajustes a los ítems, según las observaciones de los tres (3) Jueces expertos y de volver a revisar cada uno de los reactivos, se encontró que el ítem 26 y el ítem 32 estaban sobre cargados, es decir, cada uno contenía más de una categoría en sí. Por tanto, se toma la decisión de simplificarlos. De esta manera, de 66 reactivos que contenía en un principio el instrumento, se crea un reactivo más para la categoría componente comportamental o conativo, quedando la escala SAMANTO conformada por 67 ítems para su versión final y aplicación a la muestra piloto.

Por otra parte, después de haber aplicado el instrumento y de analizar el comportamiento de los ítems, se tomó la decisión de excluir los siguientes reactivos por que no funcionaron adecuadamente. Entonces, del componente cognitivo se eliminó el ítem 18; también, del componente afectivo se descartaron los ítems 25, 30, 36 y 40; mientras que del componente comportamental se excluyo el ítem 62. Por lo tanto, el instrumento SAMANTO quedo conformado por 61 ítems.

La siguiente tabla resume los puntajes de los jueces expertos que analizaron la validez de contenido para cada uno de los ítems. 
Tabla 3.

Validez de contenido de los ítems (CVI)

\begin{tabular}{|c|c|c|c|c|c|}
\hline Ítem & $\begin{array}{c}\text { Componente } \\
\text { Cognitivo CVI }\end{array}$ & Ítem & $\begin{array}{l}\text { Componente } \\
\text { Afectivo CVI }\end{array}$ & Ítem & $\begin{array}{l}\text { Componente } \\
\text { Conativo CVI }\end{array}$ \\
\hline it1 & 0,67 & it25 & 1,00 & it42 & 0,67 \\
\hline it2 & 1,00 & it26 & 1,00 & it43 & 1,00 \\
\hline it3 & 1,00 & it27 & 1,00 & it44 & 1,00 \\
\hline it 4 & 0,67 & it28 & 1,00 & it 45 & 0,89 \\
\hline it5 & 0,94 & it29 & 1,00 & it46 & 0,89 \\
\hline it6 & 0,83 & it30 & 1,00 & it47 & 1,00 \\
\hline it7 & 1,00 & it31 & 1,00 & it48 & 1,00 \\
\hline it8 & 1,00 & it32 & 1,00 & it49 & 1,00 \\
\hline it9 & 1,00 & it33 & 0,94 & it50 & 0,94 \\
\hline it 10 & 0,94 & it34 & 1,00 & it51 & 1,00 \\
\hline it11 & 1,00 & it35 & 0,94 & it52 & 0,94 \\
\hline it12 & 1,00 & it36 & 1,00 & it53 & 1,00 \\
\hline it13 & 1,00 & it37 & 1,00 & it54 & 0,67 \\
\hline it14 & 1,00 & it38 & 1,00 & it55 & 1,00 \\
\hline it 15 & 0,94 & it39 & 1,00 & it56 & 1,00 \\
\hline it16 & 1,00 & it40 & 1,00 & it57 & 0,67 \\
\hline it17 & 1,00 & it41 & 1,00 & it58 & 1,00 \\
\hline it 18 & 1,00 & & & it59 & 0,67 \\
\hline it19 & 1,00 & & & it60 & 0,50 \\
\hline it20 & 1,00 & & & it61 & 1,00 \\
\hline it21 & 1,00 & & & it62 & 1,00 \\
\hline it22 & 1,00 & & & it63 & 0,89 \\
\hline it23 & 1,00 & & & it64 & 0,67 \\
\hline \multirow[t]{2}{*}{ it24 } & 1,00 & & & it65 & 0,94 \\
\hline & & & & it66 & 1,00 \\
\hline
\end{tabular}

Nota: CVI- índice de validez de contenido, corresponde al promedio de criterio del acuerdo establecidos por los jueces expertos. 


\section{Tabla 4.}

Síntesis del índice de validez CVI

\begin{tabular}{lccc}
\hline \multicolumn{1}{c}{ Descriptivos } & $\begin{array}{c}\text { Categoría } \\
\text { Cognitiva }\end{array}$ & $\begin{array}{c}\text { Categoría } \\
\text { Afectiva }\end{array}$ & $\begin{array}{c}\text { Categoría } \\
\text { Comportamental }\end{array}$ \\
\hline Media & 0,96 & 0,99 & 0,89 \\
Desviación estándar & 0,10 & 0,01 & 0,15 \\
\hline
\end{tabular}

Nota: Resumen del CVI- índice de validez de contenido.

En términos generales, en el análisis de la evaluación cualitativa se encontró que los ítems de las tres categorías, en su mayoría puntuaron por encima de .70 como se aprecia en la tabla 3, también, la tabla 4, permitió ver la media y la desviación estándar de las tres categorías. De lo que se observa que, 22 de los ítems de la categoría componente cognitivo se mantuvieron entre .83 y 1 , encontrándose adecuado el comportamiento de estos ítems, excepto los ítems 1 y 4 que se hallaron con .67 lo cual indicó que el comportamiento de estos dos ítems era aceptable. Asimismo, se encontró que los 17 ítems que conformaron la categoría componente afectivo desde el ítem 25 al 41, se comportaron adecuadamente estando entre .94 y 1 , evidenciándose un adecuado funcionamiento en todos los ítems que integraron esta categoría. Además, se halló que de los 25 ítems que conforman la categoría componente comportamental desde el ítem 42 al 66, se encontró que 19 de sus ítems puntuaron entre .89 y 1 , evidenciándose un adecuado funcionamiento en los ítems de esta categoría, excepto los ítems 42, 54, 57, 59, 60 y 64, en los que se halló, que estos seis ítems se encontraban entre $\quad .50$ y .67 con una calificación aceptable por su funcionamiento. También, se añade que no se encontró ítems que puntuaran por debajo de 0,49 . 
Consecuentemente, se realizan las correcciones según las observaciones hechas por los tres (3) Jueces expertos y se crea un ítem más. Por consiguiente, se procede a la aplicación del instrumento SAMANTO con la muestra piloto que estuvo conformada por 10 participantes. Además, se realizó la validez aparente con una muestra de 10 participantes, quienes respondieron el instrumento que consta de 67 ítems y conforman la escala SAMANTO, de cuya muestra facial se obtuvieron las siguientes observaciones: se halló que los ítems 1, 3, 7, 25, 31, 33 y 40 requerían de mayor claridad. Razón por la cual, se revisaron nuevamente estos reactivos, haciéndose las correcciones y ajustes pertinentes según los hallazgos de la validez aparente. Una vez superado el análisis de contenido, se inició la aplicación con la muestra piloto con el fin de evaluar la validez facial aparente tomando como criterio conservar aquellos reactivos con índices iguales o superiores 0.06 en este indicador, los resultados se observan seguidamente: 


\section{Tabla 5.}

\section{Índices de validez aparente}

\begin{tabular}{ccccccccc}
\hline \multicolumn{2}{c}{ Componente Cognitivo } & \multicolumn{3}{c}{ Componente Afectivo } & \multicolumn{3}{c}{ Componente Comportamental } \\
Ítems & IVC & IVA & Ítems & IVC & IVA & Ítems & IVC & IVA \\
\hline & & & & & & & & \\
it1 & 0,67 & 0,80 & it25 & 1,00 & 0,60 & it42 & 0,67 & 0,60 \\
it2 & 1,00 & 0,70 & it26 & 1,00 & 0,70 & it43 & 1,00 & 0,70 \\
it3 & 1,00 & 0,80 & it27 & 1,00 & 0,60 & it44 & 1,00 & 0,70 \\
it4 & 0,67 & 0,70 & it28 & 1,00 & 0,60 & it45 & 0,89 & 0,70 \\
it5 & 0,94 & 0,70 & it29 & 1,00 & 0,50 & it46 & 0,89 & 0,60 \\
it6 & 0,83 & 0,80 & it30 & 1,00 & 0,70 & it47 & 1,00 & 0,50 \\
it7 & 1,00 & 0,60 & it31 & 1,00 & 0,80 & it48 & 1,00 & 0,60 \\
it8 & 1,00 & 0,80 & it32 & 1,00 & 0,70 & it49 & 1,00 & 0,60 \\
it9 & 1,00 & 0,80 & it33 & 0,94 & 0,60 & it50 & 0,94 & 0,70 \\
it10 & 0,94 & 0,60 & it34 & 1,00 & 0,70 & it51 & 1,00 & 0,60 \\
it11 & 1,00 & 0,70 & it35 & 0,94 & 0,50 & it52 & 0,94 & 0,70 \\
it12 & 1,00 & 0,80 & it36 & 1,00 & 0,60 & it53 & 1,00 & 0,60 \\
it13 & 1,00 & 0,80 & it37 & 1,00 & 0,50 & it54 & 0,67 & 0,70 \\
it14 & 1,00 & 0,80 & it38 & 1,00 & 0,70 & it55 & 1,00 & 0,70 \\
it15 & 0,94 & 0,80 & it39 & 1,00 & 0,50 & it56 & 1,00 & 0,80 \\
\hline
\end{tabular}

Nota: La validez aparente se realizó con 10 participantes y se evaluó si había claridad en la frase que componía cada ítem. (IVC) índice de validez de contenido; (IVA) índice de validez aparente.

\section{Continuación Tabla 5.}

Índices de validez aparente

\begin{tabular}{ccccccccc}
\hline \multicolumn{2}{c}{ Componente Cognitivo } & \multicolumn{3}{c}{ Componente Afectivo } & \multicolumn{3}{c}{ Componente Comportamental } \\
Ítems & IVC & IVA & Ítems & IVC & IVA & Ítems & IVC & IVA \\
\hline & & & & & & & & \\
it16 & 1,00 & 0,80 & it40 & 1,00 & 0,70 & it57 & 0,67 & 0,80 \\
it17 & 1,00 & 0,50 & it41 & 1,00 & 0,60 & it58 & 1,00 & 0,80 \\
it18 & 1,00 & 0,80 & & & & it59 & 0,67 & 0,70 \\
it19 & 1,00 & 0,80 & & & & it60 & 0,50 & 0,70 \\
it20 & 1,00 & 0,70 & & & & it61 & 1,00 & 0,70 \\
it21 & 1,00 & 0,70 & & & & it62 & 1,00 & 0,80 \\
it22 & 1,00 & 0,60 & & & & it63 & 0,89 & 0,80 \\
it23 & 1,00 & 0,60 & & & & it64 & 0,67 & 0,50 \\
it24 & 1,00 & 0,50 & & & & it65 & 0,94 & 0,70 \\
& & & & & & it66 & 1,00 & 0,60 \\
& & & & & & it67 & 0,73 & 0,80 \\
\hline
\end{tabular}

Nota: La validez aparente se realizó con 10 participantes y se evaluó si había claridad en la frase que componía cada ítem. (IVC) índice de validez de contenido; (IVA) índice de validez aparente. 
Por su parte, al realizar el análisis del índice de validez aparente (IVA) se encontró que en la categoría del componente cognitivo la mayoría de los ítems puntuaron entre .67 y 1. Evidenciándose el funcionamiento de estos ítems en un nivel adecuado. También, se halló que en la categoría del componente afectivo, los reactivos puntuaron entre 94 y .1 Lo cual, indicó que el comportamiento de estos ítems se encontraban en un nivel adecuado y alto. Además, se halló en la categoría correspondiente al componente comportamental o conativo, que los ítems 1, 54, 57, 59 y 64 se encontraban con una puntuación de .67 mientras que el resto de los ítems que conformaron dicha categoría se encontraban puntuando entre .89 y 1. Evidenciándose el funcionamiento de estos ítems en un nivel adecuado. En consecuencia, se halló que los ítems que conforman la escala SAMANTO, presentaron un buen funcionamiento ya que, se encuentran con puntuaciones entre .67 y 1 permaneciendo en un nivel adecuado y alto, según comportamiento de los ítems.

Aun así, se reviso nuevamente cada uno de los reactivos con el fin de constatar que la frase que componía cada ítem tuviera la claridad que se esperaba. De manera que, después de las minuciosas correcciones según las observaciones de los Jueces expertos y de los participantes del pilotaje que cooperaron con la validez facial o aparente, el resultados obtenido de la muestra piloto y la muestra de la validez aparente, se evidencio una clara coherencia interna en cada ítem. Asimismo, durante las etapas de corrección y ajustes a los reactivos que componían el instrumento, se tuvo presente la escala de valoración tipo Likert que se empleó para la construcción de dicho instrumento, cuyas categoría de respuestas se enunciaron así: totalmente de acuerdo (TA), acuerdo (A), desacuerdo (D), totalmente desacuerdo (TD). 
Por consiguiente, tras la aplicación final del instrumento SAMANTO, se tuvo claridad que los ítems que se dejarían debieran puntuar mayor o igual a 0.60 en el índice de validez, así, que los reactivos $18,25,30,36,40$ y 62 que registraron un índice de validez menor a 0.60 se eliminaron, dado que no cumplieron el criterio psicométrico y su aporte a la validez teórica tampoco resultó esencial. Por otro lado, se exceptuó de este criterio de eliminación a los ítems 38, 47 y 65 que se consideraron claros, pertinentes, adecuadamente ubicados y de gran relevancia teórica para la validez de constructo del instrumento. En consecuencia el fundamento de la decisión de no eliminar estos ítems a pesar de que puntuaron 0.50 en el indicador, se sustenta desde el aporte a la validez teórica de instrumento y no tanto desde su comportamiento estadístico.

A continuación, se presenta el resultado de la muestra empírica conformada por 120 participantes. 
Escala SAMANTO para medir actitudes de los operadores judiciales hacia la víctima 102

Tabla 6.

Resultado del análisis estadístico de la evaluación cuantitativa de los ítems del componente cognitivo de la escala SAMANTO

\section{Componte Cognitivo}

\begin{tabular}{ccccccccc}
\hline \multicolumn{3}{c}{$\begin{array}{c}\text { Totalmente de } \\
\text { Acuerdo }\end{array}$} & & \multicolumn{2}{c}{ Acuerdo } & Desacuerdo & \multicolumn{2}{c}{ Total } \\
\multicolumn{1}{l}{ Items } & Frec. & $\%$ & Frec. & $\%$ & Frecu. & $\%$ & Frec. & $\%$ \\
\hline 1 & 11 & 9.17 & 62 & 51.67 & 40 & 33.33 & 7 & 5.83 \\
2 & 67 & 55.83 & 42 & 35.00 & 7 & 5.83 & 4 & 3.33 \\
3 & 20 & 16.67 & 55 & 45.83 & 33 & 27.50 & 12 & 10.00 \\
4 & 49 & 40.83 & 52 & 43.33 & 15 & 12.50 & 4 & 3.33 \\
5 & 33 & 27.50 & 45 & 37.50 & 32 & 26.67 & 10 & 8.33 \\
6 & 39 & 32.50 & 66 & 55.00 & 15 & 12.50 & 0 & 0.00 \\
7 & 40 & 33.33 & 52 & 43.33 & 21 & 17.50 & 7 & 5.83 \\
8 & 30 & 25.00 & 56 & 46.67 & 31 & 25.83 & 3 & 2.50 \\
9 & 76 & 63.33 & 37 & 30.83 & 4 & 3.33 & 3 & 2.50 \\
10 & 56 & 46.67 & 52 & 43.33 & 11 & 9.17 & 1 & 0.83 \\
11 & 60 & 50.00 & 52 & 43.33 & 8 & 6.67 & 0 & 0.00 \\
12 & 24 & 20.00 & 49 & 40.83 & 38 & 31.67 & 9 & 7.50 \\
13 & 53 & 44.17 & 51 & 42.50 & 13 & 10.83 & 3 & 2.50 \\
14 & 76 & 63.33 & 35 & 29.17 & 4 & 3.33 & 5 & 4.17 \\
15 & 22 & 18.33 & 71 & 59.17 & 19 & 15.83 & 8 & 6.67 \\
16 & 49 & 40.83 & 43 & 35.83 & 23 & 19.17 & 5 & 4.17 \\
17 & 33 & 25.50 & 41 & 34.17 & 39 & 32.50 & 7 & 5.83 \\
19 & 38 & 31.67 & 54 & 45.00 & 21 & 17.50 & 7 & 5.83 \\
20 & 25 & 20.83 & 53 & 44.17 & 37 & 30.83 & 5 & 4.17 \\
21 & 27 & 22.50 & 56 & 46.67 & 29 & 24.17 & 8 & 6.67 \\
22 & 70 & 58.33 & 37 & 30.83 & 9 & 7.50 & 4 & 3.33 \\
23 & 51 & 42.50 & 54 & 45.00 & 12 & 10.00 & 3 & 2.50 \\
24 & 31 & 25.83 & 71 & 59.17 & 11 & 9.17 & 7 & 5.83 \\
\hline
\end{tabular}


Escala SAMANTO para medir actitudes de los operadores judiciales hacia la víctima 103

Continuación Tabla 6.

Resultado del análisis estadístico de la evaluación cuantitativa de los ítems del componente afectivo de la escala SAMANTO

\section{Componte Afectivo}

\begin{tabular}{ccccccccc}
\hline \multicolumn{3}{c}{$\begin{array}{c}\text { Totalmente de } \\
\text { Acuerdo }\end{array}$} & \multicolumn{2}{c}{ Acuerdo } & Desacuerdo & \multicolumn{2}{c}{$\begin{array}{c}\text { Total } \\
\text { Desacuerdo }\end{array}$} \\
\hline Ítems & Frec. & $\%$ & Frec. & $\%$ & Frecu. & $\%$ & Frec. & $\%$ \\
& & & & & & & & \\
\hline 26 & 56 & 46.67 & 51 & 42.50 & 7 & 5.83 & 6 & 5.00 \\
27 & 65 & 54.17 & 38 & 31.67 & 14 & 11.67 & 3 & 2.50 \\
28 & 77 & 64.17 & 33 & 27.50 & 7 & 5.83 & 3 & 2.50 \\
29 & 44 & 36.67 & 47 & 39.17 & 24 & 20.00 & 5 & 4.17 \\
31 & 9 & 7.50 & 23 & 19.17 & 69 & 57.50 & 19 & 15.83 \\
32 & 22 & 18.33 & 64 & 53.33 & 25 & 20.83 & 9 & 7.50 \\
33 & 64 & 53.33 & 42 & 35.00 & 13 & 10.83 & 1 & 0.83 \\
34 & 39 & 32.50 & 57 & 47.50 & 22 & 18.33 & 2 & 1.67 \\
35 & 36 & 30.00 & 59 & 49.17 & 22 & 18.33 & 3 & 2.50 \\
37 & 74 & 61.67 & 33 & 27.50 & 9 & 7.50 & 4 & 3.33 \\
38 & 34 & 28.33 & 59 & 49.17 & 22 & 18.33 & 5 & 4.17 \\
39 & 29 & 24.17 & 56 & 46.67 & 25 & 20.83 & 10 & 8.33 \\
41 & 66 & 55.00 & 39 & 32.50 & 10 & 8.33 & 5 & 4.17 \\
\hline
\end{tabular}

Nota: Aparecen los reactivos aprobados en la versión final de la escala. 
Escala SAMANTO para medir actitudes de los operadores judiciales hacia la víctima 104

Continuación Tabla 6.

Resultado del análisis estadístico de la evaluación cuantitativa de los ítems del componente comportamental de la escala SAMANTO

Componte Comportamental o Conativo

\begin{tabular}{|c|c|c|c|c|c|c|c|c|}
\hline \multicolumn{3}{|c|}{$\begin{array}{l}\text { Totalmente de } \\
\text { Acuerdo }\end{array}$} & \multicolumn{2}{|c|}{ Acuerdo } & \multicolumn{2}{|c|}{ Desacuerdo } & \multicolumn{2}{|c|}{$\begin{array}{c}\text { Total } \\
\text { Desacuerdo }\end{array}$} \\
\hline Ítems & Frec. & $\%$ & Frec. & $\%$ & Frecu. & $\%$ & Frec. & $\%$ \\
\hline 42 & 41 & 34.17 & 50 & 41.67 & 24 & 20.00 & 5 & 4.17 \\
\hline 43 & 35 & 29.17 & 51 & 42.50 & 31 & 25.83 & 3 & 2.50 \\
\hline 44 & 40 & 33.33 & 53 & 44.17 & 21 & 17.50 & 6 & 5.00 \\
\hline 45 & 33 & 27.50 & 49 & 40.83 & 30 & 25.00 & 8 & 6.67 \\
\hline 46 & 52 & 43.33 & 47 & 39.17 & 15 & 12.50 & 6 & 5.00 \\
\hline 47 & 58 & 48.33 & 48 & 40.00 & 12 & 10.00 & 2 & 1.67 \\
\hline 48 & 35 & 29.17 & 63 & 52.50 & 19 & 15.83 & 3 & 2.50 \\
\hline 49 & 39 & 32.50 & 56 & 46.67 & 23 & 19.17 & 2 & 1.67 \\
\hline 50 & 50 & 41.67 & 51 & 42.50 & 15 & 12.50 & 4 & 3.33 \\
\hline 51 & 57 & 47.50 & 51 & 42.50 & 7 & 5.83 & 5 & 4.17 \\
\hline 52 & 41 & 34.17 & 59 & 49.17 & 14 & 11.67 & 6 & 5.00 \\
\hline 53 & 44 & 36.67 & 56 & 46.67 & 18 & 15.00 & 2 & 1.67 \\
\hline 54 & 17 & 14.17 & 40 & 33.33 & 53 & 44.17 & 10 & 8.33 \\
\hline 55 & 30 & 25.00 & 59 & 49.17 & 27 & 22.50 & 4 & 3.33 \\
\hline 56 & 61 & 50.83 & 48 & 40.00 & 9 & 7.50 & 2 & 1.67 \\
\hline 57 & 37 & 30.83 & 38 & 31.67 & 38 & 31.67 & 7 & 5.83 \\
\hline 58 & 50 & 41.67 & 61 & 50.83 & 6 & 5.00 & 3 & 2.50 \\
\hline 59 & 68 & 56.67 & 42 & 35.00 & 10 & 8.33 & 0 & 0.00 \\
\hline 60 & 35 & 29.17 & 50 & 41.67 & 29 & 24.17 & 6 & 5.00 \\
\hline 61 & 27 & 22.50 & 41 & 34.17 & 40 & 33.33 & 12 & 10.00 \\
\hline 63 & 49 & 40.83 & 40 & 33.33 & 27 & 22.50 & 4 & 3.33 \\
\hline 64 & 52 & 43.33 & 54 & 45.00 & 11 & 9.17 & 3 & 2.50 \\
\hline 65 & 38 & 31.67 & 55 & 45.83 & 24 & 20.00 & 3 & 2.50 \\
\hline 66 & 44 & 36.67 & 65 & 54.17 & 10 & 8.33 & 1 & 0.83 \\
\hline 67 & 37 & 30.83 & 39 & 32.50 & 26 & 21.67 & 18 & 15.00 \\
\hline
\end{tabular}


Escala SAMANTO para medir actitudes de los operadores judiciales hacia la víctima 105

\section{Tabla 7.}

Resultados de la escala SAMANTO

\begin{tabular}{|c|c|c|c|c|c|c|c|c|c|c|c|c|c|c|c|c|}
\hline Participante & 1 & 2 & 3 & 4 & 5 & 6 & 7 & 8 & 9 & 10 & 11 & 12 & 13 & 14 & 15 & 16 \\
\hline Calificación & 145 & 128 & 110 & 139 & 117 & 101 & 125 & 110 & 136 & 125 & 111 & 113 & 130 & 124 & 181 & 125 \\
\hline Participante & 17 & 18 & 19 & 20 & 21 & 22 & 23 & 24 & 25 & 26 & 27 & 28 & 29 & 30 & 31 & 32 \\
\hline Calificación & 130 & 158 & 145 & 148 & 121 & 132 & 111 & 183 & 137 & 140 & 197 & 135 & 124 & 139 & 110 & 98 \\
\hline Participante & 33 & 34 & 35 & 36 & 37 & 38 & 39 & 40 & 41 & 42 & 43 & 44 & 45 & 46 & 47 & 48 \\
\hline Calificación & 127 & 153 & 173 & 119 & 120 & 133 & 124 & 137 & 108 & 159 & 176 & 126 & 127 & 139 & 112 & 139 \\
\hline Participante & 49 & 50 & 51 & 52 & 53 & 54 & 55 & 56 & 57 & 58 & 59 & 60 & 61 & 62 & 63 & 64 \\
\hline Calificación & 181 & 168 & 119 & 132 & 158 & 163 & 148 & 119 & 131 & 108 & 135 & 128 & 141 & 86 & 164 & 92 \\
\hline Participante & 65 & 66 & 67 & 68 & 69 & 70 & 71 & 72 & 73 & 74 & 75 & 76 & 77 & 78 & 79 & 80 \\
\hline Calificación & 137 & 134 & 132 & 134 & 111 & 128 & 106 & 116 & 113 & 98 & 146 & 146 & 140 & 139 & 155 & 142 \\
\hline Participante & 81 & 82 & 83 & 84 & 85 & 86 & 87 & 88 & 89 & 90 & 91 & 92 & 93 & 94 & 95 & 96 \\
\hline Calificación & 105 & 150 & 118 & 128 & 141 & 184 & 96 & 101 & 123 & 152 & 200 & 123 & 116 & 127 & 144 & 170 \\
\hline Participante & 97 & 98 & 99 & 100 & 101 & 102 & 103 & 104 & 105 & 106 & 107 & 108 & 109 & 110 & 111 & 112 \\
\hline Calificación & 158 & 190 & 97 & 139 & 143 & 137 & 123 & 150 & 110 & 127 & 161 & 104 & 148 & 157 & 148 & 102 \\
\hline Participante & 113 & 114 & 115 & 116 & 117 & 118 & 119 & 120 & & & & & & & & \\
\hline Calificación & 121 & 128 & 125 & 151 & 163 & 166 & 139 & 145 & & & & & & & & \\
\hline \multicolumn{3}{|c|}{ Total participante........ } & 120 & & & & & & & & & & & & & \\
\hline \multicolumn{3}{|c|}{ Promedio Calificación.. } & 134 & & & & & & & & & & & & & \\
\hline
\end{tabular}


Escala SAMANTO para medir actitudes de los operadores judiciales hacia la víctima 106

Tabla 8.

Media y desviación de todos los ítems de la muestra total

\begin{tabular}{|c|c|c|c|c|c|c|c|c|c|c|c|c|c|c|}
\hline Ítems & 1 & 2 & 3 & 4 & 5 & 6 & 7 & 8 & 9 & 10 & 11 & 12 & 13 & 14 \\
\hline Media & 2,36 & 1,57 & 2,31 & 1,78 & 2,16 & 1,80 & 1,96 & 2,06 & 1,45 & 1,64 & 1,57 & 2,27 & 1,72 & 1,48 \\
\hline $\begin{array}{l}\text { Desviación } \\
\text { típica }\end{array}$ & ,731 & ,753 & ,868 & ,791 & ,926 & 643 & ,864 & ,781 & ,684 & 683 & ,618 & ,867 & ,758 & ,756 \\
\hline Ítems & 15 & 16 & 17 & 19 & 20 & 21 & 22 & 23 & 24 & 26 & 27 & 28 & 29 & 31 \\
\hline Media & 2,11 & 1,87 & 2,17 & 1,98 & 2,18 & 2,15 & 1,56 & 1,73 & 1,95 & 1,69 & 1,63 & 1,47 & 1,92 & 2,82 \\
\hline $\begin{array}{l}\text { Desviación } \\
\text { típica }\end{array}$ & ,776 & ,869 & 901 & ,855 & ,809 & ,847 & ,776 & ,744 & ,765 & ,797 & ,789 & ,721 & ,856 & ,788 \\
\hline Ítems & 32 & 33 & 34 & 35 & 37 & 38 & 39 & 41 & 42 & 43 & 44 & 45 & 46 & 47 \\
\hline Media & 2,18 & 1,59 & 1,89 & 1,93 & 1,53 & 1,98 & 2,13 & 1,62 & 1,94 & 2,02 & 1,94 & 2,11 & 1,79 & 1,65 \\
\hline $\begin{array}{l}\text { Desviación } \\
\text { típica }\end{array}$ & ,816 & ,716 & ,754 & ,764 & ,777 & ,799 & ,879 & ,812 & ,843 & ,809 & ,843 & ,887 & ,849 & ,729 \\
\hline Ítems & 48 & 49 & 50 & 51 & 52 & 53 & 54 & 55 & 56 & 57 & 58 & 59 & 60 & 61 \\
\hline Media & 1,92 & 1,90 & 1,78 & 1,67 & 1,88 & 1,82 & 2,47 & 2,04 & 1,60 & 2,13 & 1,68 & 1,52 & 2,05 & 2,31 \\
\hline $\begin{array}{l}\text { Desviación } \\
\text { típica }\end{array}$ & ,740 & ,760 & ,793 & ,771 & ,805 & ,745 & ,840 & ,782 & ,703 & ,922 & ,686 & ,648 & ,858 & ,933 \\
\hline Ítems & 63 & 64 & 65 & 66 & 67 & & & & & & & & & \\
\hline Media & 1,88 & 1,71 & 1,93 & 1,73 & 2,21 & & & & & & & & & \\
\hline $\begin{array}{l}\text { Desviación } \\
\text { típica }\end{array}$ &, 871 &, 738 & ,786 & ,654 & 1,044 & & & & & & & & & \\
\hline
\end{tabular}

Promedio calificación......... 134

Desviación estándar total... 23.07 
Escala SAMANTO para medir actitudes de los operadores judiciales hacia la víctima 107

\section{Tabla 9.}

Estadísticos totales de los componentes cognitivo, afectivo y comportamental

\begin{tabular}{|c|c|c|c|c|}
\hline Ítems & $\begin{array}{c}\text { Media de la } \\
\text { escala si se } \\
\text { elimina el } \\
\text { elemento }\end{array}$ & $\begin{array}{c}\text { Varianza de la } \\
\text { escala si se } \\
\text { elimina el } \\
\text { elemento }\end{array}$ & $\begin{array}{l}\text { Correlación } \\
\text { elemento-total } \\
\text { corregida }\end{array}$ & $\begin{array}{c}\text { Alfa de } \\
\text { Cronbach si } \\
\text { se elimina el } \\
\text { elemento }\end{array}$ \\
\hline 1 & 113,47 & 646,369 & ,359 & ,957 \\
\hline 2 & 114,26 & 643,487 & ,424 & ,957 \\
\hline 3 & 113,52 & 642,941 & ,376 & ,957 \\
\hline 4 & 114,04 & 637,250 & ,561 & ,956 \\
\hline 5 & 113,67 & 640,510 & ,403 & ,957 \\
\hline 6 & 114,03 & 643,184 & ,510 & ,956 \\
\hline 7 & 113,87 & 641,999 & ,400 & ,957 \\
\hline 8 & 113,77 & 644,668 & ,377 & ,957 \\
\hline 9 & 114,38 & 645,178 & ,420 & ,957 \\
\hline 10 & 114,18 & 645,159 & ,421 & ,957 \\
\hline 11 & 114,26 & 642,865 & ,542 & ,956 \\
\hline 12 & 113,56 & 648,165 & ,257 & ,957 \\
\hline 13 & 114,11 & 636,484 & ,606 & ,956 \\
\hline 14 & 114,34 & 646,445 & ,344 & ,957 \\
\hline 15 & 113,72 & 640,020 & ,500 & ,956 \\
\hline 16 & 113,96 & 633,519 & ,594 & ,956 \\
\hline 17 & 113,66 & 638,193 & ,466 & ,957 \\
\hline 19 & 113,85 & 640,129 & ,448 & ,957 \\
\hline 20 & 113,64 & 637,543 & ,539 & ,956 \\
\hline
\end{tabular}


Escala SAMANTO para medir actitudes de los operadores judiciales hacia la víctima 108

Continuación tabla 9.

Estadísticos total de los componentes cognitivo, afectivo y comportamental

\begin{tabular}{|c|c|c|c|c|}
\hline Ítems & $\begin{array}{l}\text { Media de la } \\
\text { escala si se } \\
\text { elimina el } \\
\text { elemento }\end{array}$ & $\begin{array}{c}\text { Varianza de la } \\
\text { escala si se } \\
\text { elimina el } \\
\text { elemento }\end{array}$ & $\begin{array}{l}\text { Correlación } \\
\text { elemento-total } \\
\text { corregida }\end{array}$ & $\begin{array}{c}\text { Alfa de } \\
\text { Cronbach si } \\
\text { se elimina el } \\
\text { elemento }\end{array}$ \\
\hline 21 & 113,68 & 639,767 & ,461 & ,957 \\
\hline 22 & 114,27 & 639,407 & ,516 & ,956 \\
\hline 23 & 114,10 & 633,889 & ,688 & ,956 \\
\hline 24 & 113,88 & 643,522 & ,416 & ,957 \\
\hline 26 & 114,13 & 636,066 & ,586 & ,956 \\
\hline 27 & 114,20 & 640,750 & ,472 & ,956 \\
\hline 28 & 114,36 & 637,560 & 609 & ,956 \\
\hline 29 & 113,91 & 639,429 & ,464 & ,957 \\
\hline 31 & 113,01 & 655,588 & 100 & ,958 \\
\hline 32 & 113,65 & 639,591 & ,484 & ,956 \\
\hline 33 & 114,23 & 636,315 & ,648 & ,956 \\
\hline 34 & 113,93 & 637,508 & ,583 & ,956 \\
\hline 35 & 113,89 & 638,602 & ,545 & ,956 \\
\hline 37 & 114,30 & 635,960 & ,604 & ,956 \\
\hline 38 & 113,84 & 638,706 & ,518 & ,956 \\
\hline 39 & 113,69 & 640,350 & ,430 & ,957 \\
\hline 41 & 114,21 & 632,872 & ,654 & ,956 \\
\hline
\end{tabular}


Escala SAMANTO para medir actitudes de los operadores judiciales hacia la víctima 109

Continuación tabla 9.

Estadísticos total de los componentes cognitivo, afectivo y comportamental

\begin{tabular}{|c|c|c|c|c|}
\hline Ítems & $\begin{array}{c}\text { Media de la } \\
\text { escala si se } \\
\text { elimina el } \\
\text { elemento }\end{array}$ & $\begin{array}{c}\text { Varianza de la } \\
\text { escala si se } \\
\text { elimina el } \\
\text { elemento }\end{array}$ & $\begin{array}{l}\text { Correlación } \\
\text { elemento-total } \\
\text { corregida }\end{array}$ & $\begin{array}{c}\text { Alfa de } \\
\text { Cronbach si } \\
\text { se elimina el } \\
\text { elemento }\end{array}$ \\
\hline 42 & 113,88 & 633,969 & ,602 & ,956 \\
\hline 43 & 113,81 & 636,610 & ,563 & ,956 \\
\hline 44 & 113,88 & 630,322 & ,690 & ,956 \\
\hline 45 & 113,72 & 631,196 & ,634 & ,956 \\
\hline 46 & 114,03 & 630,604 & ,678 & ,956 \\
\hline 47 & 114,18 & 635,188 & ,667 & ,956 \\
\hline 48 & 113,91 & 635,244 & ,656 & ,956 \\
\hline 49 & 113,93 & 633,011 & 697 & ,956 \\
\hline 50 & 114,05 & 630,687 & ,726 & ,956 \\
\hline 51 & 114,16 & 636,202 & ,603 & ,956 \\
\hline 52 & 113,95 & 637,527 &, 543 & ,956 \\
\hline 53 & 114,01 & 633,336 & ,703 & ,956 \\
\hline 54 & 113,36 & 641,744 & ,418 & ,957 \\
\hline 55 & 113,78 & 636,171 & ,595 & ,956 \\
\hline
\end{tabular}


Escala SAMANTO para medir actitudes de los operadores judiciales hacia la víctima 110

Continuación tabla 9.

Estadísticos total de los componentes cognitivo, afectivo y comportamental

\begin{tabular}{ccccc}
\hline İ́ms & $\begin{array}{c}\text { Media de la } \\
\text { escala si se } \\
\text { elimina el } \\
\text { elemento }\end{array}$ & $\begin{array}{c}\text { Varianza de la } \\
\text { escala si se } \\
\text { elimina el } \\
\text { elemento }\end{array}$ & $\begin{array}{c}\text { Correlación } \\
\text { elemento-total } \\
\text { corregida }\end{array}$ & $\begin{array}{c}\text { Alfa de } \\
\text { Cronbach si } \\
\text { se elimina el } \\
\text { elemento }\end{array}$ \\
\hline 56 & 114,23 & 644,865 &, 417 &, 957 \\
57 & 113,70 & 643,489 &, 340 &, 957 \\
58 & 114,14 & 641,047 &, 539 &, 956 \\
59 & 114,31 & 646,551 &, 403 &, 957 \\
60 & 113,78 & 636,428 &, 533 &, 956 \\
61 & 113,52 & 638,857 &, 435 &, 957 \\
63 & 113,94 & 643,988 &, 350 &, 957 \\
64 & 114,12 & 639,482 &, 542 &, 956 \\
65 & 113,89 & 641,677 &, 451 &, 957 \\
66 & 114,09 & 637,210 &, 695 &, 956 \\
67 & 113,62 & 637,869 &, 404 &, 957 \\
\hline
\end{tabular}

Continuación tabla 9.

Estadísticos de fiabilidad Estadísticos de la escala

\begin{tabular}{rr}
\hline $\begin{array}{c}\text { Alfa de } \\
\text { Cronbach }\end{array}$ & $\begin{array}{c}\text { N de } \\
\text { elementos }\end{array}$ \\
\hline, 957 & 61 \\
\hline
\end{tabular}

\begin{tabular}{rrrr}
\hline Media & Varianza & $\begin{array}{c}\text { Desviación } \\
\text { típica }\end{array}$ & $\begin{array}{c}\mathrm{N} \text { de } \\
\text { elementos }\end{array}$ \\
\hline 115,83 & 660,246 & 25,695 & 61 \\
\hline
\end{tabular}




\section{Tabla 10.}

Correlaciones de la escala

\begin{tabular}{|c|c|c|c|c|c|}
\hline Descriptivo & & $\begin{array}{l}\text { Puntaje-total } \\
\text { cognitiva }\end{array}$ & $\begin{array}{l}\text { P. total } \\
\text { afectiva }\end{array}$ & $\begin{array}{l}\text { P.total } \\
\text { comporta } \\
\text { mental }\end{array}$ & P.total \\
\hline \multirow[t]{3}{*}{ Ptcognitiva } & $\begin{array}{l}\text { Correlación de } \\
\text { Pearson }\end{array}$ & 1 &, $589(* *)$ &, $658(* *)$ &, $871(* *)$ \\
\hline & Sig. (bilateral) & & ,000 & 000, & ,000 \\
\hline & $\mathrm{N}$ & 120 & 120 & 120 & 120 \\
\hline \multirow[t]{3}{*}{ Ptafectiva } & $\begin{array}{l}\text { Correlación de } \\
\text { Pearson }\end{array}$ &, $589(* *)$ & 1 &, $691(* *)$ &, $803(* *)$ \\
\hline & Sig. (bilateral) &, 000 & & ,000 &, 000 \\
\hline & $\mathrm{N}$ & 120 & 120 & 120 & 120 \\
\hline \multirow[t]{3}{*}{ Ptacomportamental } & $\begin{array}{l}\text { Correlación de } \\
\text { Pearson }\end{array}$ &, $658(* *)$ &, $691(* *)$ & 1 &, $927(* *)$ \\
\hline & Sig. (bilateral) &, 000 & ,000 & & ,000 \\
\hline & $\mathrm{N}$ & 120 & 120 & 120 & 120 \\
\hline \multirow[t]{3}{*}{ Ptatotal } & $\begin{array}{l}\text { Correlación de } \\
\text { Pearson }\end{array}$ &, $871(* *)$ &, $803(* *)$ &, $927(* *)$ & 1 \\
\hline & Sig. (bilateral) & ,000 &, 000 & ,000 & \\
\hline & $\mathrm{N}$ & 120 & 120 & 120 & 120 \\
\hline
\end{tabular}

Nota: $* *$ La correlación es significativa al nivel 0,01 (bilateral). 
Escala SAMANTO para medir actitudes de los operadores judiciales hacia la víctima 112

Tabla 11.

Estimación confiabilidad de la prueba Alfa de Cronbach

\begin{tabular}{lcc}
\hline \multicolumn{1}{c}{ Componente } & Ítems & Según estimación Alfa de Cronbach \\
\hline Componente cognitivo & 23 &, 894 \\
Componente afectivo & 13 &, 858 \\
Componente comportamental & 25 &, 931 \\
\hline
\end{tabular}

En consecuencia, es importante resaltar que la escala SAMANTO para su aplicación final, contaba con 67 ítems y había arrojado un Alfa de Cronbach de 0.934 pero, al efectuarse el análisis de resultado de cada ítem, se determinó eliminar los ítems 18, 25, 30, 36, 40 y 62 por que se observó que no funcionaron adecuadamente. Así pues, la escala SAMANTO quedo con 61 ítems, arrojando un Alfa de Cronbach de 0.957

A continuación, presento los parámetros de interpretación de la prueba SAMANTO, que son media y desviación estándar, para que sean utilizados como valores de referencia. Además, se mostrara una tabla de percentiles para mayor información de los resultados obtenidos. De manera que, en futuras investigaciones se insta a realizar la estandarización de la prueba a nivel local o nacional. 


\section{Tabla 12.}

Estadísticos de las escalas y total del instrumento

\begin{tabular}{lrrcr}
\hline Descriptivos & $\begin{array}{r}\text { Puntaje total } \\
\text { C. Cognitivo }\end{array}$ & $\begin{array}{c}\text { Puntaje total } \\
\text { C. Afectivo }\end{array}$ & $\begin{array}{c}\text { Puntaje total } \\
\text { C. Comportamental }\end{array}$ & Puntaje total \\
\hline Media & 46,9500 & 36,8500 & 50,8667 & 134,6667 \\
Mediana & 46,5000 & 36,0000 & 51,000 & 132,5000 \\
Moda & 47,00 & 35,00 & 56,00 & 139,00 \\
Desviación & 9,48050 & 4,75032 & 11,87182 & 23,07581 \\
típica & & & & \\
Varianza & 89,880 & 22,566 & 140,940 & 532,493 \\
\hline
\end{tabular}

Dado que el instrumento se fundamenta en la teoría de actitudes de autores como Cattel (1998), Coll, Pozo, Sarabia y Valls (1994), la puntuación de la escala total refleja la adicción de los componentes cognitivo, afectivo y comportamental, también, constituye un indicador global del grado y la intensidad de la actitud revictimizante del evaluado. Para más detalle en la siguiente tabla se destacan las propiedades estadísticas descriptivas básicas de la escala total, para tomar como valores de referencia en su aplicación cuando así se considere pertinente.

\section{Tabla 13.}

Síntesis de los estadísticos descriptivos

\begin{tabular}{cccc}
\hline $\mathrm{N}$ & Media & Mediana & Desviación estándar \\
\hline 120 & 134 & 132 & 23,07 \\
\hline
\end{tabular}




\section{Tabla 14.}

Tabla de percentiles

\begin{tabular}{ccccc}
\hline Percentil & Pt. Cognitivo & Pt. Afectivo & Pt. Comportamental & Puntaje total \\
\hline 1 & 28,4200 & 28,2100 & 29,0000 & 87,2600 \\
2 & 30,4200 & 29,0000 & 29,0000 & 93,6800 \\
3 & 31,0000 & 29,0000 & 29,6300 & 96,6300 \\
4 & 31,8400 & 29,8400 & 30,8400 & 97,8400 \\
5 & 34,0000 & 30,0000 & 32,0000 & 98,1500 \\
10 & 35,1000 & 31,0000 & 35,0000 & 106,2000 \\
15 & 36,1500 & 32,0000 & 37,1500 & 110,1500 \\
20 & 38,2000 & 33,0000 & 39,0000 & 113,6000 \\
25 & 40,2500 & 33,0000 & 42,2500 & 119,0000 \\
30 & 42,0000 & 34,0000 & 44,0000 & 123,0000 \\
35 & 44,0000 & 35,0000 & 45,3500 & 125,0000 \\
40 & 45,0000 & 35,0000 & 47,0000 & 127,0000 \\
45 & 45,0000 & 35,4500 & 48,0000 & 128,9000 \\
50 & 46,5000 & 36,0000 & 51,5000 & 132,5000 \\
55 & 47,0000 & 37,0000 & 53,0000 & 136,5500 \\
60 & 48,0000 & 38,0000 & 55,6000 & 139,000 \\
65 & 48,0000 & 38,6500 & 56,0000 & 140,0000 \\
70 & 50,4000 & 39,0000 & 57,0000 & 144,7000 \\
75 & 52,7500 & 39,7500 & 58,7500 & 148,0000 \\
80 & 54,8000 & 40,8000 & 59,8000 & 151,8000 \\
85 & 56,0000 & 42,0000 & 62,8500 & 158,0000 \\
90 & 59,0000 & 43,0000 & 67,0000 & 165,8000 \\
95 & 63,9500 & 46,0000 & 73,9500 & 181,0000 \\
96 & 68,1600 & 47,3200 & 75,0000 & 183,1600 \\
97 & 69,7400 & 49,0000 & 75,3700 & 186,2200 \\
98 & 71,5800 & 49,0000 & 76,0000 & 194,0600 \\
99 & 79,1100 & 49,7900 & 78,3700 & 199,3700 \\
\hline & & & &
\end{tabular}

Nota: La interpretación de la prueba se propone por percentiles, tomando como punto de corte el cuartil superior $75 \%$ y el inferior el $25 \%$. La tabla incluye los percentiles de referencia tanto de la puntuación total de la escala que indicaría el grado global de la actitud revictimizante del sujeto evaluado, como también, los valores de referencia por los componentes de la actitud de manera independiente (cognitivo, afectivo y comportamental). 


\section{Discusión}

La revictimización es un tema que ha empezado a tener relevancia en el ámbito de la psicología jurídica, puesto que, no solo genera aumento del daño psíquico, sino que además, propicia detrimento en la salud de la víctima, según lo afirman los siguientes autores: Albertin (2006), Beristain (2000, 2002, 2009), Cloitre y Rosenberg (2006), Gutiérrez de Piñeres, Coronel y Pérez (2009), Marchiori (1998), Marchiori, Biodo y Fortete (2004), Marchiori, Biodo, Fortete y Shulthess (2007), Marchiori (2010, 2011), Marx, Heidt y Gold (2005), Messman-Moore y Long (2003) citados en Terri, Moore, Walshb y DiLillo (2010), Soria (1991), Suárez y Espinosa (2011), y Vásquez (2003).

Los autores concuerdan en que la afectación e implicación que deja la revictimización, Albertin (2006), Beristain (1999, 2000), Cloitre y Rosenberg (2006), Gutiérrez de Piñerez, Coronel y Pérez (2009), Casey y Nurius (2005) citados en Terri et al., (2010), Landrove (1990), Marchiori (1998), Marchiori, Biodo y Fortete (2004), Marchiori, Biodo, Fortete y Shulthess (2007), Marchiori (2010, 2011), Marx, Heidt y Gold (2005), Messman-Moore y Long (2003) citados en Terri, Moore, Walshb y DiLillo (2010), Soria (1991), Suárez y Espinosa (2011), y Vásquez (2003) es una huella que en ocasiones es más dolorosa que la misma consecuencia derivada del delito padecido. Puesto que, estas secuelas producen deterioro psíquico y físico en la víctima, así como el aislamiento social, empobrecimiento de las redes de apoyo, hasta llegar al detrimento general de la víctima. Según lo afirman los autores revisados para el presente documento, quienes coinciden adicionalmente en priorizar la atención al perjudicado, antes que al delito del que fuere lesionado. 
Escala SAMANTO para medir actitudes de los operadores judiciales hacia la víctima 116

Razón por la cual, autores e instituciones como: Castañer y Griesbach (2009), Gutiérrez de Piñeres, Coronel y Pérez (2009), UNICEF (2010) entre otros, insistían en la adecuada atención a la víctima mediante el apoyo de protocolos y manuales. Por ello, una manera de optimizar la atención sería el diagnóstico de estas actitudes negativas, ante la inexistencia de un instrumento para identificar actitudes revictimizantes, se observa el aporte, del instrumento SAMANTO que contribuye a la detección, y en consecuencia orienta la intervención. Estas actitudes se identificarían en uno, o dos, o en todos los componentes que integran el lenguaje verbal o no verbal, como lo pueden ser las miradas, los gestos, el tono de voz, los ademanes, la postura corporal o el aspecto en general, todo esto transmite agrado o desagrado por el asunto que esté tratando el operador judicial en la atención a la víctima.

De tal manera que, el instrumento SAMANTO permite evidenciar si en la población de operadores que se aplique la escala existe o no la tendencia de actitudes revictimizantes que desencadenan el maltrato hacia la víctima. Por lo que, el objetivo del presente estudio fue el diseño y construcción de la escala SAMANTO para medir actitudes revictimizantes por parte de los operadores judiciales hacia la víctima. Así que, por medio del instrumento SAMANTO, se indagó a la luz de la pregunta planteada en la investigación ¿Cómo construir la escala SAMANTO que mide actitudes revictimizantes de los operadores judiciales?

Con el fin de responder a la pregunta de investigación se utilizó el índice de validez de contenido, el índice de validez aparente y el coeficiente Alfa de Crombach. La validez de contenido evalúa si el instrumento considera todos los elementos necesarios para representar adecuadamente el constructo que se desea medir, es decir, si se tienen en cuenta todos los componentes importantes del constructo para lograr la 
Escala SAMANTO para medir actitudes de los operadores judiciales hacia la víctima 117

representatividad teórica (Kerlinger, 2002). En este caso el índice de validez de contenido oscilo entre 0.67 y 1 indicando, que esta es adecuada, es decir, la prueba es válida según el criterio de los jueces expertos. "La validez facial o aparente es la idoneidad del contenido de un test o ítem(s) para un fin determinado según la percepción de los examinados y usuarios" (Secolsky, 1987), en la prueba construida la validez facial oscilo entre 0.50 y 1 indicando, que es adecuada, pero algunos ítems ameritaron revisión. La confiabilidad se entiende como el grado de exactitud y consistencia con el cual la prueba mide el constructo (Kerlinguer, 2002), en este caso la prueba arrojó un alfa global de 0.96 mostrando un excelente nivel de confiabilidad por exactitud.

Según, autores como Muñiz (2000) sostienen que, las teorías estadísticas permiten la estimación de las propiedades psicométricas de un test, sin las cuales, no se podría estimar la fiabilidad de un instrumento. Asimismo, Cortina (1993) manifiesta que en el caso de ítems con una escala tipo Likert, el índice de consistencia interna más usado es el alfa de Cronbach. Mientras Carretero-Dios y Pérez (2005) afirman que, las estimaciones sobre la fiabilidad a través de un índice de consistencia interna son calculadas para las puntuaciones de cada uno de los componentes supuestos del constructo evaluado. Además, añaden que el juicio sobre la fiabilidad obtenida a través del alfa de Cronbach debe estar conectado con el formato de los ítems o con algunas propiedades métricas de éstos que se encuentran relacionados con el resultado final del alfa de Cronbach.

Ahora bien, autores como Aiken (2003) argumentan en cuanto a la confiabilidad de un instrumento de evaluación psicológica, puesto que, se requiere que mida el constructo de una manera consistente, ya que, un instrumento confiable carece de errores de medición, por tanto, las calificaciones obtenidas en el instrumento son relativamente 
estables, lo que indicaría que se puede confiar en su uso. Por tanto, este es un elemento básico al momento de elegir una herramienta de medición y que ahora se dispone de un instrumento que es fiable, superando el vacío de conocimiento en torno a cómo medir la revictimización.

Por consiguiente, la estimación de la fiabilidad de la escala SAMANTO fue de 0,957 en el agrupamiento total y el análisis de los ítems, para lo cual se tuvo sumo cuidado en que las puntuaciones efectivamente midieran el constructo inicial y que estuvieran conectadas con el formato de los reactivos, el cual, se enfatizó en las actitudes de los operadores judiciales hacia la víctima.

El instrumento SAMANTO posee alta confiabilidad en la consistencia de los índices del Alfa de Cronbach, que fue el estadístico empleado para la medición y obtención de los resultados. En cuanto, a los valores preliminares de interpretación del instrumento, se realizaron pruebas de normalidad sobre las sub-escalas y escala total, encontrándose que todas son normales, así que, la significancia del Z de KolmogorovSmirnov para el componente cognitivo fue de 0,09 ; para el componente afectivo 0,17 ; para el componente comportamental 0,65 y para el puntaje total 0,65 lo cual indica, que los puntajes de las tres sub-escalas como la total son distribuciones normales. Este resultado se explica ya que la gran mayoría de atributos y actitudes humanas medidas en una escala Likert tienden a asumir una distribución normal (Aiken, 2003; Anastasi y Urbina, 1998).

De ahí que, los resultados agrupados con el juicio sobre la fiabilidad obtenida a través del alfa de Cronbach 0,957 permitió comprobar la importancia de haber diseñado y construido la escala SAMANTO, dado que, autoridades en el tema como (Beristain, 1999, 2000; Landrove, 1990; Marchiori, 1998; Marchiori, Biodo y Fortete, 2004 y 
Vásquez, 2003) afirman que la víctima que ya sufre las consecuencias directas del delito, ahora, se ve padeciendo el maltrato del sistema jurídico representado en sus operadores judiciales cuando acude en búsqueda de "justicia". Por ello, por medio del instrumento SAMANTO se pueden detectar actitudes revictimizantes en cualquiera de los componentes que se este presentando.

Entorno a los resultados de la aplicación del instrumento SAMANTO a la muestra de 120 profesionales que laboran para el sistema judicial, se encontraron en niveles promedio de revictimización, y aunque esto es un hallazgo positivo para el grupo de estudio, no obstante confirma la presencia de revictimización, confirmando la literatura de expertos como Albertin (2006), Beristain (1996, 1999, 2000), BoneyMcCoy y Finkellhor (1995), Briere y Elliott (2003), Finkelhor, Ormrod y Turner (2007) citados en Cuevas, Finkelhor, Clifford, Ormrod y Turner (2010), Cloitre y Rosenberg (2006), Castañer y Griesbach (2009), Casey y Nurius (2005) citados en Terri, Moore, Walshb y DiLillo (2010), Gallego (2008), Landrove (1990), Marchiori (1998), Marchiori, Biodo y Fortete (2004), Marchiori, Biodo, Fortete y Shulthess (2007), Marchiori (2010, 2011), Marx, Heidt y Gold (2005), Messman-Moore y Long (2003) citados en Terri, Moore, Walshb y DiLillo (2010), Rivera (1997), Rozanski (2003) citado en Gutiérrez de Piñeres, Coronel y Pérez (2009), Soria (1991), Suárez y Espinosa (2011), y Vásquez (2003). Este resultado realmente era esperado, empero es negativo desde la perspectiva de las víctimas, ya que confirman pensamientos, sentimientos y conductas proclives hacia descalificarlas, juzgarlas, señalarlas o maltratarlas, aunque no en altos índices, pero evidencia la presencia de esta forma de victimización secundaria y refuerza la sensibilidad del instrumento para medir el constructo que se propuso. 
Es probable que adicionalmente estos resultados puedan haberse minimizado porque los funcionarios respondieron con alta deseabilidad social, variable que no se evaluó con la escala SAMANTO, puesto que esta, no incluye escalas de validez para medir deseabilidad social. Por lo cual, valdría la pena crear escalas de validez al instrumento para saber si se está presentando deseabilidad social.

En otras palabras, la deseabilidad social es el efecto de apariencia o tendencia a “falsear para causar una buena impresión”. Además, la deseabilidad social es una descripción falsa, ya que, hay respuestas a los reactivos que puede reconocerse como socialmente más deseables o aceptables, quienes responden un cuadernillo, test o prueba, pueden sentirse motivados a "falsear para quedar bien" eligiendo respuestas que generen una impresión favorable. Diversos estudios han comprobado la facilidad con que pueden crearse deliberadamente las impresiones deseadas, las investigaciones actuales indican que en particular en los inventarios auto-descriptivos, la validez facial de un reactivo aumenta la susceptibilidad al falseamiento. De ahí que, a mayor facilidad de interpretación del rasgo que pretende evaluarse, con frecuencia habrá respuestas deseables (Anastasi y Urbina, 1998).

Entonces, la tendencia a elegir las respuestas socialmente deseables en los inventarios auto-descriptivos no indica necesariamente un engaño deliberado por parte de quienes responden, por el contrario, puede indicar falta de percepción, auto-engaño o poca disposición a enfrentar las propias limitaciones. Otros autores, sostienen que la respuesta de la deseabilidad social, está relacionada con la necesidad de la persona de protegerse, de evitar las críticas, de ser desaprobada, de conformidad y aprobación social, también, se ha demostrado que existe una correlación alta entre la frecuencia de elección y la deseabilidad social juzgada, es decir, que la auto-descripción promedio de 
una población concuerda con la descripción que en promedio hace de una personalidad deseable. La deseabilidad social examinada con reactivos particulares no es constante para todos los propósitos, sino que puede diferir para diversas ocupaciones, entonces, una prueba de elección forzada en la que se igualó la deseabilidad social general de los reactivos, puede incluir falseamiento cuando se aplica a quienes solicitan un empleo, a quienes pretenden ingresar a escuelas profesionales, y a grupos en las que se evalúa una orientación especifica (Anastasi y Urbina, 1998).

Por otro parte, los teóricos fundamentaron que existen varios manuales y protocolos para la atención a las víctimas, pero aun así, se necesitan de más herramientas que aporten a la medición de la revictimización y posteriormente la intervención con las temáticas que indiquen los ítems, con ello, se deben modificar las actitudes que causan victimización. Ahora bien, en el instrumento SAMANTO se identifican factores revictimizantes de la actitud en uno o en todos sus componentes (componente cognitivo, componente afectivo, componente comportamental), ya que, permite medir, evidenciar y hasta prevenir la revictimización en el componente en que se esté presentando. Se espera aporta a la detección temprana y reducción de las actitudes revictimizantes al identificar en cual de los componentes se genera el maltrato por parte de los operadores judiciales hacia la víctima. Así, intervenir desde la asistencia, acompañamiento y capacitación oportuna al profesional de la justicia. Toda vez, que se propenda por una atención humana por parte del aparato jurídico, quien es el garante de la atención, asistencia e intervención a las víctimas que sufren el impacto de algún delito propiciado por los infractores de la Ley.

De otra manera, con una mirada futurista, sería interesante construir un instrumento que permita medir la opinión de las víctimas con respecto a la atención que 
reciben por parte de los profesionales judiciales. En otras palabras, obtener desde las mismas víctimas como se sienten respecto de la atención recibida en cuanto a la escucha, el respeto, la consideración, el acompañamiento, la prontitud, la amabilidad, es decir el buen trato, entre otros. 


\section{Conclusiones}

Ante el vacío de conocimiento por la ausencia de un instrumento que evaluara la revictimización se diseño una herramienta denominada la escala SAMANTO, la cual se centró en la medición de la actitud de los operadores judiciales por medio de autoreporte.

La escala SAMANTO, se basó en el modelo conceptual de actitud de autores como Allport (967), Bandura (1973), Cattell (1998), Coll, Pozo, Sarabia y Valls (1994), Gallego (2008). Y el concepto de revictimización de autores como Albertin (2006), Beristain (2000), Echeburúa, Corral y Amor, (2004) citado en Tapias (2011), Gallego (2008), Méndez y Peña (2006), Rozanski (2003) citado en Gutiérrez de Piñeres, Coronel y Pérez (2009), Rivera (1997), Suárez y Espinosa (2011) así, se fundamentó la creación de un instrumento que permitiera medir dicho constructo.

La escala se logró aplicar a tres grupos, pilotaje, muestra facial y la muestra amplia, todas ellas con la pretensión de cumplir el procedimiento de diseño de instrumentos sugerido por Carretero Dios y Pérez. Y adicionalmente, se estudió la validez de contenido, la cual, se realizó por tres jueces expertos. Las medidas de validez obtenidas en la aplicación del instrumento y las fuentes de evidencias recolectadas, permitieron afirmar que la escala SAMANTO mide lo que pretendía medir, actitudes revictimizantes a partir de los tres componentes que la conforman.

Dentro de los hallazgos están que la escala posee una alta confiabilidad, con un Alfa de Cronbach de 0,957 lo que significa que la fiabilidad es elevada. No obstante, se precisa que, quienes vayan a emplear la escala sean profesionales que fundamenten sus saberes en el tema de la psicometría para optimizar el buen uso del instrumento. 
Además, se enunciaron los estadísticos descriptivos resultantes de la aplicación del instrumento a los 120 profesionales que colaboraron como siguen: Media 134; Mediana 132; Desviación estándar 23,07 resultado que corresponde en la tabla de percentiles a una tendencia media a tener actitudes revictimizantes en los participantes de la muestra, lo cual, confirma la literatura y presenta un desafío a los profesionales que apoyan la administración de justicia para erradicarla. Adicionalmente, estos puntajes puedes estar minimizados por el efecto de sesgo reactivo o deseabilidad social, situación que puede implicar un reto para la evolución del instrumento, ya que implica la inclusión de la valoración del examinado ante la escala. No obstante, la descripción del comportamiento de este grupo interdisciplinario de profesionales no era uno de los objetivos del estudio, sino un paso necesario para observar el comportamiento psicométrico de los ítems y del instrumento en general.

Finalmente, se debe tener presente los parámetros de ética profesional tocante a la autorización y uso del instrumento, puesto que, se propende por el buen trato a la víctima. Toda vez, que se fortalezca el ser interior evidenciado en actitudes humanizadas, que a su vez, permiten detectar y corregir los desaciertos que se puedan presentar por parte de los operadores judiciales desde su quehacer profesional en la atención a la víctima. 


\section{Recomendaciones}

Para próximas investigaciones se sugiere crear para el instrumento SAMANTO escalas de validez enfocadas a evaluar la deseabilidad social del examinado, con el propósito de identificar si se está presentando y así ponderar los resultados finales.

Es recomendable para futuros estudios aplicar el instrumento a una muestra mayor y de carácter nacional, teniendo en cuenta que para cada ítem se requieren de 5 participantes, para evaluar óptimamente la confiabilidad. De manera que, se propenda por un mejor análisis psicométrico de los reactivos. Y adicionalmente sería interesante la aplicación en el ámbito internacional.

Se propone realizar estudios pre y post con la escala SAMANTO y en el periodo intermedio incluir un programa de intervención para disminuir actitudes revictimizantes, lo cual sería favorable a las víctimas y útil para el ámbito jurídico, porque favorecería la generación de talleres de intervención, revisión y creación de estrategias, con miras a combatir el fenómeno revictimizante.

Se recomienda la implementación de la escala SAMANTO dentro de la evaluación que las diversas instituciones estatales realizan a su personal, toda vez, que dicha escala propende por la medición de las actitudes que causan maltrato en las víctimas.

Resultaría óptimo generar otras formas de medición de revictimización, pero dirigidas a las víctimas, ya que, esta es otra perspectiva fundamental del problema de la victimización secundaria.

Adicionalmente, se hace necesario estudiar la relación entre los suplicios generados por la victimización primaria y la victimización secundaria, y el resultado de estas dos, la revictimización. 
Escala SAMANTO para medir actitudes de los operadores judiciales hacia la víctima 126

Se sugiere continuar con investigaciones que permitan el avance sobre el fenómeno de actitudes revictimizantes, por lo tanto, es importante que a partir de este estudio se evolucione en temas de investigación que vayan más allá de los manuales y protocolos existentes, se necesitan más instrumentos de medición para evaluar y tal vez, instaurar programas de intervención que disminuyan la revictimización o el maltrato a las víctimas.

Por último, es necesario continuar con el avance de investigaciones comparativas, o integrar variables situacionales al análisis, para determinar el papel que tiene el operador judicial en la atención a las víctimas. 


\section{Referencias}

Aiken, Lewis. (2003). Tests psicológicos y evaluación. México: Pearson Educación.

Albertin, P. (2006). Psicología de la victimización criminal. En Soria, M y Saiz, D (Eds.). Psicología Criminal (pp. 245-276). Madrid, España: Pearson Educación.

Allport, G. (1967). Teorías de la personalidad. En D. Schultz y S. Schultz (Eds.). Aproximación de los rasgos (pp. 241-250). México: Thomson

American Psychological Association. (2002). Ethical principles of psychologists and code of conduct. USA.

Anastasi, A., y Urbina, S. (1998). Test psicológicos (7ª ed.). México. Prentice Hall

Anep-Consejo de Educación Primaria-CEP. (2007). Situaciones de maltrato y abuso sexual en niños, niñas y adolescentes: Mapa de ruta. UNICEF. Uruguay: Ed. PNUD. Recuperado el 3 de julio de 2012, de: http://www.unicef.org/uruguay/spanish/uy_media_Mapa_de_ruta.pdf

Bandura, A. (1973). Teorías de la personalidad. En D. Schultz y S. Schultz (Eds.). Aproximación del aprendizaje social. (pp. 397-421). México: Thomson.

Barnesa, J., Noll, J., Putnama, F. \& Trickett, P. (2009). Sexual and physical revictimization among victims of severe childhood sexual abuse [version electrónica], Child Abuse \& Neglect, 33, 412-420.

Beristaín, A. (1999). Criminología y Victimología. En A. Beristain (Eds.). El nuevo código penal de 1995 desde la victimología (pp. 219-264). Bogotá, Colombia: Leyer.

Beristaín, A. (2000). Victimología. Nueve palabras claves. Valencia, España: Tirant lo blllanch. 
Escala SAMANTO para medir actitudes de los operadores judiciales hacia la víctima 128

Castañer, A. y Griesbach, M. (2008). Colección:"El Niño Víctima del Delito frente al proceso penal" Tomo III. La denuncia como elemento terapéutico para el niño víctima del delito. Oficina de defensoría de los derechos de la infancia. México. Recuperado el 2 de octubre de 2012, de: http://www.inm.gob.mx/static/Autorizacion_Protocolos/SSP/Tomo_III_La_denu ncia_\%20como_\%20elemento_terapeutico_para_el_ni.pdf

Castañer, A. y Griesbach, M. (2009). Colección:"El Niño Víctima del Delito frente al proceso penal” Tomo IV. Acciones para evitar la revictimización del niño víctima del delito. Oficina de defensoría de los derechos de la infancia. México. Recuperado el 24 de agosto de 2012, de: http://www.gobernacion.gob.mx/work/models/SEGOB/Resource/689/1/images/T OMOI_1E.PDF

Castro, G. y Garay, M. (s.f). Revictimización en casos de Abuso sexual a Niños y Adolescentes. Recuperado el 11 de mayo de 2012, de http://www.google.es/\#h1=es\&output=search\&sclient=psyab\&q=Revictimizaci $\% \mathrm{C} 3 \% \mathrm{~B} 3 \mathrm{n}+\mathrm{en}+\mathrm{casos}+\mathrm{de}+\mathrm{Abuso}+\mathrm{sexual}++\mathrm{a}++\mathrm{Ni} \% \mathrm{C} 3 \% \mathrm{~B} 1 \mathrm{os}+\mathrm{y}+$ Adolescentes \&oq $=$ Revictimizaci $\%$ C3\%B3+en+caso

Cattell, R. (1998). Teorías de la personalidad. En D. Schultz y S. Schultz (Eds.). Aproximación de Cattell a los rasgos de personalidad (pp. 265-271). México: Thompson.

Clark, L. A. \& Watson, D. (2003). Constructing validity: Basic issues in objective scale development. En A.E. Kazdin (Ed.), Methodological Issues \& Strategies in

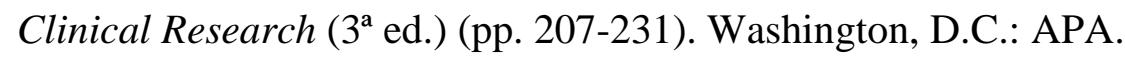


Escala SAMANTO para medir actitudes de los operadores judiciales hacia la víctima 129

Carretero-Dios, H. y Pérez, C. (2005). Normas para el desarrollo y revisión de estudios instrumentales. International Journal of Clinical and Health Psychology, 5, 521551.

Coll, C., Pozo, J., Sarabia, B. y Valls, E. (1994). Los contenidos en la reforma: Enseñanza y aprendizaje de conceptos, procedimientos y actitudes. Madrid, España: Santillana.

Congreso de Colombia, (2006). Ley 1098. Código de la Infancia y la Adolescencia. Momo ediciones.

Congreso de Colombia, (2013). Ley 1620. "Por lo cual se crea el sistema nacional de convivencial escolar y formación para el ejercicio de los derechos humanos, la educación para la sexualidad y la prevención y mitigación de la violencia escolar". Momo ediciones.

Cortina, J.M. (1993). What is coefficient alpha? An examination of theory and applications. Journal of Applied Psychology, 78, 98-104.

Cuevas, C., Finkelhor, D., Clifford, C., Ormrod, R. \& Turner, H. (2010). Psychological distress as a risk factor for re-victimization in children [versión electrónica], Child Abuse \& Neglect, 34, 235-243.

Dallos, A., Pinzón, M., Barrera, A. y González, C. (2009). Impacto de la violencia sexual en la salud mental de las víctimas en Bucaramanga, Colombia. Ed. Red Revista Colombiana de Psiquiatría, 37, 56-64.

Engler, B. (1997). Introducción a las teorías de la personalidad (4a . ed.). México: McGraw-Hill.

Elosua, P. (2003). Sobre la validez de los tests. Psicothema, 15, 315-321. 
Gallego, J. P., (2008). Abuso sexual en la infancia la revictimización. En J. Volnovich (Eds) Desprotección integral y revictimización de niños (pp.145-165). Buenos Aires, Argentina: Lumen.

Gambara, H. (2002). Métodos de Investigación en psicología y Educación. Cuaderno de prácticas ( $3^{\mathrm{a}}$. ed.). McGraw-Hill: Madrid.

Garrido, E. y Masip, J. (2004). La evaluación del abuso sexual infantil., Ponencia presentada en el I Congreso de Psicología Jurídica y Forense en Red Mayo 2004. pp. 1-170. Recuperado el 12 de mayo de 2012 http://www.copmadrid.org/congresoredforense/ Disponible en: http://psicojurix.com/pdf/asigarrido-masip.pdf

Garrido, E. y Herrero, C. (2006). El testimonio infantil. En E. Garrido y C. Herrero. (Eds.), Psicología jurídica (pp.437-467). Madrid, España. PEARSON EDUCACIÓN, S.A.

George, R. \& Brown, D. (2004). Leadership processes and follower selfidentity. Estados Unidos: Lawrence Erlbaum Associates.

Greenberg, J. \& Cropanzano, R. (2001). Advances in organizational justice. Estados Unidos: Stanford University Press.

Gregory, R. J. (1943). Evaluación psicológica: historia, principios y aplicaciones. (Trad. G. Padilla. S., 2001) En R. J. Gregory (Eds), Concepto de confiabilidad (p. 93105). México: El Manual Moderno. (Reimpreso de psychological testing history, principles, and applications, pp. 737-790/--3rd ed, por Allyn y Bacon, Ed., 2000, Illinois, USA: Pearson Education Company)

Gold, S., Sinclair, B. \& Balge, K. (1999). Risk of sexual revictimization: a theoretical model [versión electrónica], Child Abuse \& Neglect, 4, 457-470. 
Escala SAMANTO para medir actitudes de los operadores judiciales hacia la víctima 131

Gutiérrez de Piñeres, C., Coronel y Pérez. (2009). Revisión teórica del concepto de victimización secundaria. Liberabit: Revista de psicología, 15, 1, 49-58.

Hernández, R., Fernández, C. y Baptista, M. (2010). Metodología de la investigación. México: McGrawHill.

Hernández, G., y Tapias, A. (mayo, 2010). Maltrato infantil: normatividad y psicología forense. Diversitas [online] 6(2). pp. 389-413. Recuperado de http://www.scielo.org.co/scielo.php?pid=S179499982010000200013\&script=sci $\_$arttext

Instituto Colombiano de Bienestar Familiar. (Primera edición, septiembre de 2007). La Guía de atención para niños, niñas y adolescentes víctimas de violencia sexual. pp. 1-68. Bogotá, Colombia. Recuperado el 14 de mayo de 2012, https://www.icbf.gov.co/icbf/directorio/portel/libreria/pdf/5Guiadeatencionparani nos,ninasyadolescentesvictimasdeviolenciasexual.pdf

Kerlinger, F. (2002). Investigación del comportamiento: Métodos de investigación en ciencias sociales $\left(4^{\mathrm{a}}\right.$.ed.). México. MacGrawHill

Landrove, G. (1990). Victimología. En G. Landrove (Eds.). Clasificación de las víctimas y victimización secundaria (pp. 37-48). Valencia, España: Tirant lo Blanch.

Latham, G. (2006). Work motivation: history, theory, research, and practice. Estados Unidos: SAGE.

León, O. y Montero, I. (2003). Métodos de Investigación en psicología y Educación (3ª ed.). Madrid. McGraw-Hill.

Marchiori, H. (1998). Criminología. La víctima del delito. México. Porrúa. 
Marchiori, H., Biodo, M. y Fortete, C. (2004). Victimología la víctima desde una perspectiva criminológica asistencia victimológica. Córdoba, Argentina: Universitaria integral.

Marchiori, H., Biodo, J., Fortete, C. y Shulthess, (2007). Victimología 3. Principios de justicia y asistencia para las víctimas (1ª .ed.). Córdoba, Argentina: Editorial Brujas.

Marchiori, H. (2010). Victimología 9: Violencia en niños y adolescentes. Buenos Aires, Argentina: Editorial Brujas.

Marchiori, H. (2011). Victimología 10: ley y víctima: panorama internacional. Buenos Aires, Argentina: Editorial Brujas.

Meltzoff, J. (2000). Crítica a la investigación. Psicología y campos afines. Madrid. Alianza Editorial.

Melup, I. Viano, J. y Emilio, C. (2009). Victimología 3: principios de justicia y asistencia para las víctimas. Buenos Aires, Argentina: Editorial Brujas.

Méndez, L. y Peña, J. (2006). Manual práctico para el diseño de la escala Likert. México: Trillas.

Ministerio de salud. Republica de Colombia. (1993, 4 de octubre). De los aspectos éticos de la investigación en seres humanos 1993.Resolución $n^{\circ}$ 008430, cap. 1, artículos 5, 14,15. Recuperado el 25 de julio de 2012, de http//comitedeetica.clinicalili.org/docs/RESL8430.pdf

Muñiz, J. (2000). Teoría Clásica de los Tests. Madrid, España: Pirámide.

Muñiz, J., Hidalgo, A.M., García-Cueto, E., Martínez, R. y Moreno, R. (2005) Análisis de ítems. Madrid: La Muralla. 
Escala SAMANTO para medir actitudes de los operadores judiciales hacia la víctima 133

Neuman, E. (2001).Victimología, El rol de la víctima en los delitos convencionales y no convencionales. ( $3^{\mathrm{a}}$. ed.) Argentina: Universidad S.R.L.

Nunnally, J.C. y Bernstein, I.J. (1995). Teoría psicométrica. Madrid: McGraw-Hill.

Omar, A. (2006). Victimization, justice individualism- colectivism victimización, justicia individual y colectiva. México: Xalapa.

Organización de las Naciones Unidas, ONU. (1985). Resolución 40/34, definición de víctima. Recuperado el 8 de diciembre de 2012, de http://www.osce.org

Osburn, H.G. (2000). Coefficient alpha and related internal consistency reliability coefficients. Psychological Methods, 5, 343-355.

Restrepo, J. (1995). Criminología un enfoque humanístico, 108 - 157, Bogotá, Colombia: Temis S.A.

Rochel, S (2005). Revictimización y Justicia. Abordaje de casos de abuso sexual infantil en el ámbito judicial argentino. Tesis de Postgrado. Universidad Buenos Aires, Argentina.

Save the Children Alliance, ONG. (2001). El proceso judicial: victimización secundaria del menor. En Save the Children Alliance (Eds.). Abuso sexual infantil: manual de formación para profesionales (pp.66-71). Madrid, España. Disponible en: http://es.scribd.com/doc/70848007/Abuso-Sexual-Infantil-Save-the-Children

Save the Children Alliance, ONG. (2008). Protocolo policial de atención inmediata a víctimas de trata de personas. San Salvador. Save the Children. Recuperado de http://violenciaytrata.savethechildren.es/docs/Docs/31/4.pdf

Secolsky, Ch. (1987). On the Direct Measurement of Face Validity: A comment on Nevo. Journal of Educational Measurement. Spring, 24(1), 82-83. 
Escala SAMANTO para medir actitudes de los operadores judiciales hacia la víctima 134

Skinner, B. (1990). Teorías de la personalidad. En D. Schultz y S. Schultz (Eds.). Aproximación conductual. (pp. 369-393). México: Thompson.

Soria, M., (1991). Prevención del proceso de victimización psicológico en víctimas del delito. Recuperado el 1 de mayo de 2012, del sitio Web Papeles del psicólogo: http://www.papelesdelpsicologo.es/vernumero.asp?id=487

Soria, M. y Sánchez, J. (2009). El agresor sexual y la víctima. Madrid, España: Marcombo.

Suárez, R. y Espinosa, A. (2011). Victimización secundaria en menores. Fundación amparo y justicia. Recuperado el 7 de junio de 2012, de http://www.amparoyjusticia.cl/actividades/curso-psicodiagnostico-de-agresionessexuales-en-ninos/\#.USXxhB1g8qM

Spatz, C., Czaja, S. y Dutton, M. (2008). Childhood victimization and lifetime revictimization [version electrónica], Child Abuse \& Neglect, 32, 785-796.

Tamayo, M.(2006). El proceso de la investigación científica. En: M. Tamayo (Eds.). Evaluación del proyecto de investigación (pp.191-217; 324). México: Limusa.

Tapia, Ariel. "Victimar y victimizar: dos procesos distintos pero afines". En: Actas del congreso latinoamericano de psicología jurídica, Bogotá-Colombia (MuñozTapia abril de 2007), y II congreso de la sociedad Española de victimología, San Sebastián-país vasco, (junio del 2007), pp. 1-9. Recuperado el 3 de octubre de 2012 de: http://realidadjuridica.uabc.mx/realidad/files/contenidovictimizacion.pdf

Tapias, Ángela. (2011). Psicología jurídica iberoamericana. En A. Tapias (Eds.). víctimas desde la perspectiva desde la psicología jurídica (pp. 23-27). Bogotá, Colombia: Manual moderno. 
Terri, L., Moore, M., Walshb, K y DiLillo D. (2010). Emotion dysregulation and risky sexual behavior in revictimization [versión electrónica], Child Abuse \& Neglect, 34, 967-976.

Thompson, B. (1994). Guidelines for authors, Educational and Psychological Measurement, 54, 837-847.

United Nations International Children's Emergency Fund (2010, 25 de mayo). Informe de actividades 2010 a UNICEF. Recuperado el 20 de agosto de 2012, de http://www.unicef.org/lac/media_17928.htm

Vardi, Y. \& Weitz, E. (2004). Misbehavior in organizations: theory, research, and management. Estados Unidos: Lawrence Erlbaum.

Vásquez, B. (2003). Estudio de las secuelas postraumáticas. En: B. Vásquez (Eds.). Estudio de las secuelas postraumáticas en niños objeto de agresiones sexuales denunciadas (pp. 5-37). Madrid, España: Ed. Colegio Oficial de Psicólogos.

Volnovich, J. (2008). Abuso sexual en la infancia. La revictimización (3ª . ed.). Buenos Aires, Argentina: Lumen. 


\section{Apéndice}

Apéndice A: Formato de consentimiento informado

\section{Estimado participante.}

Soy estudiante de postgrado, del programa de Maestría en Psicología Jurídica y Forense de la Universidad Santo Tomás (USTA) de la ciudad de Bogotá. Como parte de los requisitos que exige la maestría se llevará a cabo una investigación que trata de las actitudes revictimizantes ocasionadas por el sistema jurídico-penal cuando se interpone la denuncia por determinado delito. El objetivo del estudio consiste en investigar la importancia de construir un instrumento que mida las actitudes revictimizantes. Esta investigación es obligatoria para acceder a mi grado. Usted ha sido seleccionado (a) para participar en esta investigación la cual consiste en contestar un cuestionario o preguntas que le tomará aproximadamente 10 minutos. Usted puede contestar solamente las preguntas que así desee. La información obtenida a través de este estudio será mantenida bajo estricta confidencialidad y su nombre no será utilizado. Usted tiene el derecho de retirarse de la investigación en el momento que lo desee. El estudio no conlleva ningún riesgo ni recibe ningún beneficio. No recibirá compensación por participar.

Las dudas sobre cualquier aspecto de este estudio pueden dirigirse al laboratorio de Postgrados de la Maestría en Psicología Jurídica y Forense Tel: 5878797 Ext. 1806 - 1807

Comprendo lo leído anteriormente y doy mi consentimiento para participar en la investigación.

(Evaluador)

(Participante)

Fecha: 
Apéndice B: Cuadernillo instrumento SAMANTO

\section{INSTRUCCIONES}

A continuación encontrará frases que hacen referencia a su manera de pensar, de sentir y de actuar. Elija marcando con una (X) su respuesta.

Seleccione de forma inmediata después de haber leído, NO emplee demasiado tiempo pensando cual casilla va a seleccionar. Trabaje rápidamente y recuerde responder todos los enunciados. No hay enunciados correctos o incorrectos; esta NO es una prueba de inteligencia, sino una apreciación de su modo de actuar.

\begin{tabular}{lll}
\hline EDAD: & SEXO: & F__ M \\
INSTITUCIÓN & & \\
ICBF: & FGN: & PONAL: \\
CAIVAS: & COMISARIA: & INMLCF \\
CARGO: & & \\
PROFESIÓN: & & \\
\hline
\end{tabular}




\section{Para responder tenga en cuenta la siguiente convención:}

\begin{tabular}{|c|c|c|c|}
\hline TA & A & D & TD \\
\hline $\begin{array}{c}\text { Totalmente de } \\
\text { acuerdo }\end{array}$ & Acuerdo & Desacuerdo & $\begin{array}{c}\text { Totalmente en } \\
\text { desacuerdo }\end{array}$ \\
\hline
\end{tabular}

\begin{tabular}{|c|c|c|c|c|c|}
\hline \multicolumn{2}{|r|}{ Afirmaciones } & TA & A & D & TD \\
\hline 1 & A mí me parece que la víctima no narra bien los sucesos del delito. & & & & \\
\hline 2 & Pienso que la mayoría de los delitos se cometen por imprudencia de la víctima. & & & & \\
\hline 3 & $\begin{array}{l}\text { Creo que la víctima espera que los servidores públicos les hagan todo el } \\
\text { papeleo del proceso. }\end{array}$ & & & & \\
\hline 4 & Suelo pensar que la víctima se quiere aprovechar del sistema judicial. & & & & \\
\hline 5 & Creo que la falta de cooperación de la víctima lentifica el proceso. & & & & \\
\hline 6 & Me parece que las víctimas que atiendo son manipuladoras. & & & & \\
\hline 7 & $\begin{array}{l}\text { Me da la impresión que la prolongación de los silencios en el relato de la } \\
\text { víctima, hace que se disminuya la confiabilidad en su testimonio. }\end{array}$ & & & & \\
\hline 8 & $\begin{array}{l}\text { Reconozco que me incomoda la falta de paciencia de la víctima hacia los } \\
\text { funcionarios judiciales. }\end{array}$ & & & & \\
\hline 9 & $\begin{array}{l}\text { Creo que en la mayoría de los casos la víctima se busca lo que le pasa por su } \\
\text { imprudencia. }\end{array}$ & & & & \\
\hline 10 & $\begin{array}{l}\text { Me parece que a la víctima le cuesta entender lo que se le dice, por eso se le } \\
\text { habla en un tono de voz fuerte. }\end{array}$ & & & & \\
\hline 11 & $\begin{array}{l}\text { Considero que es inútil explicarle el procedimiento a la víctima, porque } \\
\text { aunque lleva varios años en el proceso continúa sin entender lo que ya debería } \\
\text { saber. }\end{array}$ & & & & \\
\hline 12 & Pienso que la víctima debe recordar los detalles del suceso delictivo. & & & & \\
\hline 13 & $\begin{array}{l}\text { Me da la impresión que cuando la víctima se demora en responder al } \\
\text { interrogatorio, es porque está inventando el relato. }\end{array}$ & & & & \\
\hline 14 & En mi opinión no es necesario explicar a la víctima los tiempos procesales. & & & & \\
\hline 15 & $\begin{array}{l}\text { Considero que la víctima se concentra demasiado en el proceso judicial, } \\
\text { olvidando continuar con su vida. }\end{array}$ & & & & \\
\hline 16 & $\begin{array}{l}\text { Me parece necesario que la víctima repita la versión de los hechos delictivos } \\
\text { para saber si dice la verdad. }\end{array}$ & & & & \\
\hline 17 & $\begin{array}{l}\text { Creo que la víctima debe recordar los sucesos con claridad para poder buscar al } \\
\text { culpable. }\end{array}$ & & & & \\
\hline 18 & $\begin{array}{l}\text { Yo Pienso que al recibir una denuncia se debe guardar cierta reserva de la } \\
\text { declaración, porque lo más probable es que la víctima este fantaseando. }\end{array}$ & & & & \\
\hline 19 & $\begin{array}{l}\text { Suelo pensar que la víctima no logra entender que su colaboración es } \\
\text { pertinente para el proceso. }\end{array}$ & & & & \\
\hline 20 & $\begin{array}{l}\text { Considero que la víctima en general, no logra entender los procedimientos } \\
\text { jurídicos. }\end{array}$ & & & & \\
\hline 21 & $\begin{array}{l}\text { Creo que la versión de los hechos es lo más importante cuando se denuncia un } \\
\text { delito, por eso es indispensable que la víctima los repita. }\end{array}$ & & & & \\
\hline 22 & $\begin{array}{l}\text { Me parece vital confrontar a la víctima con el victimario para saber quien dice } \\
\text { la verdad. }\end{array}$ & & & & \\
\hline 23 & $\begin{array}{l}\text { Pienso que la víctima se aprovecha de su condición, distorsionando la } \\
\text { información para sacar mayor ganancia. }\end{array}$ & & & & \\
\hline
\end{tabular}




\section{Para responder tenga en cuenta la siguiente convención:}

\begin{tabular}{|c|c|c|c|}
\hline TA & A & D & TD \\
\hline Totalmente de acuerdo & Acuerdo & Desacuerdo & $\begin{array}{c}\text { Totalmente en } \\
\text { desacuerdo }\end{array}$ \\
\hline
\end{tabular}

\begin{tabular}{|c|c|c|c|c|c|}
\hline \multicolumn{2}{|r|}{ Afirmaciones } & TA & A & D & TD \\
\hline 24 & $\begin{array}{l}\text { Me parece que la víctima esta incapacitada para hacer las diligencias del proceso } \\
\text { judicial bien. }\end{array}$ & & & & \\
\hline 25 & $\begin{array}{l}\text { Siento que la empatía con la víctima contribuye a dilatar el proceso, generando } \\
\text { compromiso al operador judicial. }\end{array}$ & & & & \\
\hline 26 & Me impacienta perder tiempo repitiendo una y otra vez la misma pregunta a la víctima. & & & & \\
\hline 27 & Me he vuelto indiferente ante tantas manifestaciones de tristeza que veo todos los días. & & & & \\
\hline 28 & $\begin{array}{l}\text { Algunas veces siento que tanta comprensión hacia la víctima es inútil, porque lo hecho, } \\
\text { hecho esta. }\end{array}$ & & & & \\
\hline 29 & $\begin{array}{l}\text { Siento que demostrar compasión a la víctima, entorpece la función investigativa de los } \\
\text { operadores judiciales. }\end{array}$ & & & & \\
\hline 30 & $\begin{array}{l}\text { Prefiero atender a la víctima sin tanta consideración para contribuir en su pronta } \\
\text { recuperación. }\end{array}$ & & & & \\
\hline 31 & $\begin{array}{l}\text { Quisiera que la víctima lograra comprender que todo proceso tiene un protocolo, por } \\
\text { ello se requiere de paciencia para esclarecer la verdad. }\end{array}$ & & & & \\
\hline 32 & $\begin{array}{l}\text { Yo siento que con la víctima es necesario mantener la distancia para evitar cualquier } \\
\text { expresión de afectiva. }\end{array}$ & & & & \\
\hline 33 & $\begin{array}{l}\text { Me he vuelto indiferente con la víctima, porque siento que es manipuladora, } \\
\text { quejumbrosa; además, se lamentan con el propósito de despertar compasión en los } \\
\text { operadores judiciales. }\end{array}$ & & & & \\
\hline 34 & Siento que es mejor guardar distancia con la víctima, para evitar empatía. & & & & \\
\hline 35 & $\begin{array}{l}\text { Percibo desconsideración por parte de las víctimas, pues solo se quejan y critican al } \\
\text { operador judicial. }\end{array}$ & & & & \\
\hline 36 & $\begin{array}{l}\text { Considero que en la declaración, es necesario que el operador judicial demuestre duda } \\
\text { hacia lo que ve, o escucha de la víctima. }\end{array}$ & & & & \\
\hline 37 & $\begin{array}{l}\text { Siento que a la víctima le falta comprender que el operador judicial es quien posee la } \\
\text { verdad. }\end{array}$ & & & & \\
\hline 38 & $\begin{array}{l}\text { Evito la afectividad con la víctima, para lograr aproximarme a la verdad de los hechos } \\
\text { reduciendo el tiempo de la investigación. }\end{array}$ & & & & \\
\hline 39 & $\begin{array}{l}\text { Siento que es el delito el causante del daño a la víctima; no mis acciones u omisiones } \\
\text { por falta de expresión afectiva. }\end{array}$ & & & & \\
\hline 40 & $\begin{array}{l}\text { Prefiero mantenerme distante ante lo que declara la víctima para evitar establecer } \\
\text { contacto físico significativo. }\end{array}$ & & & & \\
\hline 41 & $\begin{array}{l}\text { Siento que es preferible no atender inmediatamente a la víctima cuando llega a } \\
\text { interponer la denuncia, es mejor que espere un poco, así se da cuenta que su caso no es } \\
\text { el único y que hay otras personas que también sufren. }\end{array}$ & & & & \\
\hline 42 & $\begin{array}{l}\text { Me molesta que la víctima no disponga de suficiente tiempo, cuando la justicia la } \\
\text { requiere para adelantar el proceso. }\end{array}$ & & & & \\
\hline 43 & $\begin{array}{l}\text { Me indispone que la víctima no asuma la responsabilidad de su proceso para que este } \\
\text { avance. }\end{array}$ & & & & \\
\hline 44 & Me resulta molesto que la víctima no entienda los tiempos del proceso judicial. & & & & \\
\hline 45 & $\begin{array}{l}\text { A mí me resulta incomodo encontrar víctimas que son incoherentes con el relato de los } \\
\text { hechos. }\end{array}$ & & & & \\
\hline 46 & $\begin{array}{l}\text { Tengo la impresión que a la víctima de carácter frágil, se le debe tratar con firmeza para } \\
\text { que entienda el proceso judicial. }\end{array}$ & & & & \\
\hline 47 & $\begin{array}{l}\text { Suelo mostrar confianza en mi experiencia hablándole con dureza a la víctima para } \\
\text { que reaccione. }\end{array}$ & & & & \\
\hline
\end{tabular}




\section{Para responder tenga en cuenta la siguiente convención:}

\begin{tabular}{|c|c|c|c|}
\hline TA & A & D & TD \\
\hline $\begin{array}{c}\text { Totalmente de } \\
\text { acuerdo }\end{array}$ & Acuerdo & Desacuerdo & $\begin{array}{c}\text { Totalmente en } \\
\text { desacuerdo }\end{array}$ \\
\hline
\end{tabular}

\begin{tabular}{|c|c|c|c|c|c|}
\hline \multicolumn{2}{|r|}{ Afirmaciones } & TA & $\mathbf{A}$ & D & TD \\
\hline 48 & $\begin{array}{l}\text { Me disgusta la víctima que no entiende que hay otras personas que } \\
\text { necesitan atención jurídica. }\end{array}$ & & & & \\
\hline 49 & $\begin{array}{l}\text { Me molesta que la víctima no entienda que es necesario examinarla } \\
\text { cuantas veces sea indispensable de acuerdo al protocolo. }\end{array}$ & & & & \\
\hline 50 & $\begin{array}{l}\text { Yo suelo desconfiar de la víctima que no habla con seguridad, porque } \\
\text { es señal de que está mintiendo. }\end{array}$ & & & & \\
\hline 51 & Evito dar explicaciones a la víctima para optimizar mi tiempo. & & & & \\
\hline 52 & $\begin{array}{l}\text { Estoy seguro(a) que la formación profesional del operador judicial es } \\
\text { suficiente para atender a las víctimas. }\end{array}$ & & & & \\
\hline 53 & $\begin{array}{l}\text { Me doy cuenta que la compasión es sinónimo de debilidad y la víctima } \\
\text { se aprovecha. }\end{array}$ & & & & \\
\hline 54 & $\begin{array}{l}\text { Yo quisiera que la víctima entendiera que el proceso judicial es muy } \\
\text { largo y complicado. }\end{array}$ & & & & \\
\hline 55 & $\begin{array}{l}\text { Siento que es mejor poner distancia al trato con la víctima, para evitar } \\
\text { que surjan sentimientos de empatía por su dolor. }\end{array}$ & & & & \\
\hline 56 & $\begin{array}{l}\text { Yo tengo tanto trabajo que es necesario apurar a la víctima con el relato } \\
\text { de los hechos. }\end{array}$ & & & & \\
\hline 57 & $\begin{array}{l}\text { Me doy cuenta que por mi afán laboral, se me pasa dar información } \\
\text { pertinente del proceso a la víctima. }\end{array}$ & & & & \\
\hline 58 & $\begin{array}{l}\text { Me indispone la víctima que no sabe preguntar con claridad que es lo } \\
\text { que quiere y espera del proceso judicial. }\end{array}$ & & & & \\
\hline 59 & Me desespera atender a tanta víctima. & & & & \\
\hline 60 & $\begin{array}{l}\text { Prefiero que la víctima me mire a los ojos mientras declara para } \\
\text { identificar si dice o no la verdad. }\end{array}$ & & & & \\
\hline 61 & $\begin{array}{l}\text { Considero que es importante agilizar el papeleo de la denuncia porque } \\
\text { hay muchas víctimas en espera de atención. }\end{array}$ & & & & \\
\hline 62 & $\begin{array}{l}\text { Yo hago que el protocolo de interposición de la declaración, en } \\
\text { ocasiones se dilate, porque reiteradamente le pregunto a la víctima los } \\
\text { sucesos que motivaron la denuncia. }\end{array}$ & & & & \\
\hline 63 & $\begin{array}{l}\text { Preferiría que la víctima que atiendo conozca la terminología jurídica } \\
\text { para proporcionarles una mejor atención a su caso. }\end{array}$ & & & & \\
\hline 64 & $\begin{array}{l}\text { Mi experiencia enseña que es poco recomendable proporcionar } \\
\text { información del proceso a la víctima. }\end{array}$ & & & & \\
\hline 65 & $\begin{array}{l}\text { Considero que la víctima debiera tener en cuenta que la interposición de } \\
\text { la denuncia tiene un tiempo límite para evitar el agotamiento del } \\
\text { operador judicial. }\end{array}$ & & & & \\
\hline 66 & $\begin{array}{l}\text { Suele molestarme las múltiples quejas que la víctima realiza en la } \\
\text { interposición de la denuncia, porque no tiene claridad de lo que está } \\
\text { diciendo. }\end{array}$ & & & & \\
\hline 67 & Quisiera no tener que perder el control enojándome con la víctima. & & & & \\
\hline
\end{tabular}


Apéndice C: Ficha técnica del instrumento SAMANTO

Tabla 15.

Ficha técnica del Instrumento SAMANTO

Nombre: $\quad$ Escala SAMANTO.

Autor: $\quad$ S. Mantilla Ojeda.

Administración: Individual.

Duración: $\quad 25$ minutos.

Aplicación: Auto-aplicación individual o colectiva a Jóvenes y adultos que atienden víctimas.

Calificación: Manual.

Significación: Mide las actitudes de los operadores judiciales hacia la víctima, identificando con ello, la presencia o ausencia de actitudes revictimizantes. Estas, se pueden detectar por medio de los tres componentes de la actitud, como lo son: componente cognitivo, componente afectivo, componente comportamental.

Material: $\quad$ Cuadernillo y bolígrafo. Tabla de percentiles y rangos de calificación.

Ítem invertidos Escala de valoración tipo Laiker, con cuatro (4) opciones de respuestas: Totalmente de acuerdo (TA), Acuerdo (A), Desacuerdo (D), Totalmente Desacuerdo (TD), se califica de 1 a 4, invirtiendo el valor del ítem así:

Calificación normal de los ítem........... $1114 \quad 2 \quad 3 \quad 4$

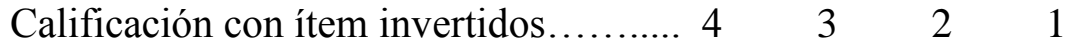

Los 61 ítems se invierten con el fin de evitar sesgos de respuestas relacionados con la deseabilidad social que es la manera de mostrarse favorable ante el otro. 
Apéndice D: Estadísticos por componentes

Tabla 16.

Estadísticos totales de los ítems del componente cognitivo

\begin{tabular}{|c|c|c|c|c|}
\hline Ítems & $\begin{array}{c}\text { Media } \\
\text { de la escala } \\
\text { si se elimina el } \\
\text { ítem }\end{array}$ & $\begin{array}{c}\text { Varianza } \\
\text { de la escala } \\
\text { si se elimina el } \\
\text { ítem }\end{array}$ & $\begin{array}{l}\text { Correlación } \\
\text { elemento } \\
\text { total corregida }\end{array}$ & $\begin{array}{c}\text { Alfa } \\
\text { de Cronbach } \\
\text { si se elimina el } \\
\text { ítem }\end{array}$ \\
\hline i1 & 44,59 & 83,571 & ,432 & ,864 \\
\hline i2 & 45,38 & 82,020 &, 535 &, 861 \\
\hline i3 & 44,64 & 83,106 & ,381 & ,866 \\
\hline $\mathrm{i} 4$ & 45,17 & 79,787 & 670 & ,857 \\
\hline i5 & 44,79 & 82,267 & ,402 & ,866 \\
\hline i6 & 45,15 & 82,566 & ,591 &, 861 \\
\hline i7 & 44,99 & 80,664 &, 546 &, 860 \\
\hline i8 & 44,89 & 83,375 & ,413 &, 865 \\
\hline i9 & 45,50 & 82,706 & ,539 &, 862 \\
\hline $\mathrm{i} 10$ & 45,31 & 82,871 &, 526 & ,862 \\
\hline i11 & 45,38 & 83,264 &, 553 &, 862 \\
\hline i12 & 44,68 & 83,479 & ,357 &, 867 \\
\hline i13 & 45,23 & 80,769 & ,627 &, 859 \\
\hline i14 & 45,47 & 83,948 & ,387 & ,866 \\
\hline i15 & 44,84 & 83,059 & ,440 & ,864 \\
\hline i16 & 45,08 & 80,396 &, 560 &, 860 \\
\hline i17 & 44,78 & 82,087 & ,427 &, 865 \\
\hline i18 & 43,80 & 99,018 &,- 597 & ,894 \\
\hline i19 & 44,98 & 82,327 & ,440 & ,864 \\
\hline $\mathrm{i} 20$ & 44,77 & 81,693 &, 515 &, 862 \\
\hline i21 & 44,80 & 80,548 & ,567 & ,860 \\
\hline $\mathrm{i} 22$ & 45,39 & 83,467 & ,410 & ,865 \\
\hline i23 & 45,23 & 81,251 & 602 &, 859 \\
\hline $\mathrm{i} 24$ & 45,00 & 84,134 & ,368 & ,866 \\
\hline
\end{tabular}

Nota: Fiabilidad del instrumento con los 24 ítems

Continúa tabla 16.

Estadísticos de fiabilidad Estadísticos de la escala

\begin{tabular}{|c|c|c|c|c|c|}
\hline $\begin{array}{c}\text { Alfa de } \\
\text { Cronbach }\end{array}$ & $\begin{array}{l}\mathrm{N} \mathrm{de} \\
\text { ítems }\end{array}$ & Media & Varianza & $\begin{array}{c}\text { Desviación } \\
\text { típica } \\
\end{array}$ & $\begin{array}{l}\mathrm{N} \text { de } \\
\text { ítems }\end{array}$ \\
\hline, 869 & 24 & 46,95 & 89,880 & 9,480 & 24 \\
\hline
\end{tabular}


Continúa tabla 16.

Estadísticos totales de los ítems del componente cognitivo

\begin{tabular}{cccc}
\hline Ítem & Media & Desviación típica & N \\
\hline i1 & 2,36 &, 731 & 120 \\
i2 & 1,57 &, 753 & 120 \\
i3 & 2,31 &, 868 & 120 \\
i4 & 1,78 &, 791 & 120 \\
i5 & 2,16 &, 926 & 120 \\
i6 & 1,80 &, 643 & 120 \\
i7 & 1,96 &, 864 & 120 \\
i8 & 2,06 &, 781 & 120 \\
i9 & 1,45 &, 684 & 120 \\
i10 & 1,64 &, 683 & 120 \\
i11 & 1,57 &, 618 & 120 \\
i12 & 2,27 &, 867 & 120 \\
i13 & 1,72 &, 758 & 120 \\
i14 & 1,48 &, 756 & 120 \\
i15 & 2,11 &, 776 & 120 \\
i16 & 1,87 &, 869 & 120 \\
i17 & 2,17 &, 901 & 120 \\
i19 & 1,98 &, 855 & 120 \\
i20 & 2,18 &, 809 & 120 \\
i21 & 2,15 &, 847 & 120 \\
i22 & 1,56 &, 776 & 120 \\
i23 & 1,73 &, 744 & 120 \\
i24 & 1,95 &, 765 & 120 \\
\hline A1 & & &
\end{tabular}

Nota: Al excluirse el ítem 18 el Alfa de Cronbach mejoró su puntaje.

Continúa tabla 16.

Estadísticos de fiabilidad Estadísticos de la escala

\begin{tabular}{cc}
\hline $\begin{array}{c}\text { Alfa de } \\
\text { Cronbach }\end{array}$ & $\begin{array}{c}\mathrm{N} \mathrm{de} \\
\text { ítems }\end{array}$ \\
\hline, 894 & 23 \\
\hline
\end{tabular}

\begin{tabular}{cccc}
\hline Media & Varianza & $\begin{array}{c}\text { Desviación } \\
\text { típica }\end{array}$ & $\begin{array}{c}\mathrm{N} \mathrm{de} \\
\text { ítems }\end{array}$ \\
\hline 43,80 & 99,018 & 9,951 & 23 \\
\hline
\end{tabular}


Escala SAMANTO para medir actitudes de los operadores judiciales hacia la víctima 144

Tabla 17.

Estadísticos totales de los ítems del componente afectivo

\begin{tabular}{cccc}
\hline Ítem & Media & Desviación típica & $\mathrm{N}$ \\
\hline i26 & 1,69 &, 797 & 120 \\
i27 & 1,63 &, 789 & 120 \\
i28 & 1,47 &, 721 & 120 \\
i29 & 1,92 &, 856 & 120 \\
i31 & 2,82 &, 788 & 120 \\
i32 & 2,18 &, 816 & 120 \\
i33 & 1,59 &, 716 & 120 \\
i34 & 1,89 &, 754 & 120 \\
i35 & 1,93 &, 764 & 120 \\
i37 & 1,53 &, 777 & 120 \\
i38 & 1,98 &, 799 & 120 \\
i39 & 2,13 &, 879 & 120 \\
i41 & 1,62 &, 812 & 120 \\
\hline
\end{tabular}

Continúa tabla 17.

\begin{tabular}{ccccc}
\hline Ítems & $\begin{array}{c}\text { Media } \\
\text { de la escala } \\
\text { si se elimina el } \\
\text { ítem }\end{array}$ & $\begin{array}{c}\text { Varianza } \\
\text { de la escala } \\
\text { si se elimina el } \\
\text { ítem }\end{array}$ & $\begin{array}{c}\text { Correlación } \\
\text { elemento } \\
\text { total corregida }\end{array}$ & $\begin{array}{c}\text { Alfa } \\
\text { de Cronbach } \\
\text { si se elimina el } \\
\text { ítem }\end{array}$ \\
\hline i26 & 22,68 & 33,263 &, 576 &, 845 \\
i27 & 22,74 & 33,655 &, 537 &, 847 \\
i28 & 22,90 & 33,418 &, 630 &, 842 \\
i29 & 22,45 & 34,082 &, 438 &, 854 \\
i31 & 21,55 & 37,174 &, 145 &, 870 \\
i32 & 22,19 & 33,434 &, 539 &, 847 \\
i33 & 22,78 & 33,336 &, 646 &, 841 \\
i34 & 22,48 & 33,428 &, 596 &, 844 \\
i35 & 22,43 & 33,659 &, 558 &, 846 \\
i37 & 22,84 & 33,244 &, 596 &, 844 \\
i38 & 22,38 & 33,465 &, 550 &, 846 \\
i39 & 22,23 & 33,340 &, 501 &, 850 \\
i41 & 22,75 & 33,752 &, 507 &, 849 \\
\hline
\end{tabular}

Nota: Al excluirse los ítems 25, 30, 36 y 40 el Alfa de Cronbach mejoró su puntaje.

Continúa tabla 17.

Estadísticos de fiabilidad

\begin{tabular}{cc}
\hline $\begin{array}{c}\text { Alfa de } \\
\text { Cronbach }\end{array}$ & $\mathrm{N}$ de ítems \\
\hline, 858 & 13 \\
\hline
\end{tabular}

Estadísticos de la escala

\begin{tabular}{cccc}
\hline Media & Varianza & $\begin{array}{c}\text { Desviación } \\
\text { típica }\end{array}$ & N de ítems \\
\hline 24,37 & 39,192 & 6,260 & 13 \\
\hline
\end{tabular}


Escala SAMANTO para medir actitudes de los operadores judiciales hacia la víctima 145

Tabla 18.

Estadísticos totales de los items del componente comportamental

\begin{tabular}{|c|c|c|c|}
\hline Ítem & Media & Desviación típica & $\mathrm{N}$ \\
\hline $\mathrm{i} 42$ & 1,94 & ,843 & 120 \\
\hline i43 & 2,02 & ,809 & 120 \\
\hline $\mathrm{i} 44$ & 1,94 & 843 & 120 \\
\hline $\mathrm{i} 45$ & 2,11 & 887 & 120 \\
\hline i46 & 1,79 & 849 & 120 \\
\hline i47 & 1,65 & ,729 & 120 \\
\hline $\mathrm{i} 48$ & 1,92 & ,740 & 120 \\
\hline i49 & 1,90 & ,760 & 120 \\
\hline $\mathrm{i} 50$ & 1,78 & ,793 & 120 \\
\hline i51 & 1,67 &, 771 & 120 \\
\hline i52 & 1,88 & 805 & 120 \\
\hline i53 & 1,82 & ,745 & 120 \\
\hline i54 & 2,47 &, 840 & 120 \\
\hline $\mathrm{i} 55$ & 2,04 & ,782 & 120 \\
\hline i56 & 1,60 & ,703 & 120 \\
\hline $\mathrm{i} 57$ & 2,13 & ,922 & 120 \\
\hline $\mathrm{i} 58$ & 1,68 & 686 & 120 \\
\hline i59 & 1,52 & 648 & 120 \\
\hline $\mathrm{i} 60$ & 2,05 & 858 & 120 \\
\hline i61 & 2,31 & ,933 & 120 \\
\hline i63 & 1,88 & 871 & 120 \\
\hline i64 & 1,71 & ,738 & 120 \\
\hline $\mathrm{i} 65$ & 1,93 & ,786 & 120 \\
\hline i66 & 1,73 & 645 & 120 \\
\hline i67 & 2,21 & 1,044 & 120 \\
\hline
\end{tabular}


Continúa tabla 18.

Estadísticos totales de los ítems del componente comportamental

\begin{tabular}{|c|c|c|c|c|}
\hline Ítems & $\begin{array}{c}\text { Media } \\
\text { de la escala } \\
\text { si se elimina el } \\
\text { ítem }\end{array}$ & $\begin{array}{c}\text { Varianza } \\
\text { de la escala } \\
\text { si se elimina el } \\
\text { ítem }\end{array}$ & $\begin{array}{l}\text { Correlación } \\
\text { elemento } \\
\text { total corregida }\end{array}$ & $\begin{array}{c}\text { Alfa } \\
\text { de Cronbach } \\
\text { si se elimina el } \\
\text { ítem }\end{array}$ \\
\hline $\mathrm{i} 42$ & 45,72 & 139,734 & ,605 & ,927 \\
\hline $\mathrm{i} 43$ & 45,64 & 140,030 & 617 & 927 \\
\hline $\mathrm{i} 44$ & 45,72 & 137,617 & ,717 & 926 \\
\hline $\mathrm{i} 45$ & 45,55 & 137,981 & 660 & 927 \\
\hline $\mathrm{i} 46$ & 45,87 & 139,427 & 617 & 927 \\
\hline $\mathrm{i} 47$ & 46,01 & 140,697 & 652 & 927 \\
\hline $\mathrm{i} 48$ & 45,74 & 140,109 & 677 & ,927 \\
\hline $\mathrm{i} 49$ & 45,76 & 138,891 & ,728 & 926 \\
\hline i50 & 45,88 & 138,793 & ,700 & ,926 \\
\hline i51 & 45,99 & 140,681 & 615 & 927 \\
\hline i52 & 45,78 & 142,104 & ,509 & 929 \\
\hline i53 & 45,84 & 139,950 & 682 & 926 \\
\hline i54 & 45,19 & 142,425 & ,468 & ,930 \\
\hline i55 & 45,62 & 141,280 & ,571 & 928 \\
\hline i56 & 46,06 & 144,223 & ,462 & 929 \\
\hline i57 & 45,53 & 142,638 & ,410 & ,931 \\
\hline i58 & 45,98 & 142,714 & ,569 & 928 \\
\hline i59 & 46,14 & 145,837 & 400 & ,930 \\
\hline $\mathrm{i} 60$ & 45,61 & 140,560 & ,551 & ,928 \\
\hline i61 & 45,35 & 141,120 & ,475 & ,930 \\
\hline $\mathrm{i} 63$ & 45,78 & 143,386 & ,401 & 931 \\
\hline i64 & 45,95 & 141,729 & ,583 & 928 \\
\hline $\mathrm{i} 65$ & 45,73 & 141,848 & ,537 & ,928 \\
\hline i66 & 45,93 & 140,759 & ,741 & 926 \\
\hline $\mathrm{i} 67$ & 45,45 & 139,510 & ,483 & ,930 \\
\hline
\end{tabular}

Nota: Al excluir el ítem 62 el Alfa de Cronbach mejoró su puntaje.

Continúa tabla 18.

Estadísticos de fiabilidad

Estadísticos de la escala

\begin{tabular}{cc}
\hline $\begin{array}{c}\text { Alfa de } \\
\text { Cronbach }\end{array}$ & $\begin{array}{c}\mathrm{N} \mathrm{de} \\
\text { ítems }\end{array}$ \\
\hline, 931 & 25 \\
\hline
\end{tabular}

\begin{tabular}{cccc}
\hline Media & Varianza & $\begin{array}{c}\text { Desviación } \\
\text { típica }\end{array}$ & $\begin{array}{c}\text { N de } \\
\text { ítems }\end{array}$ \\
\hline 47,66 & 152,513 & 12,350 & 25 \\
\hline
\end{tabular}


Tabla 19.

Estadísticos de los ítems

\begin{tabular}{|c|c|c|c|}
\hline Ítems & Media & Desviación típica & $\mathrm{N}$ \\
\hline 1 & 2,36 & ,731 & 120 \\
\hline 2 & 1,57 & ,753 & 120 \\
\hline 3 & 2,31 & ,868 & 120 \\
\hline 4 & 1,78 & ,791 & 120 \\
\hline 5 & 2,16 & ,926 & 120 \\
\hline 6 & 1,80 & ,643 & 120 \\
\hline 7 & 1,96 & ,864 & 120 \\
\hline 8 & 2,06 & ,781 & 120 \\
\hline 9 & 1,45 & ,684 & 120 \\
\hline 10 & 1,64 & ,683 & 120 \\
\hline 11 & 1,57 & ,618 & 120 \\
\hline 12 & 2,27 & ,867 & 120 \\
\hline 13 & 1,72 & ,758 & 120 \\
\hline 14 & 1,48 & ,756 & 120 \\
\hline 15 & 2,11 & ,776 & 120 \\
\hline 16 & 1,87 & ,869 & 120 \\
\hline 17 & 2,17 & ,901 & 120 \\
\hline
\end{tabular}


Continuación tabla 19.

Estadísticos de los ítems

\begin{tabular}{|c|c|c|c|}
\hline Ítems & Media & Desviación típica & $\mathrm{N}$ \\
\hline 19 & 1,98 & ,855 & 120 \\
\hline 20 & 2,18 & ,809 & 120 \\
\hline 21 & 2,15 & ,847 & 120 \\
\hline 22 & 1,56 & ,776 & 120 \\
\hline 23 & 1,73 & ,744 & 120 \\
\hline 24 & 1,95 & ,765 & 120 \\
\hline 26 & 1,69 & ,797 & 120 \\
\hline 27 & 1,63 & ,789 & 120 \\
\hline 28 & 1,47 & ,721 & 120 \\
\hline 29 & 1,92 & ,856 & 120 \\
\hline 31 & 2,82 & ,788 & 120 \\
\hline 32 & 2,18 & ,816 & 120 \\
\hline 33 & 1,59 & ,716 & 120 \\
\hline 34 & 1,89 & ,754 & 120 \\
\hline 35 & 1,93 & ,764 & 120 \\
\hline 37 & 1,53 &, 777 & 120 \\
\hline 38 & 1,98 & ,799 & 120 \\
\hline 39 & 2,13 & ,879 & 120 \\
\hline 41 & 1,62 & ,812 & 120 \\
\hline
\end{tabular}


Continuación tabla 19.

Estadísticos de los ítems

\begin{tabular}{|c|c|c|c|}
\hline Ítems & Media & Desviación típica & $\mathrm{N}$ \\
\hline 42 & 1,94 & ,843 & 120 \\
\hline 43 & 2,02 & ,809 & 120 \\
\hline 44 & 1,94 & ,843 & 120 \\
\hline 45 & 2,11 & ,887 & 120 \\
\hline 46 & 1,79 & ,849 & 120 \\
\hline 47 & 1,65 & ,729 & 120 \\
\hline 48 & 1,92 & ,740 & 120 \\
\hline 49 & 1,90 & ,760 & 120 \\
\hline 50 & 1,78 & ,793 & 120 \\
\hline 51 & 1,67 & ,771 & 120 \\
\hline 52 & 1,88 & ,805 & 120 \\
\hline 53 & 1,82 & ,745 & 120 \\
\hline 54 & 2,47 & 840 & 120 \\
\hline 55 & 2,04 & ,782 & 120 \\
\hline
\end{tabular}


Continuación tabla 19.

Estadísticos de los ítems

\begin{tabular}{|c|c|c|c|}
\hline Ítems & Media & Desviación típica & $\mathrm{N}$ \\
\hline 56 & 1,60 & ,703 & 120 \\
\hline 57 & 2,13 & ,922 & 120 \\
\hline 58 & 1,68 & ,686 & 120 \\
\hline 59 & 1,52 & ,648 & 120 \\
\hline 60 & 2,05 & ,858 & 120 \\
\hline 61 & 2,31 & ,933 & 120 \\
\hline 63 & 1,88 & ,871 & 120 \\
\hline 64 & 1,71 & ,738 & 120 \\
\hline 65 & 1,93 & ,786 & 120 \\
\hline 66 & 1,73 & ,645 & 120 \\
\hline 67 & 2,21 & 1,044 & 120 \\
\hline 18 & 3,15 & ,827 & 120 \\
\hline 25 & 3,18 & ,788 & 120 \\
\hline 30 & 3,20 & ,705 & 120 \\
\hline 36 & 3,14 & ,759 & 120 \\
\hline 40 & 2,96 & ,782 & 120 \\
\hline 62 & 3,21 & ,798 & 120 \\
\hline
\end{tabular}


Tabla 20.

Estadísticos de total de los ítems

\begin{tabular}{|c|c|c|c|c|}
\hline Ítems & $\begin{array}{c}\text { Media de la } \\
\text { escala si se } \\
\text { elimina el ítem }\end{array}$ & $\begin{array}{l}\text { Varianza de la } \\
\text { escala si se } \\
\text { elimina el ítem }\end{array}$ & $\begin{array}{l}\text { Correlación } \\
\text { ítems-total } \\
\text { corregida }\end{array}$ & $\begin{array}{c}\text { Alfa de } \\
\text { Cronbach si se } \\
\text { elimina el ítem }\end{array}$ \\
\hline 1 & 132,31 & 519,425 & ,376 & ,934 \\
\hline 2 & 133,10 & 517,385 & ,425 & ,933 \\
\hline 3 & 132,36 & 516,618 & ,383 & ,934 \\
\hline 4 & 132,88 & 511,667 & ,565 & ,933 \\
\hline 5 & 132,51 & 514,538 & ,407 & ,934 \\
\hline 6 & 132,87 & 517,259 & ,507 & ,933 \\
\hline 7 & 132,71 & 515,603 & ,412 & ,933 \\
\hline 8 & 132,61 & 518,307 & ,382 & ,934 \\
\hline 9 & 133,22 & 518,995 & ,418 & ,933 \\
\hline 10 & 133,03 & 519,201 & ,412 & ,933 \\
\hline 11 & 133,10 & 516,897 &, 541 & ,933 \\
\hline 12 & 132,40 & 521,519 & ,258 & ,934 \\
\hline 13 & 132,95 & 511,039 & ,609 & ,932 \\
\hline 14 & 133,18 & 520,319 & ,337 & ,934 \\
\hline 15 & 132,56 & 514,568 & ,492 & ,933 \\
\hline 16 & 132,80 & 509,203 & ,575 & ,932 \\
\hline 17 & 132,50 & 512,824 & ,462 & ,933 \\
\hline
\end{tabular}


Continuación tabla 20.

Estadísticos de total de los ítems

\begin{tabular}{|c|c|c|c|c|}
\hline Ítems & $\begin{array}{c}\text { Media de la } \\
\text { escala si se } \\
\text { elimina el ítem }\end{array}$ & $\begin{array}{c}\text { Varianza de la } \\
\text { escala si se } \\
\text { elimina el } \\
\text { ítems }\end{array}$ & $\begin{array}{c}\text { Correlación } \\
\text { ítems-total } \\
\text { corregida }\end{array}$ & $\begin{array}{c}\text { Alfa de } \\
\text { Cronbach si se } \\
\text { elimina el } \\
\text { ítems }\end{array}$ \\
\hline 19 & 132,69 & 514,484 & ,446 & ,933 \\
\hline 20 & 132,48 & 512,302 & ,533 & ,933 \\
\hline 21 & 132,52 & 514,269 & , 456 & ,933 \\
\hline 22 & 133,11 & 514,282 & ,501 & ,933 \\
\hline 23 & 132,94 & 508,812 & ,689 & ,932 \\
\hline 24 & 132,72 & 518,188 & ,394 & ,934 \\
\hline 26 & 132,98 & 511,302 & ,570 & ,933 \\
\hline 27 & 133,04 & 514,998 & ,471 & ,933 \\
\hline 28 & 133,20 & 512,313 & ,602 & ,932 \\
\hline 29 & 132,75 & 514,492 & ,445 & ,933 \\
\hline 31 & 131,85 & 528,061 &, 105 & ,935 \\
\hline 32 & 132,49 & 514,151 & ,477 & ,933 \\
\hline 33 & 133,08 & 511,179 & ,643 & ,932 \\
\hline 34 & 132,78 & 512,546 & ,568 & ,933 \\
\hline 35 & 132,73 & 512,685 & ,556 & ,933 \\
\hline 37 & 133,14 & 510,694 & ,603 & ,932 \\
\hline 38 & 132,68 & 514,151 & ,489 & ,933 \\
\hline 39 & 132,53 & 515,125 & ,416 & ,933 \\
\hline
\end{tabular}


Continuación tabla 20.

Estadísticos de total de los ítems

\begin{tabular}{|c|c|c|c|c|}
\hline Ítems & $\begin{array}{c}\text { Media de la } \\
\text { escala si se } \\
\text { elimina el ítem }\end{array}$ & $\begin{array}{l}\text { Varianza de la } \\
\text { escala si se } \\
\text { elimina el ítem }\end{array}$ & $\begin{array}{l}\text { Correlación } \\
\text { ítems-total } \\
\text { corregida }\end{array}$ & $\begin{array}{c}\text { Alfa de } \\
\text { Cronbach si se } \\
\text { elimina el ítem }\end{array}$ \\
\hline 41 & 133,05 & 508,082 & ,649 & ,932 \\
\hline 42 & 132,73 & 508,705 & 607 & ,932 \\
\hline 43 & 132,65 & 511,658 & ,551 & ,933 \\
\hline 44 & 132,73 & 505,865 & 683 & ,932 \\
\hline 45 & 132,56 & 506,316 & ,636 & ,932 \\
\hline 46 & 132,88 & 506,430 & 663 & ,932 \\
\hline 47 & 133,02 & 510,470 & ,652 & ,932 \\
\hline 48 & 132,75 & 510,508 & ,641 & ,932 \\
\hline 49 & 132,77 & 508,096 & ,695 & ,932 \\
\hline 50 & 132,89 & 506,030 &, 724 & ,932 \\
\hline 51 & 133,00 & 511,277 & ,592 & ,932 \\
\hline 52 & 132,79 & 511,881 & ,548 & ,933 \\
\hline 53 & 132,85 & 508,095 & ,710 & ,932 \\
\hline 54 & 132,20 & 515,943 & ,415 & ,933 \\
\hline 55 & 132,63 & 511,211 & ,584 & ,932 \\
\hline 56 & 133,07 & 518,735 & ,414 & ,933 \\
\hline 57 & 132,54 & 517,158 & ,345 & ,934 \\
\hline 58 & 132,98 & 515,327 & ,536 & ,933 \\
\hline
\end{tabular}


Continuación tabla 20.

Estadísticos de total de los ítems

\begin{tabular}{|c|c|c|c|c|}
\hline Ítems & $\begin{array}{c}\text { Media de la } \\
\text { escala si se } \\
\text { elimina el ítem }\end{array}$ & $\begin{array}{l}\text { Varianza de la } \\
\text { escala si se } \\
\text { elimina el ítem }\end{array}$ & $\begin{array}{c}\text { Correlación } \\
\text { ítems-total } \\
\text { corregida }\end{array}$ & $\begin{array}{c}\text { Alfa de } \\
\text { Cronbach si se } \\
\text { elimina el ítem }\end{array}$ \\
\hline 59 & 133,15 & 519,944 & ,410 & ,933 \\
\hline 60 & 132,62 & 511,448 &, 523 & ,933 \\
\hline 61 & 132,36 & 513,392 & ,431 & ,933 \\
\hline 63 & 132,78 & 517,835 &, 350 & ,934 \\
\hline 64 & 132,96 & 514,292 &, 528 & ,933 \\
\hline 65 & 132,73 & 515,911 & ,447 & ,933 \\
\hline 66 & 132,93 & 511,911 & 691 & ,932 \\
\hline 67 & 132,46 & 512,872 & ,392 & ,934 \\
\hline 18 & 131,52 & 556,218 &,- 626 & ,939 \\
\hline 25 & 131,48 & 554,554 &,- 611 & ,939 \\
\hline 30 & 131,47 & 550,856 &,- 570 & ,938 \\
\hline 36 & 131,53 & 552,184 &,- 568 & ,939 \\
\hline 40 & 131,71 & 549,334 &,- 476 & ,938 \\
\hline 62 & 131,46 & 552,452 &,- 549 & ,939 \\
\hline
\end{tabular}

Continuación tabla 20.

Estadísticos de fiabilidad Estadísticos de la escala

\begin{tabular}{cc}
\hline $\begin{array}{c}\text { Alfa de } \\
\text { Cronbach }\end{array}$ & $\begin{array}{c}\mathrm{N} \mathrm{de} \\
\text { ítems }\end{array}$ \\
\hline, 934 & 67 \\
\hline
\end{tabular}

\begin{tabular}{cccc}
\hline Media & Varianza & $\begin{array}{c}\text { Desviación } \\
\text { típica }\end{array}$ & $\begin{array}{c}\mathrm{N} \mathrm{de} \\
\text { ítems }\end{array}$ \\
\hline 134,67 & 532,493 & 23,076 & 67 \\
\hline
\end{tabular}


Tabla 21.

Estadísticos de los resultados en las sub-escalas y puntaje total

\begin{tabular}{|c|c|c|c|c|}
\hline Descriptivo & $\begin{array}{c}\text { Puntaje } \\
\text { C. Cognitivo }\end{array}$ & $\begin{array}{c}\text { Puntaje } \\
\text { C. Afectivo }\end{array}$ & $\begin{array}{c}\text { Puntaje } \\
\text { C. Comportamental }\end{array}$ & $\begin{array}{l}\text { Puntaje } \\
\text { Total }\end{array}$ \\
\hline Media & 46,9500 & 36,8500 & 50,8667 & 134,6667 \\
\hline Mediana & 46,5000 & 36,0000 & 51,5000 & 132,5000 \\
\hline Moda & 47,00 & 35,00 & 56,00 & 139,00 \\
\hline Desv. típ. & 9,48050 & 4,75032 & 11,87182 & 23,07581 \\
\hline Varianza & 89,880 & 22,566 & 140,940 & 532,493 \\
\hline Asimetría & ,710 & ,592 & ,191 &, 517 \\
\hline Error típ. de asimetría & ,221 & ,221 & ,221 &, 221 \\
\hline Curtosis & ,941 & , 116 &,- 502 & , 187 \\
\hline Error típ. de curtosis & ,438 & ,438 & ,438 & ,438 \\
\hline Mínimo & 28,00 & 28,00 & 29,00 & 86,00 \\
\hline Máximo & 81,00 & 50,00 & 79,00 & 200,00 \\
\hline
\end{tabular}


Tabla 22.

Estadísticos del puntaje componente cognitivo

\begin{tabular}{|c|c|c|c|c|}
\hline Válidos & Frecuencia & Porcentaje & Porcentaje válido & Porcentaje acumulado \\
\hline 28,00 & 1 &, 8 &, 8 & ,8 \\
\hline 30,00 & 1 &, 8 &, 8 & 1,7 \\
\hline 31,00 & 2 & 1,7 & 1,7 & 3,3 \\
\hline 32,00 & 1 & ,8 & ,8 & 4,2 \\
\hline 34,00 & 3 & 2,5 & 2,5 & 6,7 \\
\hline 35,00 & 4 & 3,3 & 3,3 & 10,0 \\
\hline 36,00 & 6 & 5,0 & 5,0 & 15,0 \\
\hline 37,00 & 1 & ,8 & ,8 & 15,8 \\
\hline 38,00 & 5 & 4,2 & 4,2 & 20,0 \\
\hline 39,00 & 5 & 4,2 & 4,2 & 24,2 \\
\hline 40,00 & 1 & ,8 & ,8 & 25,0 \\
\hline 41,00 & 4 & 3,3 & 3,3 & 28,3 \\
\hline 42,00 & 4 & 3,3 & 3,3 & 31,7 \\
\hline 43,00 & 3 & 2,5 & 2,5 & 34,2 \\
\hline 44,00 & 4 & 3,3 & 3,3 & 37,5 \\
\hline 45,00 & 10 & 8,3 & 8,3 & 45,8 \\
\hline 46,00 & 5 & 4,2 & 4,2 & 50,0 \\
\hline 47,00 & 11 & 9,2 & 9,2 & 59,2 \\
\hline 48,00 & 8 & 6,7 & 6,7 & 65,8 \\
\hline 49,00 & 5 & 4,2 & 4,2 & 70,0 \\
\hline 51,00 & 1 & ,8 & ,8 & 70,8 \\
\hline 52,00 & 5 & 4,2 & 4,2 & 75,0 \\
\hline 53,00 & 4 & 3,3 & 3,3 & 78,3 \\
\hline 54,00 & 2 & 1,7 & 1,7 & 80,0 \\
\hline 55,00 & 3 & 2,5 & 2,5 & 82,5 \\
\hline 56,00 & 6 & 5,0 & 5,0 & 87,5 \\
\hline 58,00 & 1 & ,8 & ,8 & 88,3 \\
\hline 59,00 & 3 & 2,5 & 2,5 & 90,8 \\
\hline 61,00 & 4 & 3,3 & 3,3 & 94,2 \\
\hline 63,00 & 1 & ,8 & ,8 & 95,0 \\
\hline 64,00 & 1 & ,8 & ,8 & 95,8 \\
\hline 68,00 & 1 & ,8 & ,8 & 96,7 \\
\hline 69,00 & 1 & ,8 & ,8 & 97,5 \\
\hline 71,00 & 1 & ,8 & ,8 & 98,3 \\
\hline 72,00 & 1 & ,8 & ,8 & 99,2 \\
\hline 81,00 & 1 & ,8 & ,8 & 100,0 \\
\hline Total & 120 & 100,0 & 100,0 & \\
\hline
\end{tabular}


Tabla 23.

Estadísticos del puntaje componente afectivo

\begin{tabular}{|c|c|c|c|c|}
\hline Válidos & Frecuencia & Porcentaje & Porcentaje válido & Porcentaje acumulado \\
\hline 28,00 & 1 & ,8 & ,8 & ,8 \\
\hline 29,00 & 3 & 2,5 & 2,5 & 3,3 \\
\hline 30,00 & 5 & 4,2 & 4,2 & 7,5 \\
\hline 31,00 & 5 & 4,2 & 4,2 & 11,7 \\
\hline 32,00 & 8 & 6,7 & 6,7 & 18,3 \\
\hline 33,00 & 10 & 8,3 & 8,3 & 26,7 \\
\hline 34,00 & 7 & 5,8 & 5,8 & 32,5 \\
\hline 35,00 & 15 & 12,5 & 12,5 & 45,0 \\
\hline 36,00 & 9 & 7,5 & 7,5 & 52,5 \\
\hline 37,00 & 6 & 5,0 & 5,0 & 57,5 \\
\hline 38,00 & 9 & 7,5 & 7,5 & 65,0 \\
\hline 39,00 & 12 & 10,0 & 10,0 & 75,0 \\
\hline 40,00 & 6 & 5,0 & 5,0 & 80,0 \\
\hline 41,00 & 5 & 4,2 & 4,2 & 84,2 \\
\hline 42,00 & 5 & 4,2 & 4,2 & 88,3 \\
\hline 43,00 & 3 & 2,5 & 2,5 & 90,8 \\
\hline 44,00 & 3 & 2,5 & 2,5 & 93,3 \\
\hline 45,00 & 1 & ,8 & ,8 & 94,2 \\
\hline 46,00 & 2 & 1,7 & 1,7 & 95,8 \\
\hline 47,00 & 1 &, 8 & ,8 & 96,7 \\
\hline 49,00 & 3 & 2,5 & 2,5 & 99,2 \\
\hline 50,00 & 1 & ,8 & ,8 & 100,0 \\
\hline Total & 120 & 100,0 & 100,0 & \\
\hline
\end{tabular}


Escala SAMANTO para medir actitudes de los operadores judiciales hacia la víctima 158

Tabla 24.

Estadísticos del puntaje componente comportamental

\begin{tabular}{|c|c|c|c|c|}
\hline Válidos & Frecuencia & Porcentaje & Porcentaje válido & $\begin{array}{l}\text { Porcentaje } \\
\text { acumulado }\end{array}$ \\
\hline 29,00 & 3 & 2,5 & 2,5 & 2,5 \\
\hline 30,00 & 1 &, 8 &, 8 & 3,3 \\
\hline 31,00 & 1 & 8 & ,8 & 4,2 \\
\hline 32,00 & 2 & 1,7 & 1,7 & 5,8 \\
\hline 33,00 & 2 & 1,7 & 1,7 & 7,5 \\
\hline 34,00 & 2 & 1,7 & 1,7 & 9,2 \\
\hline 35,00 & 2 & 1,7 & 1,7 & 10,8 \\
\hline 36,00 & 3 & 2,5 & 2,5 & 13,3 \\
\hline 37,00 & 2 & 1,7 & 1,7 & 15,0 \\
\hline 38,00 & 3 & 2,5 & 2,5 & 17,5 \\
\hline 39,00 & 4 & 3,3 & 3,3 & 20,8 \\
\hline 41,00 & 4 & 3,3 & 3,3 & 24,2 \\
\hline 42,00 & 1 &, 8 &, 8 & 25,0 \\
\hline 43,00 & 4 & 3,3 & 3,3 & 28,3 \\
\hline 44,00 & 3 & 2,5 & 2,5 & 30,8 \\
\hline 45,00 & 5 & 4,2 & 4,2 & 35,0 \\
\hline 46,00 & 4 & 3,3 & 3,3 & 38,3 \\
\hline 47,00 & 5 & 4,2 & 4,2 & 42,5 \\
\hline 48,00 & 4 & 3,3 & 3,3 & 45,8 \\
\hline 50,00 & 2 & 1,7 & 1,7 & 47,5 \\
\hline 51,00 & 3 & 2,5 & 2,5 & 50,0 \\
\hline 52,00 & 4 & 3,3 & 3,3 & 53,3 \\
\hline 53,00 & 3 & 2,5 & 2,5 & 55,8 \\
\hline 54,00 & 4 & 3,3 & 3,3 & 59,2 \\
\hline 55,00 & 1 &, 8 &, 8 & 60,0 \\
\hline 56,00 & 11 & 9,2 & 9,2 & 69,2 \\
\hline 57,00 & 3 & 2,5 & 2,5 & 71,7 \\
\hline 58,00 & 4 & 3,3 & 3,3 & 75,0 \\
\hline 59,00 & 6 & 5,0 & 5,0 & 80,0 \\
\hline 60,00 & 2 & 1,7 & 1,7 & 81,7 \\
\hline 61,00 & 3 & 2,5 & 2,5 & 84,2 \\
\hline 62,00 & 1 &, 8 &, 8 & 85,0 \\
\hline 63,00 & 2 & 1,7 & 1,7 & 86,7 \\
\hline 64,00 & 2 & 1,7 & 1,7 & 88,3 \\
\hline 66,00 & 1 &, 8 &, 8 & 89,2 \\
\hline 67,00 & 2 & 1,7 & 1,7 & 90,8 \\
\hline 68,00 & 1 & ,8 &, 8 & 91,7 \\
\hline 69,00 & 1 &, 8 &, 8 & 92,5 \\
\hline 71,00 & 2 & 1,7 & 1,7 & 94,2 \\
\hline 73,00 & 1 &, 8 &, 8 & 95,0 \\
\hline 74,00 & 1 &, 8 &, 8 & 95,8 \\
\hline 75,00 & 2 & 1,7 & 1,7 & 97,5 \\
\hline 76,00 & 2 & 1,7 & 1,7 & 99,2 \\
\hline 79,00 & 1 &, 8 &, 8 & 100,0 \\
\hline Total & 120 & 100,0 & 100,0 & \\
\hline
\end{tabular}


Tabla 25.

Estadísticos de los puntajes totales de los componentes

\begin{tabular}{|c|c|c|c|c|}
\hline Válidos & Frecuencia & Porcentaje & Porcentaje válido & Porcentaje acumulado \\
\hline 86,00 & 1 & ,8 & ,8 & ,8 \\
\hline 92,00 & 1 & ,8 & ,8 & 1,7 \\
\hline 96,00 & 1 &, 8 &, 8 & 2,5 \\
\hline 97,00 & 1 &, 8 & ,8 & 3,3 \\
\hline 98,00 & 2 & 1,7 & 1,7 & 5,0 \\
\hline 101,00 & 2 & 1,7 & 1,7 & 6,7 \\
\hline 102,00 & 1 &, 8 & ,8 & 7,5 \\
\hline 104,00 & 1 &, 8 &, 8 & 8,3 \\
\hline 105,00 & 1 & ,8 & ,8 & 9,2 \\
\hline 106,00 & 1 &, 8 & ,8 & 10,0 \\
\hline 108,00 & 2 & 1,7 & 1,7 & 11,7 \\
\hline 110,00 & 4 & 3,3 & 3,3 & 15,0 \\
\hline 111,00 & 3 & 2,5 & 2,5 & 17,5 \\
\hline 112,00 & 1 &, 8 & ,8 & 18,3 \\
\hline 113,00 & 2 & 1,7 & 1,7 & 20,0 \\
\hline 116,00 & 2 & 1,7 & 1,7 & 21,7 \\
\hline 117,00 & 1 & ,8 & ,8 & 22,5 \\
\hline 118,00 & 1 &, 8 & ,8 & 23,3 \\
\hline 119,00 & 3 & 2,5 & 2,5 & 25,8 \\
\hline 120,00 & 1 & ,8 & ,8 & 26,7 \\
\hline 121,00 & 2 & 1,7 & 1,7 & 28,3 \\
\hline 123,00 & 3 & 2,5 & 2,5 & 30,8 \\
\hline 124,00 & 3 & 2,5 & 2,5 & 33,3 \\
\hline 125,00 & 4 & 3,3 & 3,3 & 36,7 \\
\hline 126,00 & 1 & ,8 & ,8 & 37,5 \\
\hline 127,00 & 4 & 3,3 & 3,3 & 40,8 \\
\hline 128,00 & 5 & 4,2 & 4,2 & 45,0 \\
\hline 130,00 & 2 & 1,7 & 1,7 & 46,7 \\
\hline 131,00 & 1 & ,8 & ,8 & 47,5 \\
\hline 132,00 & 3 & 2,5 & 2,5 & 50,0 \\
\hline 133,00 & 1 & ,8 & ,8 & 50,8 \\
\hline 134,00 & 2 & 1,7 & 1,7 & 52,5 \\
\hline 135,00 & 2 & 1,7 & 1,7 & 54,2 \\
\hline 136,00 & 1 & ,8 & ,8 & 55,0 \\
\hline 137,00 & 4 & 3,3 & 3,3 & 58,3 \\
\hline 139,00 & 7 & 5,8 & 5,8 & 64,2 \\
\hline 140,00 & 2 & 1,7 & 1,7 & 65,8 \\
\hline 141,00 & 2 & 1,7 & 1,7 & 67,5 \\
\hline
\end{tabular}


Continuación tabla 25.

Estadísticos de los puntajes totales de los componentes

\begin{tabular}{|c|c|c|c|c|}
\hline Válidos & Frecuencia & Porcentaje & Porcentaje válido & Porcentaje acumulado \\
\hline 142,00 & 1 & ,8 & ,8 & 68,3 \\
\hline 143,00 & 1 & ,8 &, 8 & 69,2 \\
\hline 144,00 & 1 &, 8 & ,8 & 70,0 \\
\hline 145,00 & 3 & 2,5 & 2,5 & 72,5 \\
\hline 146,00 & 2 & 1,7 & 1,7 & 74,2 \\
\hline 148,00 & 4 & 3,3 & 3,3 & 77,5 \\
\hline 150,00 & 2 & 1,7 & 1,7 & 79,2 \\
\hline 151,00 & 1 & ,8 & ,8 & 80,0 \\
\hline 152,00 & 1 & ,8 & ,8 & 80,8 \\
\hline 153,00 & 1 & ,8 & ,8 & 81,7 \\
\hline 155,00 & 1 & ,8 &, 8 & 82,5 \\
\hline 157,00 & 1 & ,8 & ,8 & 83,3 \\
\hline 158,00 & 3 & 2,5 & 2,5 & 85,8 \\
\hline 159,00 & 1 & ,8 &, 8 & 86,7 \\
\hline 161,00 & 1 & ,8 &, 8 & 87,5 \\
\hline 163,00 & 2 & 1,7 & 1,7 & 89,2 \\
\hline 164,00 & 1 & ,8 & ,8 & 90,0 \\
\hline 166,00 & 1 & ,8 & ,8 & 90,8 \\
\hline 168,00 & 1 & ,8 & ,8 & 91,7 \\
\hline 170,00 & 1 & ,8 & ,8 & 92,5 \\
\hline 173,00 & 1 & ,8 & ,8 & 93,3 \\
\hline 176,00 & 1 &, 8 & 8 & 94,2 \\
\hline 181,00 & 2 & 1,7 & 1,7 & 95,8 \\
\hline 183,00 & 1 & ,8 & ,8 & 96,7 \\
\hline 184,00 & 1 & ,8 &, 8 & 97,5 \\
\hline 190,00 & 1 & ,8 & ,8 & 98,3 \\
\hline 197,00 & 1 & ,8 & ,8 & 99,2 \\
\hline 200,00 & 1 & ,8 & ,8 & 100,0 \\
\hline Total & 120 & 100,0 & 100,0 & \\
\hline
\end{tabular}




\section{Figura 1. Resultado de los datos del componente cognitivo}

\section{ptcognitiva}

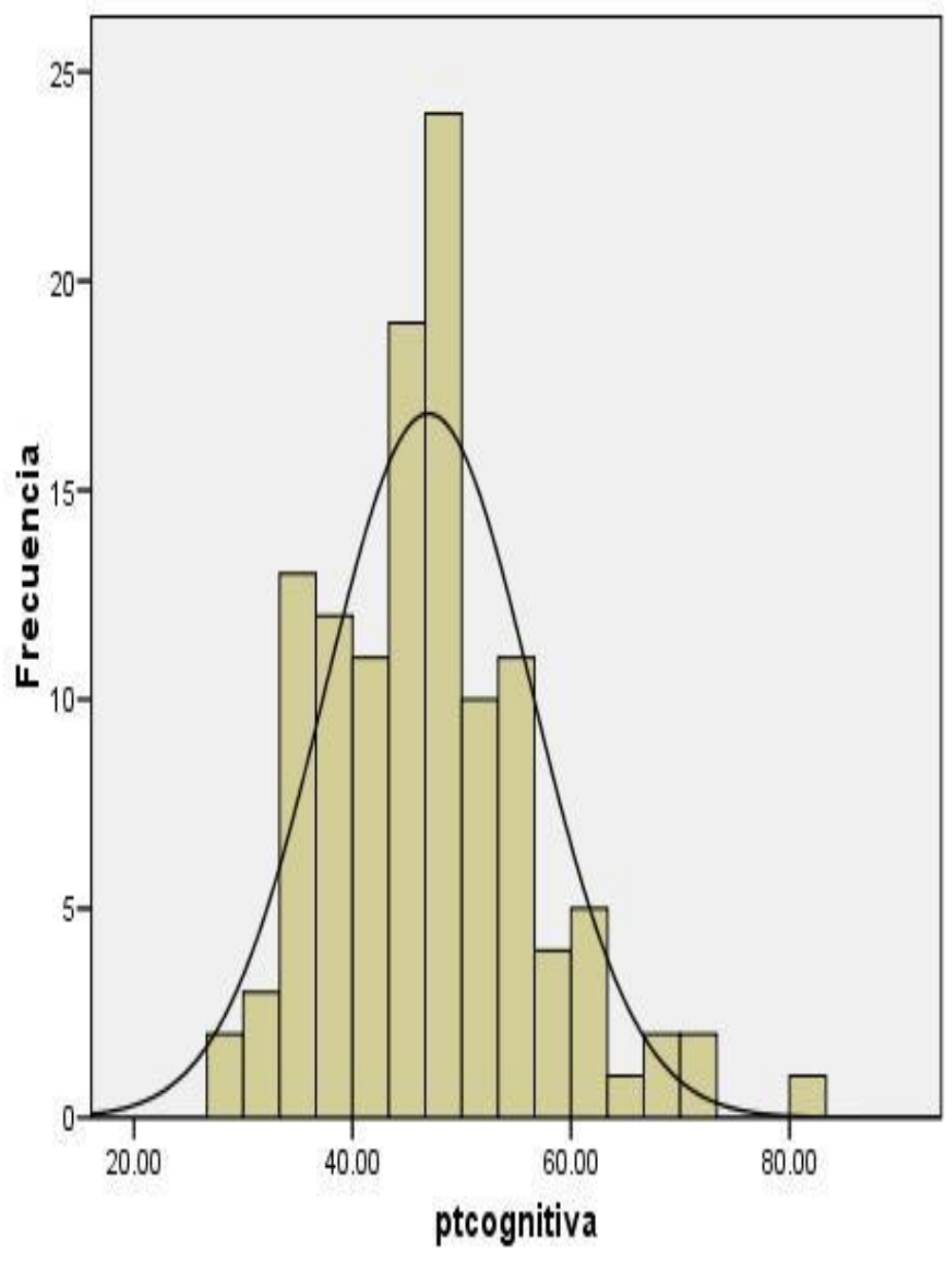

Media $=46.95$

Desviación típica $=9.48$ $N=120$

Figura 1. El histograma evidencia que hay tendencia central, es decir, concentración de la muestra en el promedio de actitudes revictimizantes. 
Figura 2. Resultado de los datos del componente afectivo

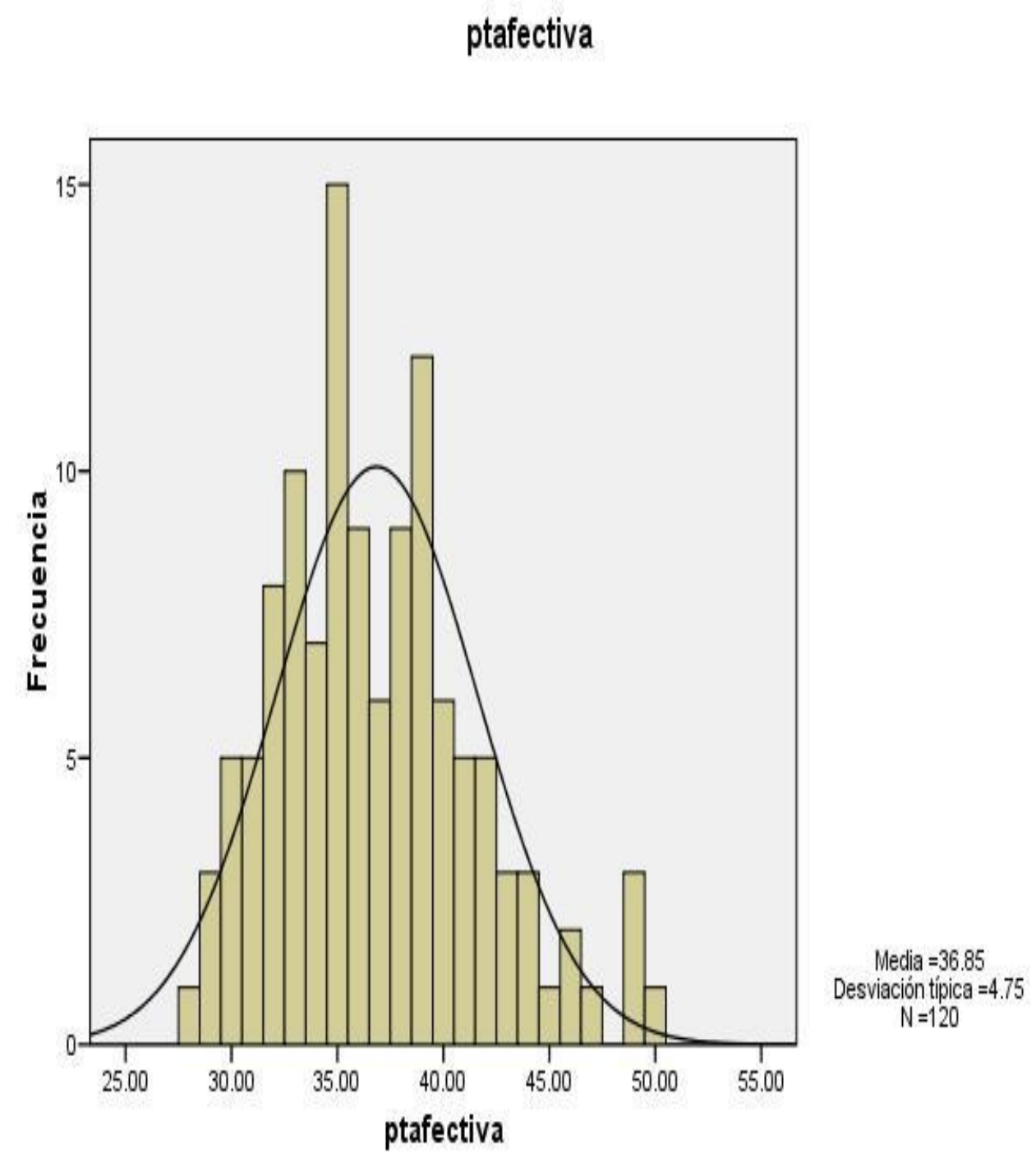

Figura 2. El histograma evidencia tendencia central, es decir, concentración de la muestra en promedio de actitudes revictimizantes. 


\section{Figura 3. Resultado de los datos del componente comportamental}

\section{ptacomportamental}

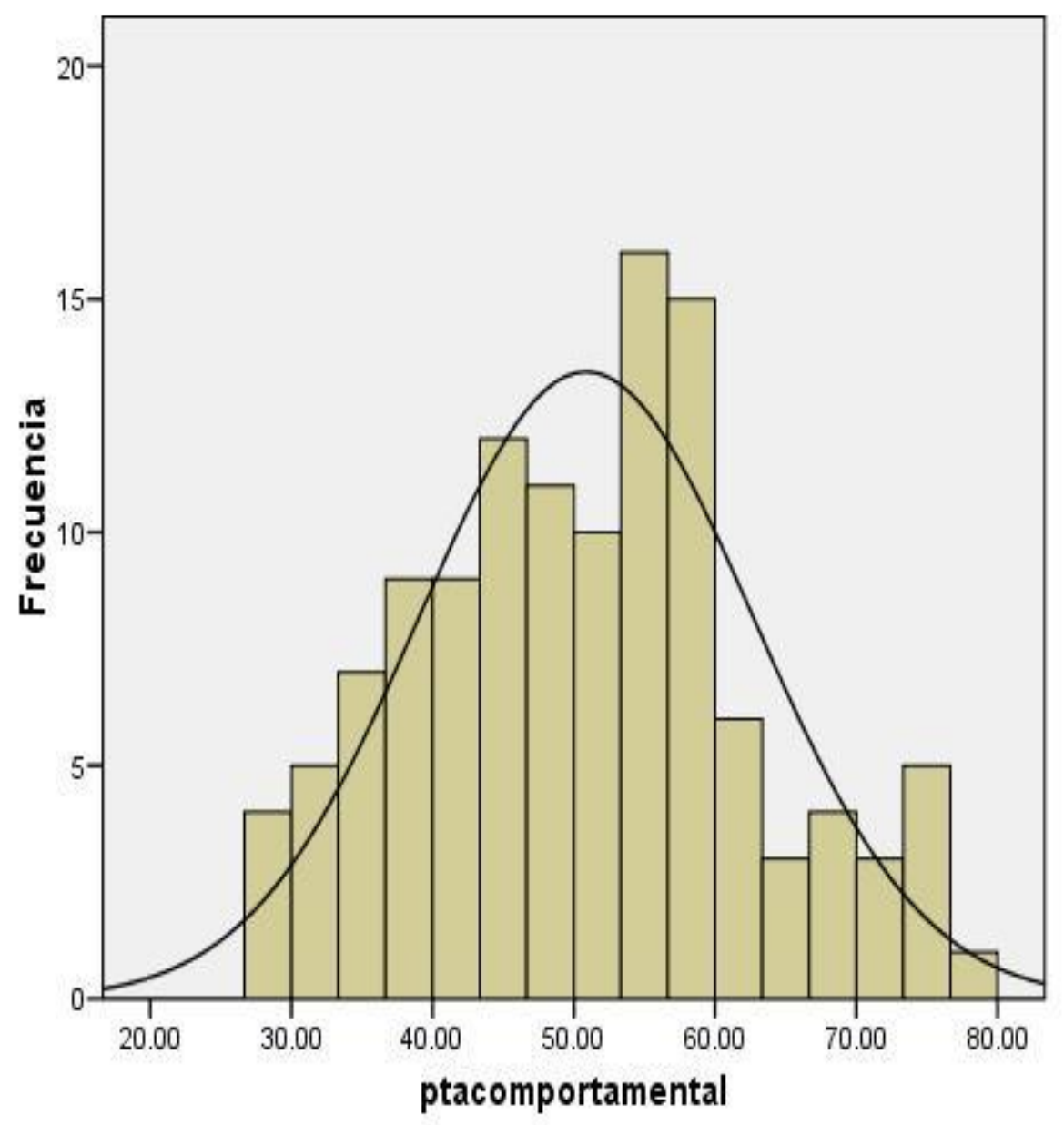

Media $=50.87$

Desviación típica $=11$. 872

$N=120$

Figura 3. El histograma indica presencia central, es decir, concentración de la muestra en promedio de actitudes revictimizantes. 


\section{Figura 4. Resultados de los datos totales de los tres componentes}

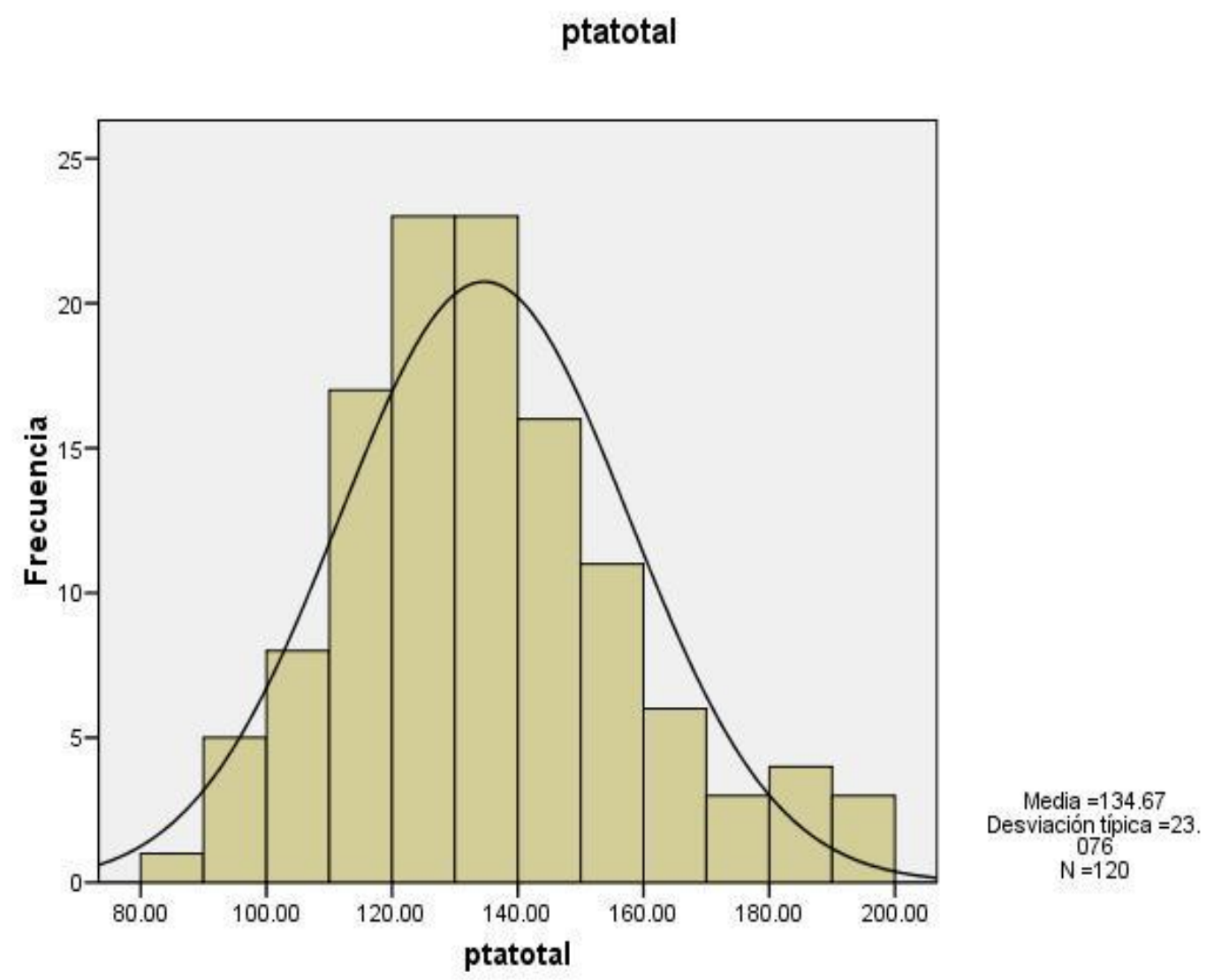

Figura 4. El histograma evidencia que la curva mantiene tendencia central, es decir, concentración de la muestra total en promedio de actitudes revictimizantes. 
Tabla 26.

Prueba de Kolmogorov-Smirnov

\begin{tabular}{|c|c|c|c|c|c|}
\hline & & $\begin{array}{c}\text { Puntaje } \\
\text { Cognitivo }\end{array}$ & $\begin{array}{l}\text { Puntaje } \\
\text { Afectivo }\end{array}$ & $\begin{array}{c}\text { Puntaje } \\
\text { Comportamental }\end{array}$ & $\begin{array}{c}\text { Puntaje } \\
\text { Total }\end{array}$ \\
\hline $\mathrm{N}$ & & 120 & 120 & 120 & 120 \\
\hline \multirow[t]{2}{*}{ Parámetros normales $(\mathrm{a}, \mathrm{b})$} & Media & 46,9500 & 36,8500 & 50,8667 & 134,6667 \\
\hline & $\begin{array}{l}\text { Desviación } \\
\text { típica }\end{array}$ & 9,48050 & 4,75032 & 11,87182 & 23,07581 \\
\hline \multirow[t]{3}{*}{ Diferencias más extremas } & Absoluta &, 114 &, 102 & 067 & 067 \\
\hline & Positiva &, 114 & 102 & 054 &, 067 \\
\hline & Negativa &,- 044 &,- 041 &,- 067 &,- 036 \\
\hline Z de Kolmogorov-Smirnov & & 1,253 & 1,112 & ,737 & ,736 \\
\hline Sig. asintót. (bilateral) & & ,086 &, 168 & ,649 & ,651 \\
\hline
\end{tabular}

Nota: (a) la distribución de contraste es la normal; (b) Se han calculado a partir de los datos. 
Escala SAMANTO para medir actitudes de los operadores judiciales hacia la víctima 166 